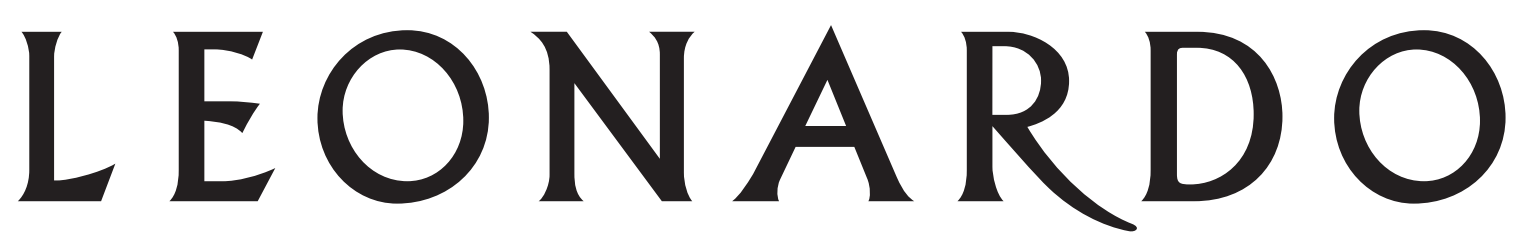

Journal of the International Society for the Arts, Sciences and Technology

VOLUME 49 | NUMBER 4 | 2016

\section{LEONARDO SPECIAL ISSUE}

SIGGRAPH 2016 Art Papers

and Data Materialities Art Gallery

300 ACM SIGGRAPH Distinguished

Artist Award for Lifetime

Achievement in Digital Art

Steina Vasulka
ART PAPERS

$\begin{array}{cl}302 & \text { Art Papers Jury } \\ 304 & \begin{array}{l}\text { Introduction } \\ \text { Edward Shanken }\end{array} \\ 306 & \begin{array}{l}\text { Perceptual Cells: James Turrell's } \\ \text { Vision Machines Between Two } \\ \text { Paracinemas }\end{array} \\ & \text { Alla Gadassik } \\ 317 & \begin{array}{l}\text { Pulse Shape 22: Audiovisual } \\ \text { Performance and Data } \\ \text { Transmutation } \\ \text { Mark Cetilia }\end{array}\end{array}$

324 Deletion Process_Only you can see my history: Investigating Digital Privacy, Digital Oblivion, and

Control on Personal Data Through an Interactive Art Installation Kyriaki Goni

334 Visual History with Choson Dynasty Annals Seong Kuk Park Eun Ju Lee Jin Wan Park Raised on YouTube: Cultural Dat
Materialization Using Plants Misha Rabinovich

DATA MATERIALITIES ART GALLERY

\author{
352 Introduction and Art Gallery \\ Jonah Brucker-Cohen \\ Featuring works by \\ Tine Bech \\ Squidsoup \\ Deqing Sun and Peiqi Su \\ Niklas Roy \\ Viktor Jan \\ Dmitry Morozov \\ Disney Research and ETH Zürich \\ Mogens Jacobsen \\ THÉORIZ Studio \\ Benjamin Grosser
}

\section{Leonardo Network News}

Front Cover

The beginning of Choson dynasty: The Purging (1388-1420). (@ 2016 Jin Wan Park)

Back Cover

Submergence, Bristol, U.K. (๔ 2013 Squidsoup. Photo: Paul Blakemore.) 


\title{
ACM SIGGRAPH Distinguished Artist Award for Lifetime Achievement in Digital Art
}

\author{
Steina Vasulka
}

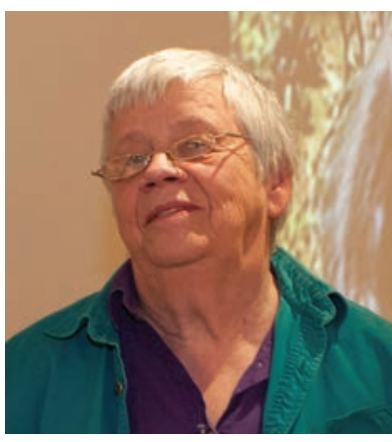

Steina Vasulka. (Photograph courtesy of Kristin Scheving)
The 2016 ACM SIGGRAPH Distinguished Artist Award for Lifetime Achievement in Digital Art is awarded to Steina Vasulka, a major contributor to the development of an intellectual and institutional framework for video and installation art, which she has continued to nurture and promote in a variety of contexts.

Vasulka's unique vision owes much to her background in music. She studied violin and music theory, attended the State Music Conservatory in Prague, and played with the Icelandic Symphony Orchestra. After moving to New York City in 1965 she found herself part of the avant-garde "intermedia" — an intermingling of music, dance, theater, and film communities. Steina says, "There is no grander life than creative artistic life. It is the unknown, the exploration, and the fact of being your own person in your own time."

She began working with video in 1969, co-founding The Kitchen, an electronic media theater in SoHo, described as "An Image and Sound Laboratory" by the late film and video maker Jud Yalkut. This artist-run venue favored discussion and experimentation; Vasulka called it LATL (Live Audience Test Laboratory). It enabled meetings, production, and showings of electronic image work, and attracted many musicians, dancers, and performers operating outside the mainstream, including Nam June Paik. It was a central part of the early movement of New York City intellectuals exploring video as an art medium and as a tool for social and cultural change, inspired initially by Marshall McLuhan's influential media theories.

For Vasulka, both sound and imaging devices are instruments. For example, she used her violin to control the video image in Violin Power (1969-1978): the violin is patched through an audio synthesizer to a video switcher, which activates switching between two camera views of the artist playing.

The artist explains her methods thus: "Between taping and editing, there is usually an intermediary step during which I alter and mix the images, change color or run things upside down or backwards. This is where the particular uniqueness of working with the electronic image comes into play."

For the ongoing series Machine Vision (1975-present), born out of her research into perception, Vasulka has utilized customized machines, kinetic devices, and optical tools to control the camera. Her long fascination with a sphere's potential for producing complex optical environments resulted in several works, including Of the North (200I) and Seven Spheres (2005), a series of variations on the sphere utilizing Boris software to shape the video signal into a sphere. 


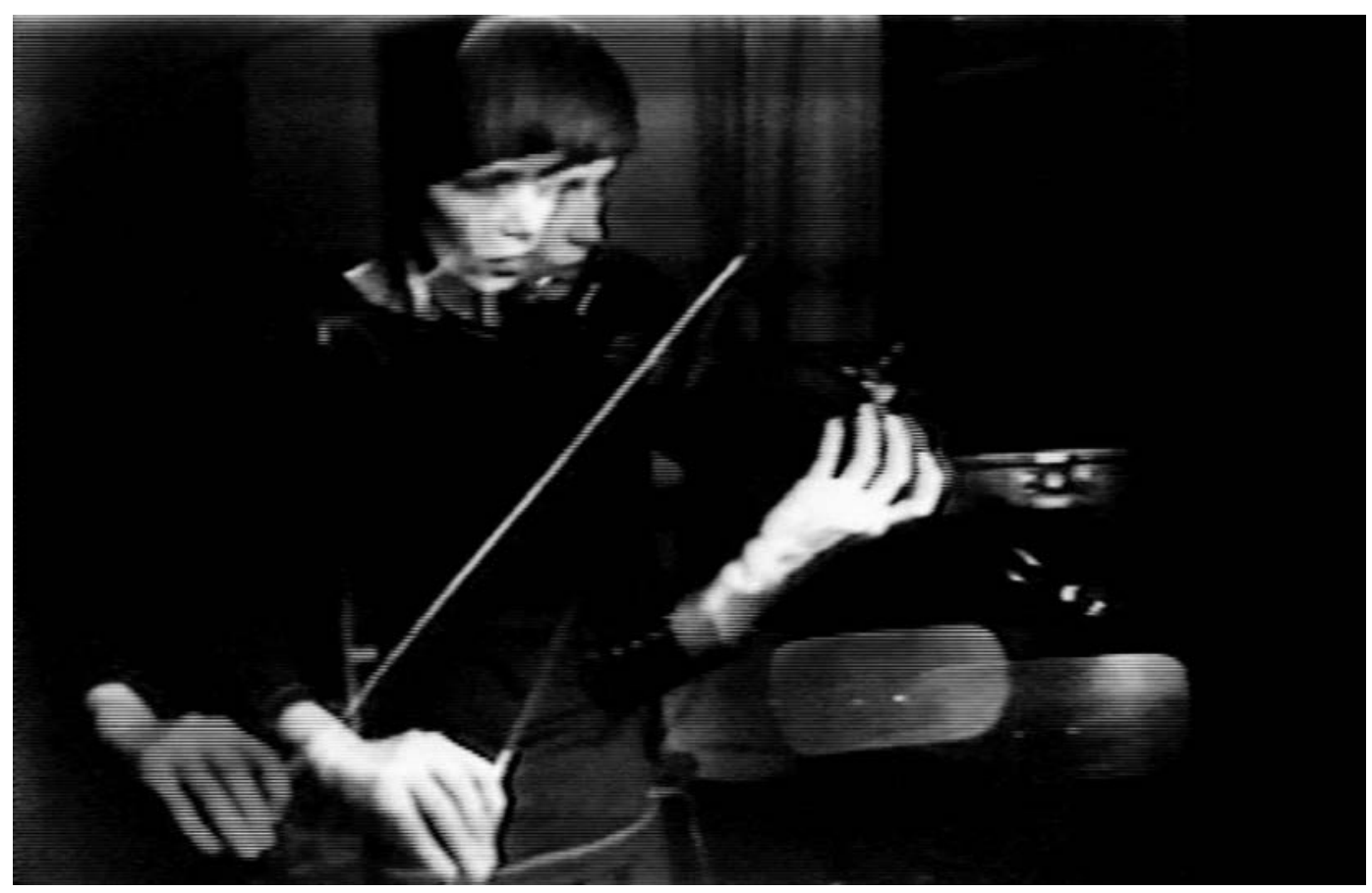

Steina Vasulka performing in Violin Power, 1978. (๑ Steina Vasulka)

Recently she has become involved in producing interactive performances in public places, playing a digitally adapted violin to move video images displayed on large video projectors (Violin Power, 1992).

Throughout her career Steina held artist-in-residence posts at various television companies and institutions across the United States and in Tokyo. She was guest artistic co-director and software collaborator at STEIM (Studio for Electronic Instrumental Music) in Amsterdam, 1996-1997. In addition, she has exhibited widely, presenting video and new media worksoccasionally collaborating with her husband Woody_including at the San Francisco Museum of Modern Art. Other projects have taken place in New Mexico, Reykjavik, and Milano, and at many international festivals; she represented her home country of Iceland at the Venice Biennale in 1997. Her archive has recently been donated to the Vasulka Chamber at the National Gallery of Iceland.

ACM SIGGRAPH is honored to recognize Steina Vasulka as an important pioneer in the early history of video as a creative medium.

\section{Sue Gollifer}

CHAIR

ACM SIGGRAPH DISTINGUISHED ARTIST AWARD FOR LIFETIME ACHIEVEMENT IN DIGITAL ART 


\section{Kayla Anderson}

Kayla Anderson is an artist, writer, and organizer based in Chicago. Taking a playful approach to methods of excavation, her work engages with cultural artifacts of the past in order to propose parallel worlds. Her writing has been published by Leonardo/ISAST, the Royal College of Art, and MU TXT, and presented internationally. She curates exhibitions, lectures, and mentors students in the creation of artists' publications at the School of the Art Institute of Chicago.

\section{Stephanie Boluk}

Stephanie Boluk is an assistant professor in the Department of English and the Cinema and Digital Media program at University of California, Davis. She is co-editor of the Electronic Literature Collection Volume 3, co-director of the Alt-Ctrl lab, and her first book, Metagaming: Videogames and the Practice of Play, is forthcoming this year from University of Minnesota Press. For more information, see <stephanieboluk.com>.

\section{Alejandro Borsani}

Alejandro Borsani is an artist and educator who explores the intersection of natural and artificial systems by creating videos, installations, custom software, and electronics. His research is driven by a curiosity about physical phenomena and the exploration of emergent technologies. His work has been presented in solo and group exhibitions internationally. Borsani is assistant professor in the Experimental \& Foundation Studies Division at Rhode Island School of Design.

\section{Garnet Hertz}

Garnet Hertz is Canada Research Chair in Design and Media Arts at Emily Carr University of Art + Design. His research explores DIY culture, electronic art, and critical design practices. He holds a PhD from the University of California, Irvine, and has exhibited his studio work in 17 countries. For more information, see $<$ conceptlab.com/ $>$.

\section{Varnelle Noel}

Vernelle Noel is a research scientist, computational designer, and architect who has worked in the United States, the Caribbean, India, and Singapore. Currently a PhD candidate in design computing at Penn State, she investigates craft, computational making, and technology in cultural design practices. Noel was also a presenter at TEDxPortofSpain in 2015, where she gave a talk entitled, "The Power of Making: Craft, Computation, and Carnival."

\section{Edward Shanken, Chair}

Edward Shanken writes and teaches about the entwinement of art, science, and technology with a focus on interdisciplinary practices involving new media. Recent work addresses systems theory, art-science collaboration, surveillance culture, sound art and the environment, and bridging the gap between new media and contemporary art. His books include Systems (2015), Inventar el Futuro (2013), Art and Electronic Media (2009), and Telematic Embrace: Visionary Theories of Art, Technology and Consciousness (2003).

\section{Ruth West}

Ruth West is both artist and researcher. Her background spans new media, design, virtual and augmented reality, molecular genetics, psychology, participatory mobile and social technologies, and data visualization and sonification. Her work envisions a future in which art and science integration opens new portals of imagination, creative expression, invention, knowledge, and communication across cultures. West directs the xREZ Art + Science Lab and is an associate professor at the University of North Texas.

\section{Jichen Zhu}

Jichen Zhu is assistant professor in Digital Media at Drexel University. Her research focuses on the intersection of artificial intelligence, human-computer interaction, creative expression, and critical theory. Her emphasis is on developing new forms of cultural artifacts afforded by intelligent systems, as well as innovating new Al techniques informed by expressive goals. Her current interests include interactive narrative, serious games, computational creativity, and digital humanities. She received a $\mathrm{PhD}$ in Digital Media from Georgia Tech.

\section{Tertiary Reviewers}

Julieta Aguilera, U Hawaii at Hilo + Imiloa Astronomy Center Asli Arpak, Massachusetts Institute of Technology John Berton, Drexel University Lee Blalock, School of the Art Institute of Chicago Tega Brain, Purchase College

Jon Cates, School of the Art Institute of Chicago

Kelly Christian, School of the Art Institute of Chicago

Evelyn Eastmond, SAP

Jill Fantauzza, Exploratorium/Stanford University Angus Forbes, University of Illinois, Chicago Kai Franz, Rhode Island School of Design Abdul-Jabbar Fulla, School of the Art Institute of Chicago Jacob Gaboury, Stony Brook University Madeline Gannon, Carnegie Mellon University Laura Garafolo, University of Buffalo

Esteban Garcia Bravo, Purdue University
Paul Hertz, School of the Art Institute of Chicago Todd Kesterson, Oregon State University Omar Khan, University of Buffalo Patrick LeMieux, University of California, Davis Christopher Lueg, University of Tasmania, Australia Paho Mann, University of North Texas Valentina Nisi, University of Madeira Joel Ong, University of Washington Danielle Oprean, The Pennsylvania State University Andrea Polli, University of New Mexico Ozge Samanci, Northwestern University Geoffrey Thomas, Independent Artist James Thurman, University of North Texas Adam Trowbridge, School of the Art Institute of Chicago Robert Twomey, University of Washington Jessica Westbrook, School of the Art Institute of Chicago 
Art Papers 


\section{Introduction}

SIGGRAPH 2016 and Leonardo/ISAST present the eighth joint publication of SIGGRAPH Art Papers. Art Papers investigates the roles of artists and the methods of art-making in an increasingly global, networked, and technologically mediated world. Art Papers contributes to our understanding of the history of art, informs contemporary artistic and critical practices, and anticipates and stimulates future trajectories. At the SIGGRAPH 2016 conference, authors present their papers, which, along with a digital supplement, appear in this special issue of Leonardo.

In addition to the core topics of digital and interactive arts, Art Papers highlights excellent practices in the field and addresses both artistic and technical audiences. This year, we especially encouraged papers that consider transdisciplinary research at the frontiers of art, design, science, and engineering; that expand the international and cultural breadth of SIGGRAPH discourses; and that dovetail with the 2016 Art Gallery theme of Data Materialities. An art paper might consist of a project description; a work of history, theory, or criticism; or an exposition of a novel method or technique. With one exception, the 2016 Art Papers consists of descriptions of new creative works, with particular emphasis on their historical and/or theoretical significance. The span of topics is very diverse, ranging from a visualization of Korean genealogy during the Choson dynasty to an appraisal of artist James Turrell's work in the context of computerprogrammed perception.

The jurying process is intense. The Art Papers Committee takes primary responsibility for reviewing the submissions. As chair, I convened an eight-person committee, representing expertise in visualization, gaming, DIY, physical computing, interdisciplinary collaboration, architecture and design, history and theory, and other fields. Each submission was evaluated by at least two Committee members, plus two additional jurors selected by the Committee. Reviews included extensive written comments, which authors have reported are particularly valuable. SmithBucklin (the association management firm that supports SIGGRAPH) was instrumental to the organization of 2016 Art Papers. 
The jury evaluated each submission according to the following criteria:

- Scope and magnitude of its contribution to literature on digital arts, computer graphics, and/or interactive techniques

- Clarity of thesis and compelling exposition

- Quality and relevance of references to establish context and support the author's claims

- Quality and relevance of support media to reinforce the author's claims

After extensive virtual communications, the Committee gathered at Rhode Island School of Design, which hosted the in-person jury meeting in March. After a full day of deliberations, and taking into account feedback from the editorial team at Leonardo, the Committee selected what we deemed to be the best, most publishable papers. However, our work was not yet over. The selected papers required improvements specified by the jury before being accepted for presentation at SIGGRAPH and publication in Leonardo. To oversee this process, Committee members communicated required changes to the authors and "shepherded" the papers to final draft stage on a very tight deadline.

It must be highlighted that, aside from the professional organizational support, all of this work was done on a voluntary basis. For all of their hard work, commitment, and sharing of expertise and ideas, I would like to thank the members of the Art Papers Committee and the extended jury. We hope that our efforts have made a valuable contribution to SIGGRAPH, to Leonardo, and to discourse in the field in general.

\section{Edward A. Shanken}

ASSOCIATE PROFESSOR, ARTS DIVISION DIRECTOR, DIGITAL ARTS AND NEW MEDIA UNIVERSITY OF CALIFORNIA, SANTA CRUZ SIGGRAPH 2016 ART PAPERS CHAIR 


\section{Perceptual Cells: James Turrell's Vision Machines Between Two Paracinemas}

Alla Gadassik

Assistant Professor

Emily Carr University of Art + Design

School of Media History \& Theory

1399 Johnston St.

Vancouver, BC V6H 3R9, Canada

gadassik@ecuad.ca

See <www.mitpressjournals.org/toc/leon/49/4> for supplemental files associated with this issue.

\author{
Alla Gadassik
}

\begin{abstract}
A B S T R A C T
James Turrell's perceptual cells incorporate the neurophysiological apparatus as an active participant not only in the reception of projected moving-images, but also in the very production and transmission of virtual moving-images. Combining two perceptual phenomena-the stroboscopic effect and the Ganzfeld Effect-Turrell's perceptual cells integrate the architecture of projection with the architecture of organic vision to produce a single networked extra-sensory medium. This paper performs a phenomenological analysis of Turrell's Light Reignfall (2011) perceptual cell, following its design, effects on the viewer, and cultural and material history. In the process, the paper situates the perceptual cell between the history of avant-garde cinema (what historians have called "paracinema") and the history of perceptual psychology and parapsychology (what the author terms "para-cinema"). Between these two paracinemas, Turrell's perceptual cells activate the aesthetic potential of what the author discusses as "edgeless projection."
\end{abstract}

\section{Introduction}

This paper swings farther afield from the kinds of techniques and devices that we typically associate with computer-rendered artwork. It begins by describing an unsettling and moving encounter with a programmed viewing chamber titled Light Reignfall_-one of artist James Turrell's "perceptual cells" - and it expands into a discussion of the virtual images produced by the device's edgeless projection. James Turrell is a seminal American artist, who gained more widespread international recognition in recent years due to a major retrospective exhibition, a prestigious National Medal of Arts award, and (much to his dismay) a viral music video by the rapper Drake. Among Turrell's different types of artwork, the perceptual cells are the least discussed pieces, even though they should be of interest to media artists and historians. In some respects the perceptual cells rely on the same principles of visualization and reception as programmed animation, moving-image projection, and virtual environment design. However, their design goes further in incorporating and animating the spectator's neurophysiological optical apparatus to produce an unpredictable and irreproducible moving-image perception with every single viewing. The often ineffable and ephemeral qualities of the animated images that are produced by the cell demand recognition of the spectator's body as an active medium not only in the reception of moving-images, but also in their actual generation. By analyzing the design of Light Reignfall and considering its phenomenological effects, this paper traces the trajectories of two very different forms of paracinema that intersect in the perceptual cell. The first is what Jonathan Walley has called the postwar "paracinema" of gallery experiments in light projection [I], and the second is a largely neglected history of what we can call the "para-cinema" of laboratory parapsychology. In bringing together these two different trajectories, I highlight the important role of edgeless projection in activating the body as a potential medium of extrasensory transmission - a potential that still remains largely ignored by contemporary developers of emerging viewing devices. 


\section{The Perceptual Cell and the Body of Paracinematic Perception}

A major reason why James Turrell's "perceptual cells" receive little attention in the press or in art criticism is that their formal structure and effects are difficult to describe and (by design) impossible to photographically document. As such, I must begin by asking the reader to follow me in the experience of one of these cells, a spherical light projection chamber titled Light Reignfall (20II). This chamber was a major public draw in Turrell's 20I3-20I4 retrospective at the Los Angeles County Museum of Art (LACMA) — part of a major internationally coordinated retrospective of the artist's five decades of pioneering contributions to what has been called California's Light and Space movement. Special tickets to the cell were available in fifteenminute appointments and were sold out months in advance, despite, or perhaps because of, the vague and metaphysical language used to describe the piece. Most promotional material and press reviews offered some variation on the introspective (or navel-gazing) promise that one would "see oneself seeing." What this entailed, and whether it would take the shape of a mystical staring contest or something more akin to René Magritte's Not to be Reproduced, remained a tantalizing puzzle.

After successfully loitering at the museum entrance until a cancellation opens a slot in the schedule, I arrive at the site of Light Reignfall with coveted ticket in hand, well in advance of my appointment time. Two young women in crisp lab coats greet every visitor upon arrival. Behind them, raised on a platform of carpeted stairs, like a small temple towering over pilgrims, the cell's white metal sphere betrays nothing to any of the visitors waiting on a bench below (Figure Ia). Each visitor's ticket allows access to one encounter, one viewing of whatever plays inside the dome. Before I am able to enter the cell, I must sign a waiver promising - as one would at a medical clinic or a psychology experiment - that I have been sufficiently informed about the risks of strobe lights and enclosed spaces, and that I absolve this projection
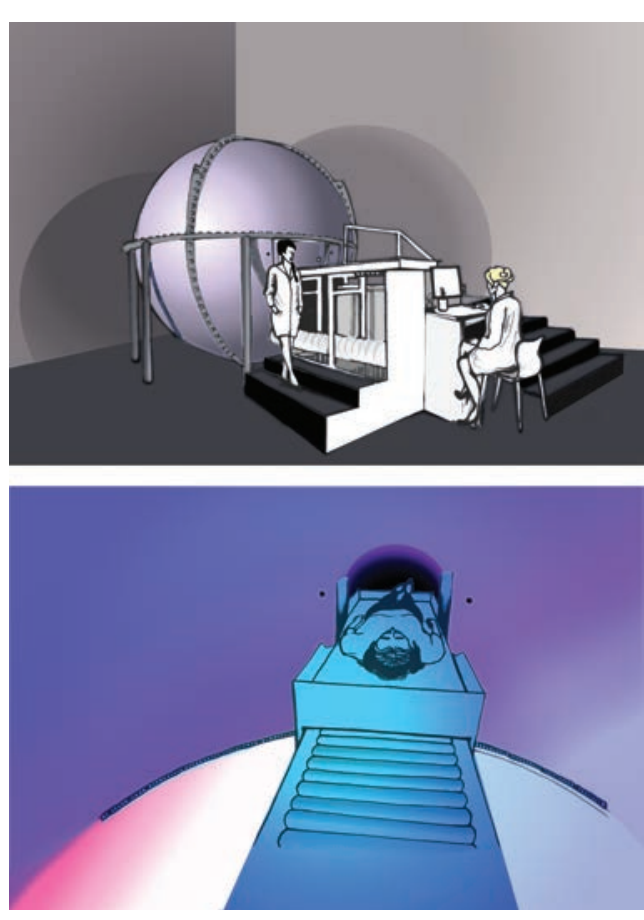

Figure 1a (top). Illustrated rendering of the external appearance of James Turrell's Light Reignfall. Figure $1 \mathrm{~b}$ (bottom). Illustrated rendering of the internal view of Light Reignfall, upon sliding into the dome. Illustrations made with permission from James Turrell Studio. (๑) 2016 Alla Gadassik) machine and its distributing institution of responsibility for any perceptual damage. Then, an unexpected choice is presented: do I want to watch the Soft or the Hard program? The Soft program, upon clarification, is described as a "soothing bath" of light, whereas the Hard program is characterized as a more intense and "wild" experience. I boldly opt for the hardcore light show.

When my turn comes, the women smile and beckon me to the top of the platform. Their presence and performance evokes something between a magician's assistant and a laboratory technician; this framing setup continues a century-old tradition of using young female assistants or characters to introduce apprehensive spectators to unfamiliar and potentially intimidating new technologies [2]. At the top of the staircase, a human-length sliding platform rolls out of a small rectangular door in the cell, bearing the previous occupant. One of the lab coats helps a dazed man off the platform and leads him to the railing, which he uses for support as he silently wobbles down the stairs. 
The other assistant instructs me to recline on the platform and points to a small covered peephole in the dome, informing me that I will be monitored for my safety and security. After lying down on my back, a small remote with a panic button is placed into my hands, so that I can end the show at any time. Headphones placed over my ears drown out all sounds of the surrounding environment and leave a low drone, like melodic white noise. Glasses off, headphones on, I am rolled into the tight slot of the dome, watching the edge of the opening

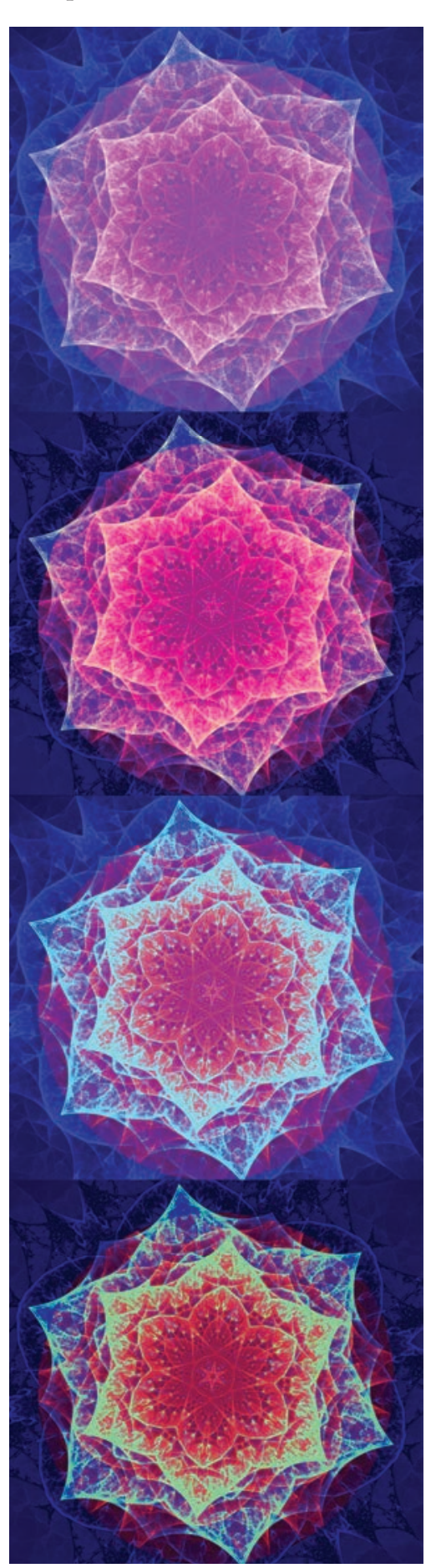

Figure 2. Illustrated rendering of imagined frames of the virtual animated sequence seen during my time inside James Turrell's Light Reignfall. (๑ 2016 Alla Gadassik) pass inches above my face. My stomach tenses with traces of the kind of anxiety one might feel when entering an MRI imaging machine, the body about to be tested by invisible rays and found wanting. I cannot help but think of the rolling tray of a morgue drawer; perhaps the same association leads the visitor going after me to push his panic button after a few seconds in the cell, before his softcore show even gets going.

However, once the opening passes overhead and I am inside the cell, all sense of tight enclosure dissipates. Without any edges, borders, or perspective markers inside the dome, the space is at once tiny and immense (Figure $\mathrm{Ib}$ ). A dim white glow illuminating the entire field of vision turns the dome into a metallic womb, until a saturated blue floods the space to transform it into a small private planetarium or simulated sky. The cell contracts only if one remembers how it appears from the outside, not as it is felt from the inside. The color fields begin to change, and then a strobe light flickers with variable rhythm throughout the transformations, so rapidly that I lose track of its actual tempo and cannot tell with certainty when and if it actually appears. Almost immediately my entire field of vision is filled with moving shapes and forms, many of them tinted with whatever hue fills the dome, but some of them appearing in a contrasting hue or eliding any clear association with an identifiable color. The moving forms speed up, slow down, morph, blend, substitute one for another-I am watching what could only be described, somewhat inadequately, as a geometric abstract animated film that hovers in some indeterminate zone between my body and the dome's architectural shell, between the perceptual cells of my organism and the technological frame that envelops them.

My mind struggles to memorize, to mentally fix the images, so that I can recreate or describe them later, but they mutate and evade recognition as they flicker in and out of the field of vision. I grasp at futile analogies in hopes that they will galvanize my memory later: empty crosses, bird footprints, fractal snowflakes, houndstooth patterns, and lattices. Only three impressions remain long enough to stay with me: first, the hard lines and geometric, crystalline shapes; second, their radial emanation from a single blind 
spot right in the center of the field of vision; third, their cloned repetition, like a prismatic refraction of an image or a kaleidoscope (Figure 2). One reviewer described these moving images as "a honeycomb of hexagons delineated in concentric colors" [3]. Another wrote: "There was an ebb and flow of different colors and shifts in tone and hue, forms in different combinations grew along mostly linear patterns, drawn out and truncated forms came and went at various intervals" [4].

Two conditions facilitate the cell's production of a complex animated image using solely projected uniform color fields. First, the visual field changes over time without allowing the eyes to focus on any particular area or externally recognizable figure. Light Reignfall achieves this through its rapid alteration of different hues. Since optical perception tends to presume a natural environment when interpreting color (a type of neurophysiological "white balance"), any continuous color field lacking in identifiable contrasts will gradually lose perceived saturation. A constant shift in color, however, maintains a dynamic effect, amplified as the afterimage left by the passage of one hue mixes with the impression of the subsequent one. Similar to the structure of sped-up or slowed-down cinematography or film montage, the rhythm of image variation forms the impression of motion and the passage of time. However, without any representational or recognizable figures to be discerned on the projection surface, time becomes especially elastic. My ten-minute Hard program inside Light Reignfall gave me the impression of lasting two minutes, and when my reclining tray was rolled out I worried I had pressed the panic button by mistake. One of the lab coat assistants assured me that almost everyone experiences the Hard program at half the time or less of its measurable duration. Elsewhere, my two-minute encounter with a different Turrell space, the blacked-out Dark Space, felt like ten minutes, and I wondered if the attendant responsible for leading me out had forgotten about her charge. The same thing happened to art critic John D. O'Brien, who impatiently tried to leave the dark space independently, became disoriented and ultimately led astray by the surrounding curvilinear walls and blurred shapes dancing in front of his eyes. O'Brien had to find his way out by touch on his hands and knees—-he wrote: "I may be the first person to have had to break out of a James Turrell" [5].

Second and equally important, the formation of animated shapes in the perceptual cell's Hard program depends on a programmed pattern of interruption that divides the flow of light into discrete flickering instances. In Light Reignfall the animating effect is achieved not by inserting a dark interval between successive frames (as occurs with the shutter of a film projector) or by producing a sharp edge of a viewing slit (as occurs with a nineteenth-century optical animation device like a zoetrope), but by a stroboscopic flash of light. The bursts of light, combined with the neurophysiological structure of optical perception, stimulate the apparition of graphic moving shapes and kaleidoscopic metamorphoses that one sees inside the cell. The rhythm of interruption must push the very boundary of the body's sensory responsiveness and memory, straining the retina's ability to register change and the brain's ability to process it. As Raymond Bellour wrote about the function of vision in stroboscopic projection: "the eye is reduced to the state of an automatic and wild machine." [6] Yet the human optical machine, too, must be calibrated and take into account. Any tempo that is too slow would create the effect of a periodically flashing dome, whereas a tempo that is too fast would become a buzzing irritation, like a broken fluorescent bulb. Balancing between continuity and interruption to probe the outer limit of optical sensitivity, Light Reignfall is an open audiovisual medium that incorporates the body's perceptual frequency as an integral component, turning the viewer into a filter and processor that produces phenomenally experienced but materially intangible moving images. 
By using the dual structure of the shifting afterimage and flickering interruption to produce a virtually experienced moving image, the perceptual cell embodies what theorist Friedrich Kittler called the two "theoretical conditions of cinema" that have occupied both scientists and philosophers of vision since the nineteenth century and that preceded the development of film technology [7]. This dual structure of the cinematic effect, argued Kittler, was conceptually discovered even before the invention of specific film technology, and its consequences on the limits of human perception shaped many disciplines outside the bounds of what is typically considered to be media history. In the I960s and I970s, the tactile and kinetic dimensions of modulated light became increasingly important to artists interested in extending the sensorial dimensions of the cinema beyond the confines of the movie theater. Film historian Jonathan Walley has proposed the term "paracinema," originally coined by avant-garde filmmaker Ken Jacobs, to describe the emergence of "an array of phenomena that are considered 'cinematic' but that are not embodied in the materials of film as traditionally defined" [8]. Although James Turrell's career and work are rarely considered in the context of media history, the perceptual cell undoubtedly functions more like a paracinematic device than an architectural space or sculptural light projection. Whereas most of Turrell's work permits or actively encourages extended duration and slow time of reception-from architectural time to celestial timethe perceptual cell foregrounds the fleeting temporality and finitude of neurophysiological perception, generating accelerating images that disappear in the same instant that they are impressed on the retina. In this, Light Reignfall shares affinities with other media objects in the history of paracinema: the flicker films of Tony Conrad [9] and Paul Sharits [ro]; Anthony McCall's dynamic light gallery installations [II]; Jordan Belson's planetarium projection
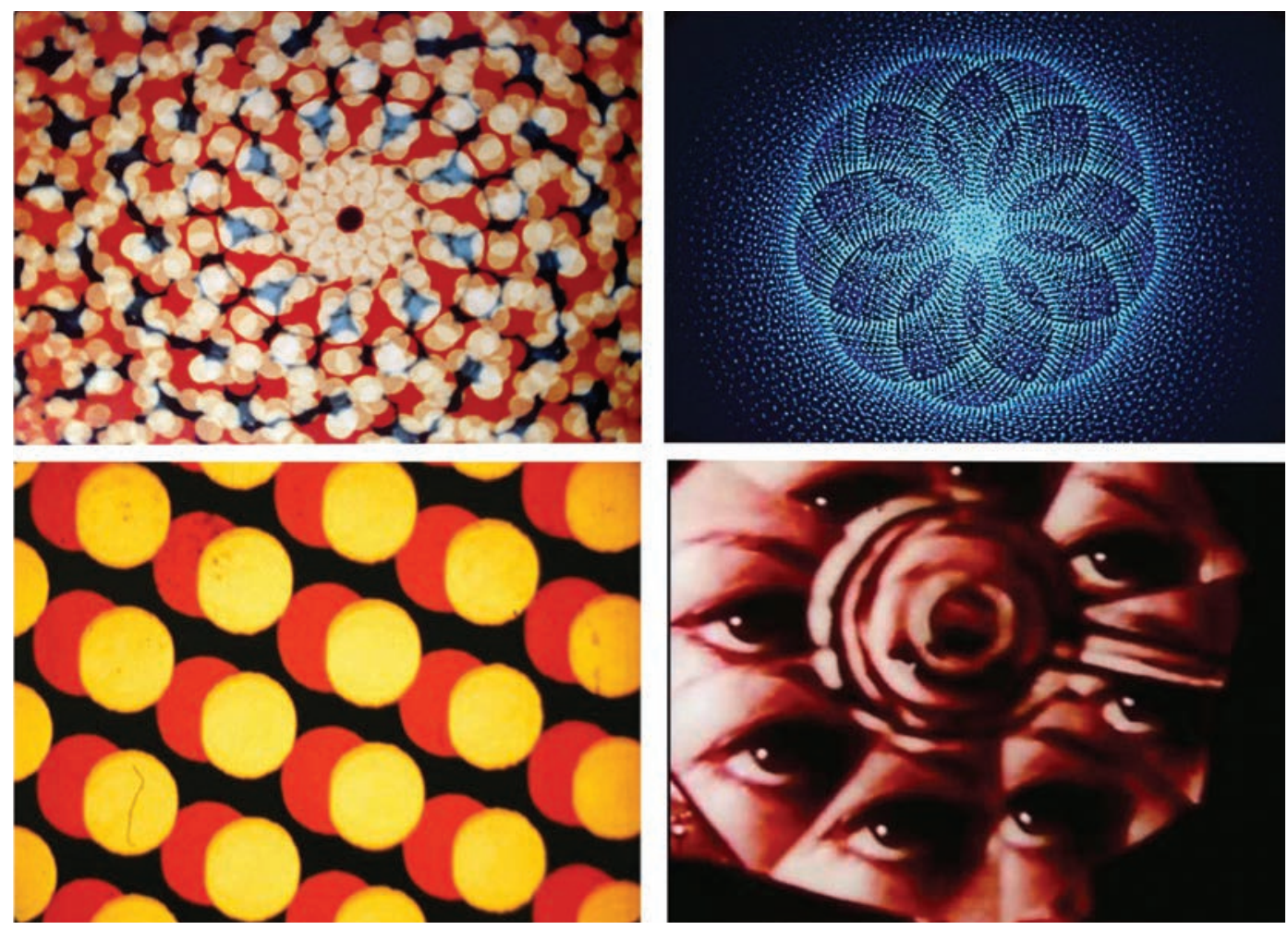

Figure 3. Clockwise from top left: two still frames from James Whitney's film Lapis (1965) (Courtesy of John Whitney Jr. ๑ James Whitney.); still frame from Storm de Hirsch's film Peyote Queen (1965) (Courtesy of The Film-Makers' Cooperative. $\odot$ Storm de Hirsch.); still frame from Len Lye's film All Souls Carnival (1956) (Courtesy of The Len Lye Foundation. ๑ The Len Lye Foundation.) While all three experimental filmmakers differed in their artistic philosophies and preferred materials, their shared interest in expanded sensory phenomena (from meditative trance to subconscious dream images) expressed itself in recurring abstract kaleidoscopic motifs that echo the retinal images one would see in a perceptual cell. 
pieces [I2]; Robert Breer's single-frame animated films; and Stan VanDerBeek's hemispherical "Movie-Drome" spaces for communal viewing [13]. When trying to find graphic analogies for the ephemeral and indescribable spherical abstractions that appeared during my viewing of Light Reignfall, I found myself recognizing their shapes and kaleidoscopic effects in recurring visual motifs found in the work of postwar experimental animators interested in expanding their own optical perception and rendering the resulting graphic forms in two dimensions (Figure 3).

There is one important quality of the perceptual cell that differentiates it from all other experiments in expanded cinema: its complete erasure of screen edges, spatial boundaries, rectilinear planes, and depth markers that carve out lines in space. These optical differentiating cues are integral to establishing the distinction between internal and external phenomena. Without the presence of a film frame, a floor horizon line, or even the spectator's own body in the field of vision, the spatial dimension of perception loses coherence. This quality distinguishes the perceptual cell from Turrell's other works, which, art historian Georges Didi-Huberman argues, depend on the production of "edges—extraordinarily complex and subtle articulations of planar, volumetric, and chromatic elements" that "constitute the very place where seeing takes place." Describing his own experience of entering and traversing one of Turrell's light spaces, Didi-Huberman continues: "The object of vision, habitually in front of us, becomes the place of our seeing. We are inside it. And yet this place presents itself only as a pure and mysterious tactility of light" [I4]. Building on Didi-Huberman's account, Giuliana Bruno proposes that Turrell's viewing chambers turn walls of light into porous screens and cinematic veils:

As in film, the observer encounters a "sheet" of reflective luminous matter. Here we sense the very fabric of light, the layers that constitute it, as we perceive the filtering and transparency of a light screen. A textural fabrication, the light screen is a fabric so absorbent that it fully absorbs us. [I5]

Both Didi-Huberman and Bruno, however, focus on those of Turrell's works that allow the spectator to move around or inside a particular projection space, to enjoy a more intentional mobility of vision, and to have the benefit of framing devices (openings, edges, apertures, other viewers) that become perceptual anchors for the experience of volume and spatial density. In a perceptual cell like Light Reignfall there are no marked lines or identifiable contours in the dome; no figures of proportional scale; no interference of one light beam with another; no architectural corner or edge to interfere with, swallow, or selectively screen just some of the light. While the dome functions as an absorbing and reflecting screen, the absence of any further differentiation or architectural framing erodes the sense of an external surface of projection and collapses the distinction between the chamber and the eye. One does not require prescription glasses in the perceptual cell, because in some respects there is no thing to see. The accompanying humming tones playing in the headphones also preclude any sonic cues from assisting in spatial awareness.

Without any visible or aural spatial cues, the resultant retinal images seem to appear on some invisible layer between the exterior shell of the eyeball and the interior shell of the dome.

Fluctuations in the hue of light shape the perceived position of this virtual "screen," its depth, and its density. As the body's muscles contract or relax in response to the different hues, the image falls alternately on top of or beneath the skin. During my time inside Light Reignfall, some hues and tones—the aquamarines, forest greens, azure blues—felt like a more external caress, and their related abstract images gave the impression of hovering just in front of my eyes, as if I were watching them in near proximity. Others—fire reds, neon pinks, and electric violets—felt like they flooded the entire body, as if the shapes were projected inside of the head, eliciting a tight pressure that moved throughout my ribcage and resonated down my spine. One sequence 
of bright fiery reds, in particular, evoked a feeling of contracting lungs and stomach, catching the breath. This sequence was alarming, as if the light was pulsing through the body and overwhelming its capacity to accommodate the stimulus. Avoiding the urge to temporarily close my eyes, I nevertheless felt my perception fighting to somehow re-frame and thus contain the image. The act of raising my hand to form a barrier between the body and the dome immediately introduced differentiation into the field of vision and dissolved the apparition.

Light Reignfall thus enacts both spatially and optically the radical collapse of the distance between spectator and image which, according to Christian Metz's famous analysis of film spectatorship, threatens the body with sensory ecstasy and brings "an end to the scopic arrangement" [I6]. While any cinematic projection relies on the spectator's unconscious and automatic optical participation in order to produce the moving-image effect, the perceptual cell fuses the programmed light rhythm of the device with the neurologically programmed rhythm of the flesh to turn the body into the primary conduit for light and a supplier of ephemeral visions. The audiovisual sequence playing inside the dome is generated by both the constructed environment and by the body, working together as a single apparatus to produce a moving-image sequence without any external or internal referent, any tangible screen surface, or any discretely identifiable storage medium. The moving image seems to appear from nowhere, exist in no space, and produce nothing but affective impressions tied to loose associations.

The Autoganzfeld and the Limit of Para-Cinematic Transmission

The blueprint for the effect of edgeless projection is the Ganzfeld, or "complete field" in German, a term that refers to a homogeneous visual field without a defined surface or edge lines, which produces what is known as the Ganzfeld effect. In the I930s, German psychologist Wolfgang Metzger noted that a subject looking at an encompassing and wholly undifferentiated, unified field would begin to hallucinate and exhibit signs of an altered state of consciousness. Subsequent researchers into this mode of hallucination would produce the effect by placing diffusing goggles or halved ping-pong balls over subjects' eyes to create two mini-domes, then flooding them with external light, while also putting headphones on them that played noise to eliminate any grounding sound cues [I7]. In the I950s and I960s, Ganzfeld experiments were taken up by American psychologist James Gibson, who expanded the structure to include different types of surfaces and modulated light. As Gibson described his experience of the experiments:

What my observers and I saw under these conditions could better be described as "nothing" in the sense of "no thing." It was like looking at the sky. There was no surface and no object at any distance. Depth was not present in the experience but missing from it. What the observer saw, as I would now put it, was an empty medium. [I8]

Yet if that empty medium included light modulation, then strange visions, shapes, and forms would appear. The Ganzfeld effect provided evidence for Gibson's vehement critique of Gestalt psychology and cognitive psychology, and it supported his insistence on an ecological model of perception, in which sensory phenomena occurred neither in the organism nor the environment, but in the circuitous process of interaction between them [ig].

The scientific interest in this dimension of human vision owes a debt to the history of aviation, as numerous pilots flying during the two World Wars reported optical apparitions in the edgeless sky. Soaring above the clouds with a homogeneous visual field and without clear depth and space markers, pilots reported seeing walls of light of different densities as actual topographical protrusions and boundaries. Some reported losing all sense of their orientation and even hallucinating. The perceptual adaptation developed to cope with this kind of experience, as well 
as for flying in low visibility or dark light, was instrumental aviation. The pilot had to discount or at least view with scepticism her own sensory experience and trust the readings of the instruments, working together to navigate the airplane in an environment that was vertiginous in its perceptual emptiness. As a lifelong pilot, James Turrell experienced the effect in flight. It likely informed his later collaboration with experimental psychologist and NASA engineer Edward Wortz in the planning and design of the first perceptual cell, incorporating the results of emerging research into the effects of edgeless visual fields [20].

Importantly, the Ganzfeld effect is not a product of sensory deprivation, but a product of perceptual deprivation. The senses are engaged, but there are no boundaries, edges, or spatial gaps in the sensory input that would produce clear and identifiable cues of distance and figure-ground relationships. With the senses aroused, other images (visual, sonic, tactile) flood the field of vision to form perceptual figures. The effect has been alternately compared with lucid dreaming, meditative states, and hallucination. It was this indescribability and ephemerality of the images that made the Ganzfeld effect and its modified stroboscopic variation an object of interest for many American psychologists in the I950s and I960s. As historian Jimena Canales argues, the appearance of artificially generated images that seemed wholly divorced from any original referents or screening surfaces fed into already existing debates about the nature of perceptual reality and the reliability of observation as a mode of scientific discovery. Moreover, the optical apparitions promised to offer potential insights into other forms of hallucinatory experiences such as dreams, psychotic breaks, or drug-induced visions. Canales notes that observing and recording the visual patterns posed a challenge, and while some researchers published drawn illustrations of commonly described figures, actually fixing and replicating individual experiences was nearly impossible because of their rapidly changing and subjective qualities [2I]. The specificity and complexity of each individual experience also made comparative analysis difficult, and the frequent combination of stroboscopic hallucinations with psychedelic drugs rapidly eroded the reputation of this area of study.

However, even as the Ganzfeld Effect lost its popularity among most scientists, it became increasingly adopted by a fringe area of perceptual research, which the broader scientific community has called, with some cringing embarrassment, its dabbling in parapsychology. Beginning in the $1960 s$, viewing chambers that stimulated and produced ephemeral visions were used to bolster the case for extra-sensory perception, and until the I990s these studies were reviewed — if grudgingly and with skepticism—even in more established journals. Ganzfeld inquiries into parapsychology were funded by various organizations, including the National Research Council, who wanted to ascertain whether the effect's dynamic hallucinations could actually increase the body's sensitivity, allowing into the mind hitherto invisible modes of transmission and reception of information, such as externally beamed "theta waves" and "alpha waves." In parapsychology, the strategy of triggering these waves and mobilizing them to produce perceptual hallucinations was linked to the "psi-effect" (or just "psi"), referring to phenomenal telepathy and clairvoyance. Without giving credibility to the results, the Ganzfeld experiments were quite innovative in how they adapted various media strategies and devices in attempts to find documented proof that virtual images could be communicated and verified by remote participants without the unconscious interference of a mediator (researcher).

First, the experiments invariably required a specially constructed space, in which different subjects could be placed in proximity to but also isolation from one another (Figure 4). One subject, the "Sender," would be shown one of four randomly selected targets, initially slides of photographs and artwork, but eventually film clips, since some reports indicated that dynamic images "transmitted better." The other subject, placed in a Ganzfeld or flickering Ganzfeld field, 


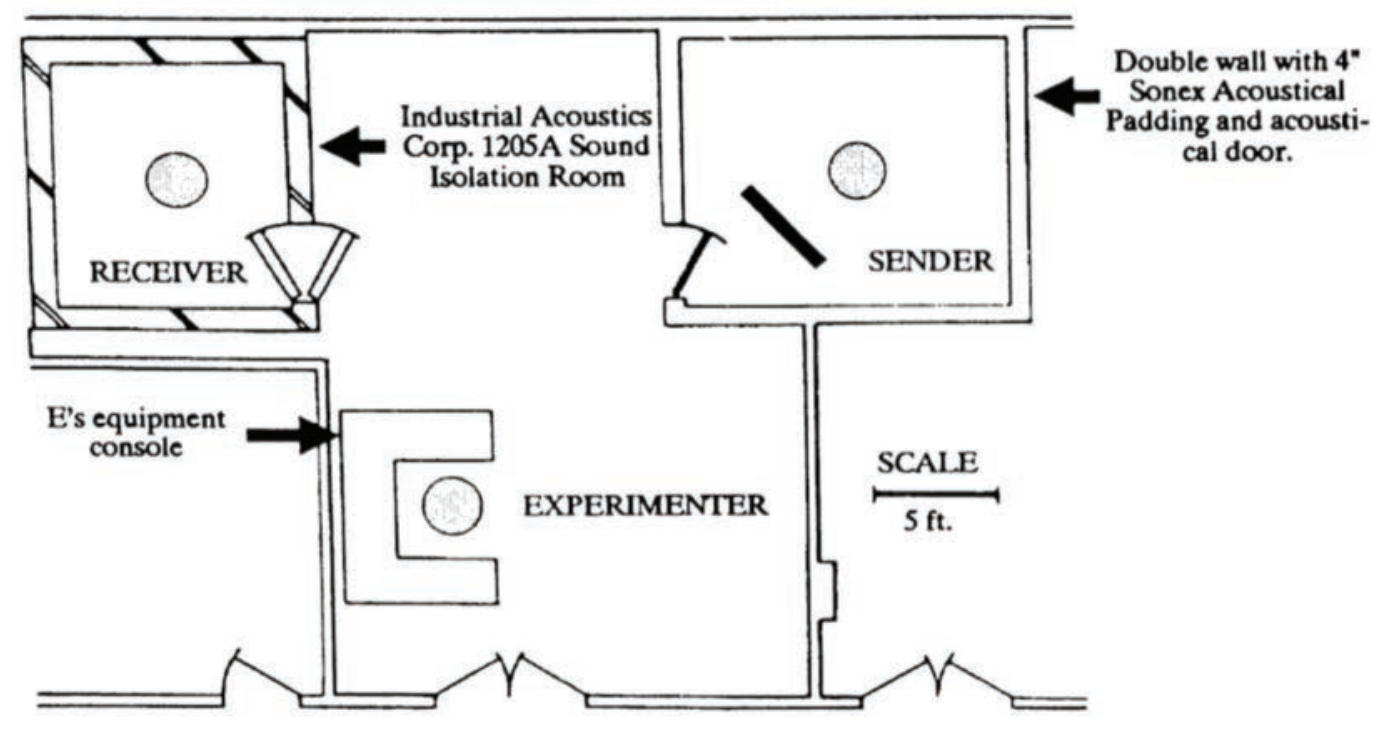

Figure 4. The floor plan of a typical autoganzfeld experiment. The "Sender" and the "Receiver" are isolated from each other within the larger architectural space, while an automated programmable console operated by the experimenter facilitates the experiment. The various bodies and devices are imagined as a single networked apparatus of transmission, reception, and interpretation. (๑) 1990 Charles Honorton)

would act as the "Receiver," trying to experience and describe the images that appeared under the conditions of perceptual deprivation—called "mentating." A researcher would try to record all the mentations, which frequently sounded like disjointed dream ramblings. At the end of the mentation, the Receiver would be shown four clips and would have to identify which one had the most affinities with the animated apparitions experienced in the Ganzfeld. If the Receiver accurately pointed to the same clip that the Sender was shown in another room, then the transmission was coded as a "hit." Different experiments tested different kinds of human mediums, testing whether siblings or friends made for better broadcasting systems, or whether artists or psychologically sensitive people developed better images (in the ways that one might, for example, test out different film stocks or antennae). In the parapsychological variation of the Ganzfeld experiment, human bodies were reconfigured within a kind of constructed apparatus of bodies and machines that could transmit immaterial images and information. The Sender would "compress" the viewed clips into some kind of mental schema, the Receiver would translate the fleeting images into words, and the loop would ostensibly close in a correct identification.

Almost immediately, this compression and projection system ran into a series of problems. First, the coding of every stage of the process resisted a linguistically bound and measurable framework. How clips would be selected without prejudice was unclear, other than the claim that the four clips in the chosen set must be dynamic and different from one another. How one could code and describe those clips was immediately a matter of debate-some rated clips based on degree of emotion, others based them on a predetermined binary code of subjects and objects, asking Senders to mentally code the clips they were viewing through sets of zeroes and ones, like some kind of digital compression filter. How one might turn Ganzfeld-generated images into words was also without precedent.

Then, there were perceived cracks in the experiment's design. The researchers were accused of giving unconscious cues to either of the subjects identifying or confirming certain images. To address this critique, researchers became obsessed with designing the perfect projection and reception space for high-fidelity extra-sensory transmission unpolluted by human interference. 
To this end, the Ganzfeld experiments adopted computer programming to automate the selection and order of specific images, calling the automated version an autoganzfeld experience. Parapsychologists were also among the earliest promoters and enthusiastic adopters of Random Number Generator algorithms, which helped them select random clips without repetition or bias. VHS tapes were replaced with Apple computers as soon as those became commercially available. Eventually, even the human sender was replaced by an automated device, so that the receivers in the experiment were ostensibly receiving and deciphering images beamed out by a computer in another room or part of the building.

However, short of replacing every component of the experiment with computers, save for a single self-reporting subject (a configuration that was also attempted), the experiments were doomed in their inability to ever locate and isolate pure information (the pure transmitted "psi" image) from the situated, fleshy, imperfect bodies that saw and described them. As a marginal paracinema - a media device designed to send and receive wireless mental images — the autoganzfeld was ultimately a failed technology, losing federal funding and eventually all attention from the established scientific community.

\section{Return to the Cell}

James Turrell's perceptual cells, such as Light Reignfall, exist somewhere in between the history of paracinematic devices and the history of para-cinematic experiments. Positioned in the art gallery as a chamber of mysterious wonder, it nevertheless also evokes the space of the laboratory, with its theater of administrative forms, preparation, and anticipation. At the LACMA retrospective, the cell offered the most private experience, and yet it also seemed to demand the most communal and social corroboration. Couples, families, or strangers following each other into and out of Light Reignfall struggled and failed to explain their experiences, and yet continued in their attempts to verify or confirm each other's visions. Were they seeing the same animated apparitions? Were we unwittingly catching sensory transmissions from other visitors in the gallery? These questions echo more widespread ontological anxieties about the origins and intra-subjective verifiability of sensory phenomena; but with the help of the perceptual cell as shared medium, they become opportunities for creative, generative, productive attempts to visually render one's own retinal screen (Figure 5). The perceptual cell considers the ways in which a media device or space of projection can become a method for generating unique and unrepeatable moving-images that have nothing to do with a user's intentions or choices. At a time when wearable brainwave-measuring headsets, virtual goggles, and biofeedback meditation applications are once again coming into vogue, the perceptual cell challenges us to rethink the centrality of the bounded screen (or the defined edge of the virtual window) and to incorporate the animated flesh of the body into an expanded field of projection.

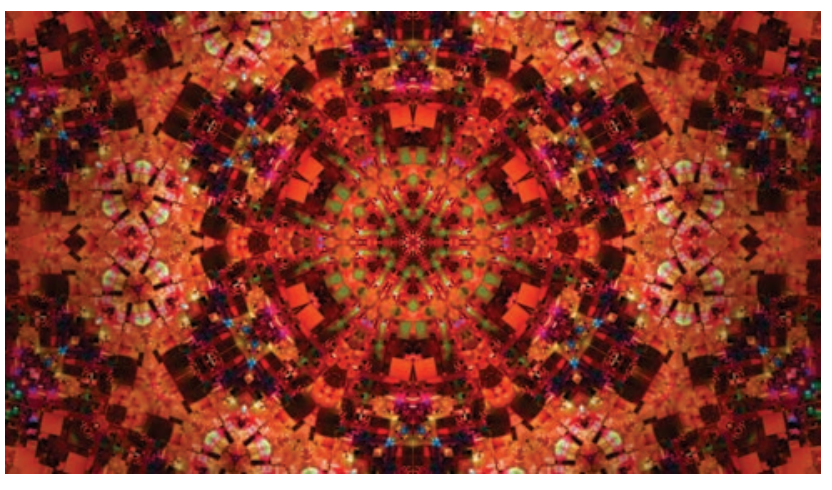

Figure 5. Illustrated rendering of a virtual image seen inside James Turrell's Light Reignfall. (๑ 2016 Alla Gadassik)

\section{Acknowledgment}

This paper was supported by a fellowship from the Social Sciences and Humanities Research Council (SSHRC) of Canada. 


\section{References and Notes}

I. J. Walley, "The Material of Film and the Idea of Cinema: Contrasting Practices in Sixties and Seventies Avant-Garde Film," October Vol. I03, I5-30 (Winter 2003).

2. According to James Turrell, the original design called for one male one female viewer (email correspondence, March 24, 20I6). However, every single instance I have encountered in person or in publicity images and catalogs features two young women.

3. E. C. Krupp, "Under the Dome," LACMA Unframed (February 13, 2014), <http://unframed.lacma. org/2014/02/13/under-the-dome/>.

4. J.D. O'Brien, "Light Happens: Based Upon a Distant Memory and a Recent Viewing of James Turrell: A Retrospective at LACMA,” The Los Angeles Review of Books (January 25, 2014), <https:// lareviewofbooks.org/essay/light-happens/>.

5. Ibid.

6. Raymond Bellour, "Of Another Cinema," in Art and the Moving Image: A Critical Reader, ed. Tanya Leighton (London: Tate Publishing, 2008), p. 420.

7. F.A. Kittler, Gramophone, Film, Typewriter, trans. G. Winthrop-Young and M. Wutz (Stanford, CA: Stanford University Press, 1999), I22.

8. Walley, I8.

9. For a discussion of Tony Conrad's flicker films in relationship to the post-war avant-garde's interest in cybernetic theory and neurophysiological perception, see B.W. Joseph, Beyond the Dream Syndicate: Tony Conrad and the Arts After Cage (Cambridge, MA: MIT Press, 2008).

IO. P. Sharits, L.L. Cathcart, and R.E. Krauss, Paul Sharits: Dream Displacement and Other Projects (Buffalo, NY: Albright-Knox Art Gallery, 1976).

II. See McCall's remarks on his shift to gallery light installation from an initial interest in cinematographic projection in A. McCall, "Line Describing a Cone and Related Films," October Vol. IO3, 42-62 (Winter 2003).

I2. Jordan Belson's planetarium projections received special attention in Gene Youngblood's seminal book Expanded Cinema (New York: P. Dutton \& Co., I970).

13. Gloria Sutton offers an excellent analysis of VanDerBeek's Movie-Dromes in her book The Experience Machine: Stan VanDerBeek's Movie-Drome and Expanded Cinema (Cambridge, MA: MIT Press, 20I5).

I4. G. Didi-Huberman, “The Fable of the Place," in James Turrell: The Other Horizon, ed. P. Noever (Vienna: MAK and Hatje Cantz, 200I), 48.

I5. G. Bruno, Surface: Matters of Aesthetics, Materiality, and Media (Chicago: University of Chicago Press, 20I4), 67.

16. C. Metz, The Imaginary Signifier: Psychoanalysis and the Cinema, trans. C. Britton et al. (Bloomington, IN: Indiana University Press, 1982), 60.

17. J. Wackermann, P. Pütz and C. Allefeld, "Ganzfeld-induced Hallucinatory Experience, Its Phenomenology and Cerebral Electrophysiology," Cortex Vol. 44, No. 10, I364-1378 (2008).

I8. J.J. Gibson, The Ecological Approach to Visual Perception: Classic Edition (New York: Taylor and Francis, 20I5), I43.

19. For a different discussion of James Turrell's color fields in relationship to James Gibson's model of perception, see P. Beveridge, "Color Perception and the Art of James Turrell," Leonardo Vol 33.4, 305-313 (2000).

20. For a detailed account of James Turrell's interest in perceptual psychology and the role of emerging technology in California's Light and Space movement, see C.E. Adcock, James Turrell: the Art of Light and Space (Berkeley, CA: University of California Press, 1990), 6I-84.

21. J. Canales, "A Number of Scenes in a Badly Cut Film," Histories of Scientific Observation, ed. L. Daston and E. Lunbeck (Chicago: University of Chicago Press, 2011), 223. 


\title{
Pulse Shape 22: Audiovisual Performance and Data Transmutation
}

\author{
Mark Cetilia
}

\begin{abstract}
A B S TR A C T
Pulse Shape 22 is an improvisational audiovisual performance featuring shortwave radio transmissions as the sole source material for real-time audio processing alongside video of the sun projected through cast-glass lenses designed specifically for this piece. The structure of the piece is derived from metrics on energy accumulation over a period of 2.2 nanoseconds resulting from the targeting of 60 laser beams on a single tetrahedral hohlraum in weapons testing experiments as carried out by the Los Alamos Inertial Confinement Fusion unit, at the Omega Laser Facility at the University of Rochester. Pulse Shape 22 is an exploration of architectural space through the use of site- and time-specific information found in regions of the electromagnetic spectrum outside the reaches of the human sensory apparatus. It is an attempt to alter the audience's perceptions of their surroundings and create a moment of rupture from hidden worlds found in our local environment.
\end{abstract}

\section{Experimental Data as Formal Structure}

The formal structure for Pulse Shape 22 is based on energy accumulation in tetrahedral hohlraum experiments undertaken at the University of Rochester's Omega Laser Facility. The OMEGA laser "stands Io meters tall and is approximately Ioo meters in length" and is used to "[deliver] pulses of laser energy to targets in order to measure the resulting nuclear and fluid dynamic events" [I].

A hohlraum is the closest physical approximation of an "ideal radiator" that "absorbs all incident radiation and reflects none" and is found in nuclear weapons and reactors [2]. In these experiments, the hohlraum is targeted by a number of laser beams simultaneously and, rather than simply absorbing all radiation without reflection, evenly redistributes the energy in all directions in the form of X-rays, triggering an implosion that starts a nuclear reaction [3].

In Pulse Shape 22, data derived from a burst of energy lasting 2.2 nanoseconds is stretched out to the length of a performance. This data is mapped to the rate at which a single frame of video held in a Frame Buffer Object is replaced within custom video processing software, and is used as a visual aid for the performer, who is able to follow the progressing accumulation of energy by watching a "playback head" advance. Higher values are taken to represent a greater sonic "intensity," produced through an increase in spectral density (especially at frequencies within the range of the human voice) and overall amplitude, as well as through the use of more chaotic and tumultuous transmissions as raw material for manipulation, and by decreasing the number of bits used to represent a given signal.

In addition to the energy accumulation data, Pulse Shape 22 also utilizes pointing parameters for the laser beams to drive the spatialization engine throughout the piece. These pointing parameters are used to determine location in quadraphonic sound space for each of I2 possible buffer playback engines within the SuperCollider scripting language, which exchange positions 60 times throughout the duration of a performance. Thus, in a half-hour 
performance, the position of each buffer playback engine in quadraphonic space shifts every 30 seconds with a cold, mechanical accuracy.

The piece begins almost imperceptibly, with gentle visual pulsations and a dull roar far in the distance. Stretched out nearly a trillion times the duration of the original experiment, Pulse Shape 22 creeps into the consciousness of its audience, slowly filling every space with blinding light and full-frequency noise. When the implosion finally occurs, all that is left is a sharp ringing in the ears and blurred vision, fading into darkness—and silence.

\section{Data Transmutation}

While the foundation of Pulse Shape 22 is data derived from scientific experiments, this work does not seek to reveal patterns in complex data, as in most data visualization/sonification projects. Instead, it is a phenomenological response to the data that situates the viewer/listener inside a new experiment. The data itself is transformed and mutated into an artistic work through a personal process that does not seek decoding or quantification.

\section{Electromagnetic Transmissions as Source Material}

Throughout the history of electronic music-making practice, numerous artists have worked with radio transmissions as source material for compositions and performances. John Cage mentioned "the sound of... static between the stations" as one of a number of potential sonic materials to "capture and control... not as sound effects but as musical instruments," as far back as 1937 in "The Future of Music: Credo" [4]. Radio transmissions were equally important for writer William Burroughs, who would "leave 'three off-tuned radios blaring static' in his room in Tangier," and carry out "experiments using tape recorders, many of which incorporated radio sound and static" from which "words would emerge" [5]. This act of listening to radio transmissions for voices hidden within the static dates back to the early days of radio. In 1920, Thomas Edison claimed that he had "been thinking for some time of a machine or apparatus" that would be "so delicate that if there are personalities in another existence or sphere who wish to get in touch with us in this existence or sphere, the apparatus will... give them a better opportunity to express themselves than... the other crude methods now purported to be the only means of communication" [6].

Mining recordings of radio static for voices of the dead is a technique commonly used within the Electronic Voice Phenomena (EVP) community. In 1960, Friedrich Jürgenson, namesake of the Jürgenson Frequency (I485.o kHZ), was instructed to "use the radio" as a means of communicating with the dead; he "connected a microphone and a radio receiver to the tape recorder" in order to have "real-time [conversations] with his 'friends" by asking questions and listening to responses on frequencies between 1445 and $1500 \mathrm{kHz}[7]$.

Belief in EVP has become widespread since Jürgenson's time, and with the advent of the internet, numerous groups and forums have appeared wherein users trade tips on how best to capture these recordings. Joe Banks, perhaps best known for his recordings of radio anomalies released under the moniker "Disinformation" (1995-present), has, in Rorschach Audio, framed EVP as sound recordings whose existence is "as relevant to the emergent field of sound art as studies of optical illusions have been to the study of visual art" [8].

Though I am not looking to communicate with the dead, the concerns of my artistic practice are somewhat analogous to the concerns of the EVP community. I not only carefully scrutinize the radio noise I use as raw sonic material in my performances, I also look for ways to make meaning from this material—both for myself and for my audience. 


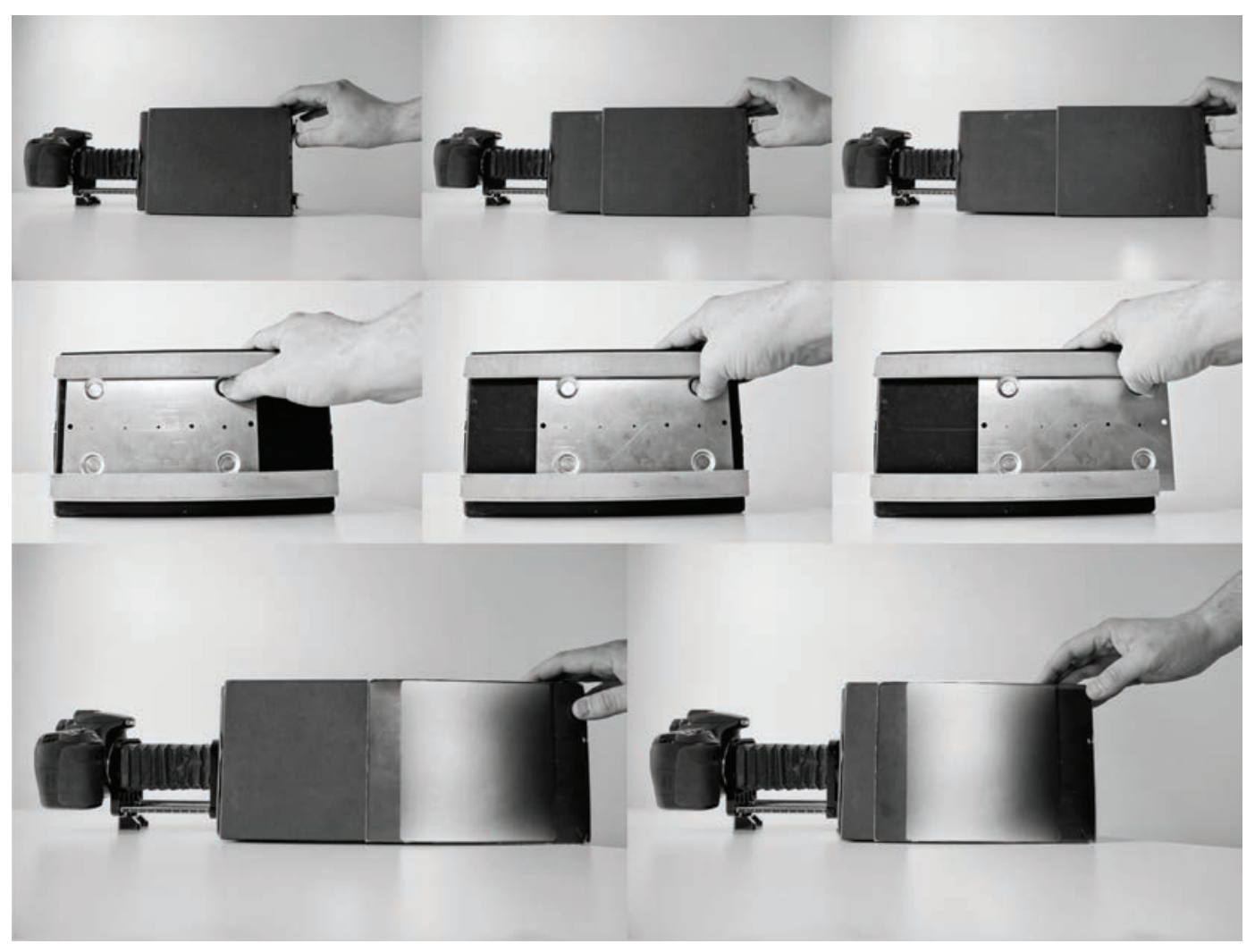

Figure 1. Demonstration of custom pinhole camera's focal length, aperture, and positive meniscus lens. (๑ 2012 Mark Cetilia)

This meaning-making is impacted by the very presence of radio transmissions in the performance space itself. John Cage once remarked to Morton Feldman that radio "[makes] available to your ears what was already in the air and available to your ears but you couldn't hear it.... [All] it is, is making audible something which you're already in" [9]. Pulse Shape 22 allows audience members to consider their relationship to their local environment: the raw sonic materials used in the performance are in fact transmutations of changes in the electromagnetic fields in which the audience is subsumed.

\section{Visual Material and Historical Precedents}

The visual material used in Pulse Shape 22 is comprised entirely of images of the sun shot through a custom cast-glass lens designed for this purpose, via custom hardware used in conjunction with a Digital Single-Lens Reflex (DSLR) camera (Figure I).

The hardware used to collect images for Pulse Shape 22 is comprised of a pinhole camera with an adjustable aperture (a sliding metal plate with holes of different sizes), adjustable focal length (obtained by adjusting how far the lid of the box slides into its base), and support for multiple lenses, including a positive meniscus lens affixed to the outer shell of the box, and "external" lenses in the form of cast-glass blocks with various inclusions. This hardware is utilized in conjunction with a DSLR via a commercially available bellows attachment (Figure 2).

The sun was chosen as the sole source of visual material, due both to its connection to nuclear activity and to its properties as generator of electromagnetic energy received by our bodies themselves. Plants are already dialed into higher regions of the electromagnetic spectrum through photosynthesis. They utilize a transductive mechanism, called a light-harvesting complex, that absorbs sunlight and transfers it into a system of proteins and pigments that feed the plant. Plants harvest light, and we harvest plants. We feed on them feeding on light. The 
term "light-harvesting complex" cropped up in the I930s, at a time when biophysicists retained a closer connection to agrarian culture than they would during the Cold War years of the I950s, when the same mechanism came to be called a "light-harvesting antenna." For artist James Turrell, plants are not the only consumers of sunlight: "As human beings, we drink light in the form of vitamin D through the skin, so we are literally light eaters" [Io] (Figure 3).

Though Pulse Shape 22 uses projected imagery rather than fields of pure color, it is nonetheless an investigation into the physicality of light as medium and is closely tied to the history of the "flicker effect," as demonstrated by Brion Gysin and Ian Sommerville's Dream Machine, as well as in films by Tony Conrad, Peter Kubelka, and others.

The Dream Machine is "a simple flicker machine" consisting of "a slotted cardboard cylinder which turns on a gramophone at $78 \mathrm{rpm}$ with a light bulb inside" [II]. Users of the Dream Machine face the flickering light with their eyes closed, so that kaleidoscopic patterns of color will wash over them at the same rhythm as alpha waves, electrical waves that occur in the brain during periods of deep relaxation.

Tony Conrad's The Flicker (1965) is a 30-minute film comprised solely of alternating bits of white and black film leader. Over the course of the piece, the alternation of these frames "progresses from twenty-four frames per second down to four then back up to twenty-four" [I2].

In conjunction with the "crescendo/ diminuendo" structure of the stroboscopic light, The Flicker features a "tonal pitch in the 'lower ranges of audibility' and rapid rhythms" meant to "[give] unexpected birth to a sense of aural vastness and spaciousness" analogous to the "harmonic structures of light" [13]. The same year, John Cavanaugh created a work known alternately as Flicker or Blink [I4]. The intent of Cavanaugh's film was to assault the viewer's eye to the point of fatigue, creating "temporary blindness characterized by slowly moving, pulsating colorless blobs that hover over the continuous flash of the film" [I5].

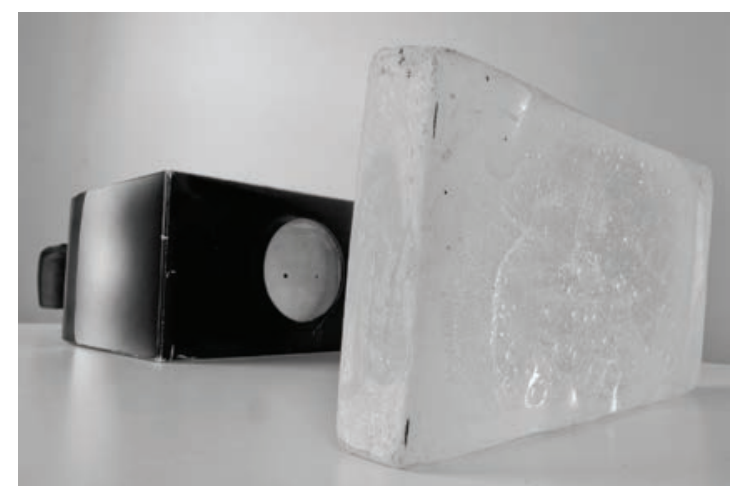

Figure 2. Custom pinhole camera positioned to shoot through an “external” lens. (๑ 2012 Mark Cetilia)

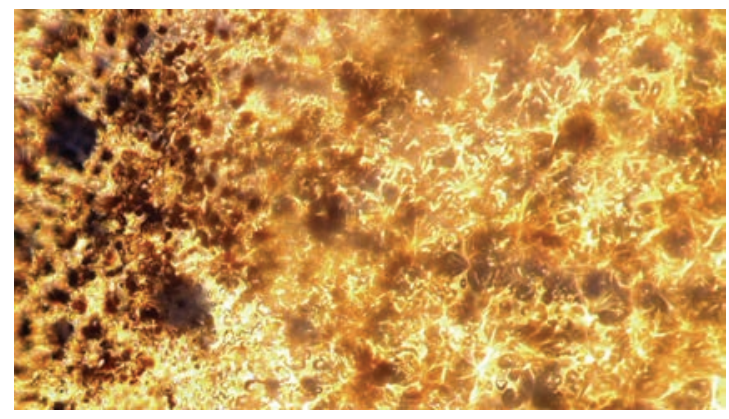

Figure 3. Video still from a Pulse Shape 22 performance, 2012. (๑ 2012 Mark Cetilia)

In addition to Conrad and Cavanaugh, a number of filmmakers_-notably Peter Kubelka and Paul Sharits-incorporated this effect into their work around this time (Kubelka's Arnulf Rainer, widely considered the first "flicker film," actually dates back to 1960). The flicker effect is listed as one of the four characteristics of "structural film," as defined by P. Adams Sitney:

The structural film insists on its shape, and what content it has is minimal and subsidiary to the outline. Four characteristics of the structural film are a fixed camera position (fixed frame from the viewer's perspective), the flicker effect, loop printing (the immediate repetition of shots, exactly and without variation), and rephotography off of a screen. [I6] 
Though Sitney quickly qualifies this definition by stating that one will seldom find "all four characteristics in a single film, and there are structural films that avoid these usual elements" [I7], this definition nonetheless created a conceptual framework for understanding a new type of filmmaking: one concerned primarily with the structure of a film, rather than plot, character development, or any of the characteristic qualities typically associated with film.

Pulse Shape 22 follows in the tradition of this filmmaking practice, and despite the fact that the images change throughout the piece, the visual aspect of the piece is primarily propelled by the intensity of the light and the pacing of the strobe, which in turn acts as a means of relating the underlying data structure to the audience.

The flicker effect is, in fact, an essential element common to all motion pictures, and was even employed in many pre-cinematic devices such as the zoetrope. Filmmaker Ken Jacobs's work, including his "Nervous System" (1975-2000) [r8] and "Nervous Magic Lantern" (1990-present) [I9], has employed overtly stroboscopic projections for decades. Jacobs calls these performances "paracinematic" [20], a term he coined in the I970s to allow for discussion of works "equivalent [to] cinema... created by other than filmic means or by using film in other than standard ways" [2I]. His influence may still be felt throughout this burgeoning field today, in the work of artists such as Sandra Gibson and Luis Recoder, Bruce McClure, and Alex MacKenzie, whose performances feature stroboscopic light and various forms of physical intervention with the projection apparatus by the artists themselves. The "Nervous Magic Lantern" performances were also incredibly influential in the development of the visual element of Pulse Shape 22: they led me to consider the utilization of "gentle" strobing during the opening and closing sequences, which slowly ramp up and down in luminosity, as well as strategies for projection extending beyond the confines of a traditional projection screen. I ultimately accomplished this through the use of "water lenses"-glass vessels filled with water, placed in front of a projector.

\section{Sinesthesia}

It is important to note that Pulse Shape 22 is not built on a foundation of sound-to-image data transmutation, but instead finds both sound and image driven from a common source of data. This allows the sonic and visual elements to function within their own native languages.

Contemporary discourse regarding audiovisual works often includes discussion of synaesthesia, a neurological condition in which "regions of the brain which do not usually communicate, such as the visual and auditory cortexes, show signs of what is known as 'crosstalk"' [22]. While a handful of composers—notably Scriabin, Messiaen, and Ligeti—were truly "synaesthetic" [23], most artists (and their audiences) do not experience the world in this manner, and simply mapping sound to vision does not take into account the complexities of visual language. Christoph Cox summed up the problem with such mappings in 2005:

Sound is real... something too quickly forgotten by the fantasy of a "union of the senses," which remains a visual fantasy. Genuine sound art today is fostered not by... consensus, but by a dis-sensus that gives sound and hearing their due. [24]

The necessity of working with media in ways that take into account the intricacies of sonic and visual languages has long been understood by experimental (or "structural") filmmakers such as Paul Sharits, who, in 1978, said:

I do not wish to suggest that I was or am captivated by the notion of "synesthesia".... I am not proposing that there exist any direct correspondences between, say, a specific 
color and a specific sound, but that operational analogues can be constructed between ways of seeing and ways of hearing (and sometimes, when such structural analogues are composed, one can thereby experience those levels of ultimate difference between the two systems)... Can there exist a visual analogy of that quality found in a complex aural tone, the mixture of a fundamental tone with its overtones?... But how can one film frame of one solid color possess such a quality? It cannot. Yet, a series of single frames of different colors, which creates "flicker," can, depending upon the order and frequency of the tones, suggest such a quality; but, it can only suggest. [25]

In works such as Ray Gun Virus (1966), Sharits explored the use of stroboscopic color fields in a way that suggests simultaneity, which he purports to be a visual analogue to the use of complex overtones in a piece of music. In this process, Sharits breaks down sonic and visual elements to their essential components, then recombines them, but he does not expect the viewer/listener to perceive these newly combined elements as a single "linked" synaesthetic experiencerather, he states that this pairing may in fact be used to reveal the differences between these modes of perception.

In an interview, contemporary sound and visual artist Steve Roden (born 1964, active 1985present) discusses his strategy for considering sonic and visual elements of audiovisual works separately:

I'm very firm about something until I kind of "know" it and then I contradict myself to open new territory. And so, I decided to try something where a sound and visual work could converse in a single space. What I like about this situation... is that it is a somewhat unresolved relationship. Rather than each enhancing each other,... the two things tend to pull apart from each other.... I can explore my ideas in various languages without worrying about how much they relate on the surface-I'm striving for connections that are much deeper. [26]

Pulse Shape 22 is the result of such a separation of thought and labor. My initial investigations into this piece were solely concerned with its sonic component and the development of the necessary tools and technologies for this performance. Throughout this developmental phase, I spent time learning how to play the instrument I was creating; this allowed for a degree of flexibility in designing the performance system, ultimately arriving at a design that was best suited to the needs of the piece and my desires as a performer. Upon completion of this phase, I put together a sound-only performance of the piece, before ever considering the visual component-and when I began work on the visual component of the piece, I set aside the sound entirely. I feel that this process was incredibly important for the success of the piece, as it allowed me to focus on the data transmutations that would be most appropriate for its sound and visual elements.

\section{Observations and Future Directions}

I am interested in continuing the evolution of my working process to include the development of systems for data transmutation that do not always need to provide answers to the audience, or demonstrate features of the data itself. By defining and refining ways to draw inspiration from primary sources without constantly seeking justification of my artistic intent or disallowing self-questioning, I hope to engage more deeply with source material and learn directly through the process of artistic production. 


\section{Acknowledgments}

Thanks to Joseph Rovan, Todd Winkler, Shawn Greenlee, Ed Osborn, and Jocelyne Prince for their feedback and encouragement. This work is dedicated, as ever, to Laura Cetilia.

\section{References and Notes}

I. OMEGA, <http://www.lle.rochester.edu/omega_facility/omega/>, accessed March 2016.

2. S.P. Parker, ed., McGraw-Hill Dictionary of Physics, 2nd ed. (New York: McGraw-Hill, 1997), 42.

3. Los Alamos National Laboratory, Tetrahedral Hohlraum High-Convergence Implosion Experiments on Omega ID4-FYg8 (Los Alamos, NM: Los Alamos National Laboratory, 1998), 2.

4. J. Cage, Silence (Hanover, NH: Wesleyan University Press, 196I), 3.

5. D. Kahn, “Three Receivers," Experimental Sound and Radio, ed. Allen S. Weiss (Cambridge, MA: MIT Press, 200I), 73.

6. T. Edison, "Edison's Views on Life and Death," Scientific American, 446 (October 1920).

7. C.M. von Hausswolff, "I485.o kHZ," Cabinet Magazine, Issue I, 60 (Winter 200o/oI).

8. J. Banks, "Rorschach Audio: Ghost Voices and Perceptual Creativity," Leonardo Music Journal Volume II, 77 (200I).

9. J. Cage, and M. Feldman, Radio Happenings: Conversations / Gespräche (Cologne: MusikTexte, 1993), I9.

Io. D. Kahn, "Electrical Atmospheres," Invisible Fields: Geographies of Radio Waves, eds. José Luis de Vicente, Honor Harger, and Josep Perelló (Barcelona: Arts Santa Mònica, 20I2), 26.

II. B. Gysin, "Dreamachine," Flickers of the Dreamachine, ed. Paul Cecil (Hove, UK: Codex, 1996), 5.

I2. A. Powell, Deleuze, Altered States and Film (Edinburgh: Edinburgh University Press, 2007), I07.

13. Ibid.

14. Cavanaugh later withdrew all of his films from the Anthology Film Archives "at a time in his life when, due to extreme LSD experiences, he sank into a period of insanity during which he was institutionalized for several years," cf. Fluxfilm Anthology, <http://home.utah.edu/-klm6/3905/ff5_ Blink.html>, accessed March 2016.

I5. H. Higgins, Fluxus Experience (Berkeley: University of California Press, 2002), I7.

I6. P. Adams Sitney, "Structural Film," Film Culture Reader, ed. P. Adams Sitney (New York: Cooper Square Press, 2000), 327.

I7. Ibid.

I8. W. Rose, "Annotated Filmography and Performance History," Optic Antics: The Cinema of Ken Jacobs, eds. M. Pierson, D. E. James, and P. Arthur (New York: Oxford University Press, 20II), 270.

19. Ibid., 272.

20. J. Walley, "The Material of Film and the Idea of Cinema: Contrasting Practices in Sixties and Seventies Avant-Garde Film," October Volume 103, I7 (Winter 2003).

21. M. Pierson, "Introduction: Ken Jacobs-A Half-Century of Cinema," Optic Antics: The Cinema of Ken Jacobs, eds. M. Pierson, D. E. James, and P. Arthur (New York: Oxford University Press, 20II), I6.

22. C. van Campen, The Hidden Sense: Synaesthesia in Art and Science (Cambridge, MA: MIT Press, 2008), 45 .

23. Ibid., 20-23, 50-53.

24. C. Cox, "Lost in Translation: Sound in the Discourse of Synaesthesia," ArtForum, 24I (October 2005).

25. P. Sharits, "Hearing: Seeing," The Avant-Garde Film: A Reader of Theory and Criticism, ed. P. Adams Sitney (New York: Anthology Film Archives, 1978), 256-7.

26. Y. Novak, "Interview with Steve Roden," <http://www.tokafi.com/Isquestions/interview-steveroden/>, accessed March 2016. 


\section{Deletion Process_Only you can see my history: Investigating Digital Privacy, Digital Oblivion, and Control on Personal Data Through an Interactive Art Installation}

Kyriaki Goni

Independent Artist

Evrou str. 4, 11528

Athens, Greece

contact@kyriakigoni.com

kyriakigoni.com

See <www.mitpressjournals.org/toc/leon/49/4> for supplemental files associated with this issue.
Kyriaki Goni

\begin{abstract}
A B S T R A C T
In light of recent controversies surrounding massive data collection by corporations and government agencies, digital privacy, the right to oblivion, and data ownership have become increasingly important concerns. This paper describes the author's artwork, Deletion Process_Only you can see my history, an interactive art installation based on her eight-year personal search history in the Google search engine. While the personal search history maintains a sense of privacy, according to the company's own declaration, the author reveals this archive to viewers in order to raise awareness and provoke reflection on the aforementioned subjects. The author discusses her motivation, describes the making process and the decisions made at each step of designing the installation, while integrating at the same time a deeper discussion on the place of digital privacy and oblivion within the contemporary approach to art and technology.
\end{abstract}

\section{Introduction}

Queries on search engines, status updates, friendship connections, preferences generated in social media, geo-location data from smart phones, purchasing history, and more provide businesses, governments, and scientists a wealth of insights and a new way of understanding the world.

The increased practice of surveillance and the continuous accumulation of data and metadata have been met by a parallel increase in their study. A dedicated open-access electronic journal, Surveillance \& Society, was created in 2002, designed to address and push forward the thennascent transdisciplinary field of surveillance [I]. The journal continues to publish work that bridges disciplines and perspectives.

What David Lyon refers to as the "electronic panopticon" [2] has led to a contemporary existential crisis, questioning the construction, reinvention, and privacy of the individual and his identity, the right to be forgotten, and the control and distribution of this personal dataset.

Building on Michel Foucault, Gilles Deleuze underlined the telos of panoptic discipline and the rise of "societies of control" [3]. He argues that much remains to be discovered about the forces that control societies. What is clear is that a strategic shift in power relations is underway.

Complementing the formal academic study of surveillance, the topic has also drawn the attention of many digital artists [4]. In Surveillance \& Society, Jonathan Finn names several researchers from different disciplines who interrogate the subject.

Within this theoretical frame and in the context of related artworks, this paper presents two versions of an interactive installation. In the first version, the personal search history dataset is opened to the public upon consent. In the second, the same dataset is presented on a website. 
Before delving into the descriptions, I will start by providing some context on the aforementioned subjects.

\section{Context}

Digital forgetting and oblivion

Witnessing humanity's historical efforts to preserve memory, one might conclude that forgetting is a weakness of the human mind. In fact both forgetting and remembering are active processes of equal importance.

As Liam J. Bannon states, "forgetting is a necessary mental activity that helps us filter the incoming sensory flood and thus allows us to act in the world" [5]. Viktor Mayer-Schönberger [6] and Alexander Luria [7] mention cases where remembering everything had detrimental effects on a person's cognition. The positive impact of forgetting has been recognized by society as well. People are given a fresh start by having their past criminal records erased and credit information from long ago expunged.

In the digital world, organizations such as Google have gone to great lengths to preserve everything that passes through their machines. A user's search history, emails, and sites visited can be stored potentially forever. Google itself encourages users to preserve everything-one of the selling points of their services is that subscribers won't have to delete any of their data in order to make space [8].

Amassing all this data is seen as the next generational step in delivering better, more personalized search results. Companies collect and store all of this data, because the basic revenue model of the internet is built on the invasion of users' privacy. As European Consumer Commissioner Kuneva stated, "Personal data is the new oil of the internet and the new currency of the digital world" [9].

Dataveillance and privacy

Since personal data is often managed by third parties, serious issues regarding the privacy of the individual have been raised. People are often prevented from having knowledge of how their information is being used [Io], and its aggregation can lead to probabilistic predictions based on behavior patterns.

Many people are unaware of the extent to which their electronic activity is recorded, while others put forth the "nothing to hide" argument, which stems from the faulty premise that privacy is about hiding hideous actions [II]. The European Union has unveiled the Data Protection Regulation, which includes a provision for the "Right to Be Forgotten" [I2] in order to update European privacy laws to the shifting digital landscape.

Data ownership

The issue of data ownership and data governance gains importance in this data deluge.

Individuals are becoming increasingly aware of the value of their data and they are less willing to give their personal datasets away. Crucial questions arise about legal rights regarding use, access, and distribution of personal data. The digital footprints left in the continuously improving algorithms result in improved personalization, meaning more successfully targeted search results for the user.

On the other hand, the aggregation of information about the thoughts, needs, and desires of the user lead to better insight into the individual, as Neil Lawrence rightly observes [13]. The queries 
and desires that users type into the search engine are connected to their profiles, and offer a detailed description of what and how they think.

In this vast ocean of information (created by both data and metadata) there is a desperate need to find meaning. For that reason, Google (and all search engines) utilizes algorithms for datamining in fields such as artificial intelligence, pattern recognition, economics, etc.

At the 2016 Transmediale festival in Berlin, Matteo Pasquinelli [I4] discussed the two universal functions of algorithms for data mining: pattern recognition and anomaly detection. He writes: "beneath the surface of the web, gigantic datacenters have been turned into monopolies of collective data. If networks were about open flows of information (as Manuel Castells used to say), datacenters are about the accumulation of information about information, that is metadata" [I5].

He continues, explaining that pattern recognition seeks to recognize something meaningful in the landscape of apparently meaningless data, to find what Manuel DeLanda has described as the emergence of singularities. Anomaly, he continues, can be detected exactly within this regularity of patterns. In that sense pattern recognition and anomaly detection are the two epistemic tools of algorithmic governance [I6].

\section{The Art Practice}

This deluge of information and the introduction of digital technology into many realms of everyday life has provided fertile ground for artists who add a critical voice to the discussion around dataveillance and society. In "Art in a Time of Surveillance," Peter Maass provides a thorough list of artists working on these subjects [I7].

The most significant compendium of related work is the 2002 exhibition catalogue, CTRL [SPACE]: Rhetorics of Surveillance from Bentham to Big Brother, published by the ZKM Center for Art and Media in Germany [I8].

The list of artwork on these subjects is rather long and includes several that, like Deletion Process, reveal private/personal information to the public. From 2000 to 2003, Eva and Franco Mattes, in their work Life Sharing, made the contents of their hard drive open to the public online. It was possible to read their emails and search their folders [I9, 20].

Since 2002, when the U.S. government mistakenly listed him on its terrorist watch list, and after being interrogated for several years by the FBI, Hasan Elahi has made his whereabouts known by publishing his GPS coordinates online in real time in Tracking Transience [2I, 22].

PRISM, a work by Danja Vasiliev and Julian Oliver that successfully hijacked the cellular connections of at least 740 phones - without any interaction from users - and sent text messages during the opening night of Transmediale 20I4, was taken down the same night [23].

To complete this short list, Laura Poitras, director of Citizen 4 (the award-winning 2014 documentary film concerning Edward Snowden and the NSA spying scandal), is currently the subject of a 2016 solo exhibition at the Whitney Museum in New York [24].

The following sections discuss the philosophical implications of forgetting [25] and describe two versions of an interactive art installation in which I use my private data in order to provoke and disrupt public debate on the issues of privacy, dataveillance, and data ownership. 
As an artist working across media, with a background in cultural anthropology, I consider artistic practice to be also a form of research. For that reason, with this art project I attempt to investigate our digital culture and our potential to reclaim ownership and control of our digital lives, and to gain an understanding about the current and future conditions regarding technological progress.

\section{The Art Project: An Interactive Installation}

Google offers a wide range of online services. In order to access them, the user has to create a Google account which consolidates the user's activity under one name. Once logged in, most users choose to remain so while browsing the internet. This allows Google to match each user to all terms searched.

I0,650 search terms, the corpus of my web history during the period 2008-2013, are used in this project. For each term searched, Google stores and provides the time and date of the search, the search results clicked on, as well as the frequency that these were visited.

When I was working on the first version of the project back in 20I3, the company's account policies made it painstakingly difficult to download one's own data; custom software in Python and Ruby had to be written in order to obtain it. Since April 2015 these policies have been changed and it is possible to download one's search history and store it locally.

This project comments on digital privacy, the right to be forgotten, and the ownership of personal data. Most of the searches are personal and rather banal; but at the same time, this search history composes a rich and detailed user profile in Google's data centers, to which the user has few to no rights. Google Inc. assures users that their search history is strictly private-as stated on its website, "Only you can see your history." Both versions of this project are described in detail in this paper.

The Google engine is the only search engine used, since it was the only one that I used from 2008-20I3. Moreover, this search engine is a unique paradigm of a business corporation that dominantly indexes and documents the public archive. The capacity of search-engine advertising based on such databases to reach consumers at the precise moment their desires are transmitted and tracked through search entries is a key component of the engine's economic advantage [26].

The potential of the state and other actors and agents to use Google's database to monitor, understand, target, and make determinations about the activities of particular individuals who have searched through Google makes it a potentially dangerous mechanism of surveillance and social control [27]. Furthermore, Google's ubiquity, hegemony, and consecration mean that its power to shape access to information is unprecedented; accordingly, PageRank has received considerable academic attention [28]. It is indicative that the verb "to google" was added to the Oxford English Dictionary on June 15, 2006 [29] and is used worldwide as a synonym for searching for information on the internet.

Deletion process: Table of disclosure (version I)

The entire Google web history was downloaded and this unique local copy was transferred to a Raspberry Pi microcomputer. Following this, all web history associated with me was deleted from the Google servers. A screenshot of the empty profile was taken and printed as a certificate (Figure I). 


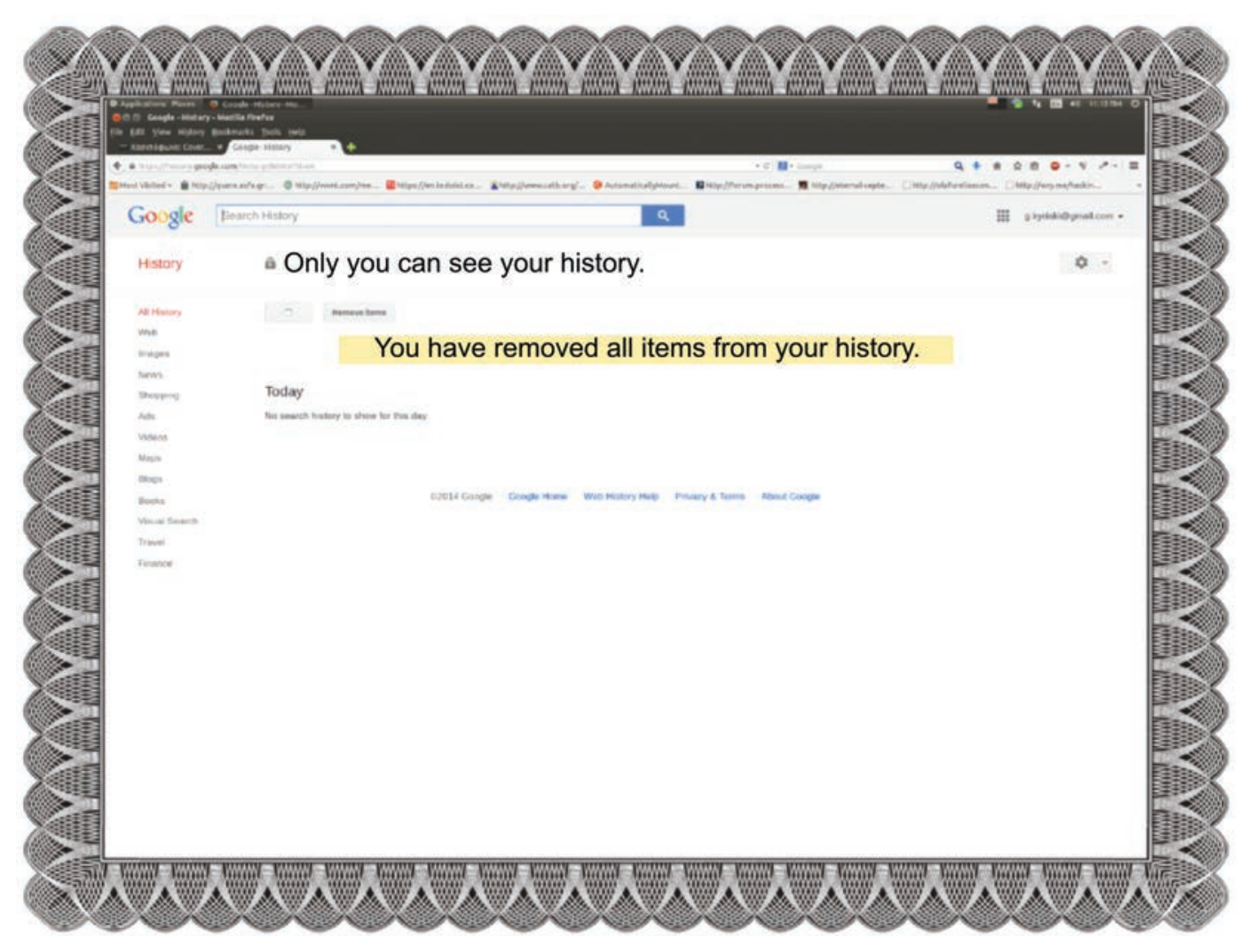

Figure 1. A screenshot of the empty profile was taken and printed as a certificate. (๑ 2015 Kyriaki Goni)

Additionally, a hardcover book containing the entire web history, including its associated metadata, was printed and encased in a glass box on a handcrafted table (Figure 2). The microcomputer running a web server hosting the aforementioned data was embedded inside the table while remaining visible under a glass cover.

A button on the table activates the wireless transmission of one search string from the personal data, along with its timestamp, to all connected devices. This is summarized to the spectator with the following sign next to the button:

This button initiates the transmission of the artist's personal web history.

If you consent:

I. Press the button

2. Connect your device to the Active Oblivion network

3. Visit any page using your browser

If the spectator consents to the data transfer, the singular piece of information he receives appears on the screen of his device. Along with that, a notification appears stating that the transmitted data has just been permanently deleted from the only existing electronic copy.

Deletion Process_Only you can see my history (version II)

I noticed that the first version of the project was more introverted than I had planned; my main scope was to strongly engage viewers in the voyeuristic condition of searching my personal search history. Moreover, the issue of ownership was not brought into consideration. To that end I produced a second version of the project. 

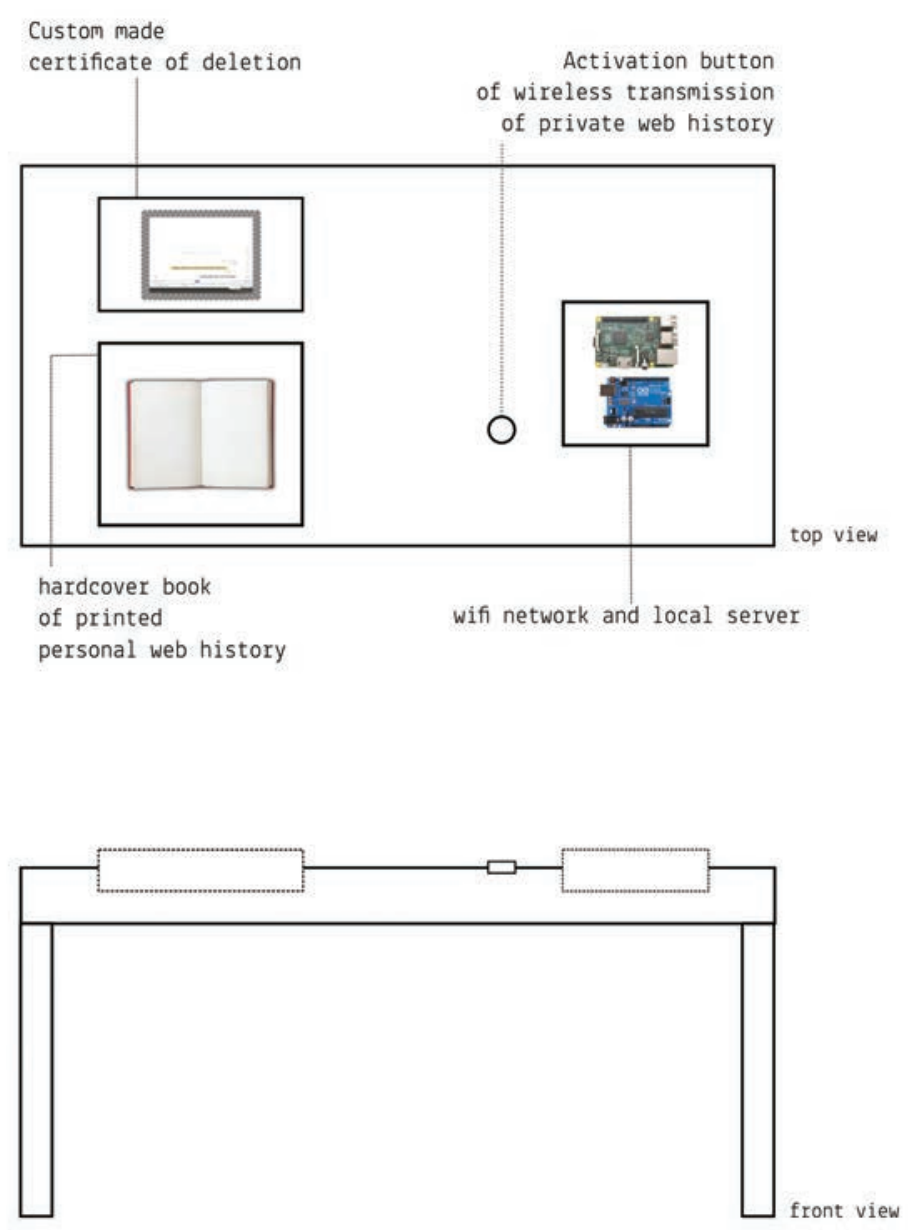

Figure 2. Top and front view of the Table of Disclosure. (๑) 2015 Kyriaki Goni)

The main difference between the two versions was that the second one was online, completely open to the public [30]. The consent button was abandoned, so now everyone has unlimited access to my personal history archive. Regarding the data ownership, I decided to sell parts of my search terms, in a kind of humorous and provocative act (Figure 3).

As mentioned above, the I0,650 terms that I searched for over the last eight years have been downloaded from my personal search history and stored locally. In the second version of the work, the search terms are depicted as white squares on a webpage (Figure 4).
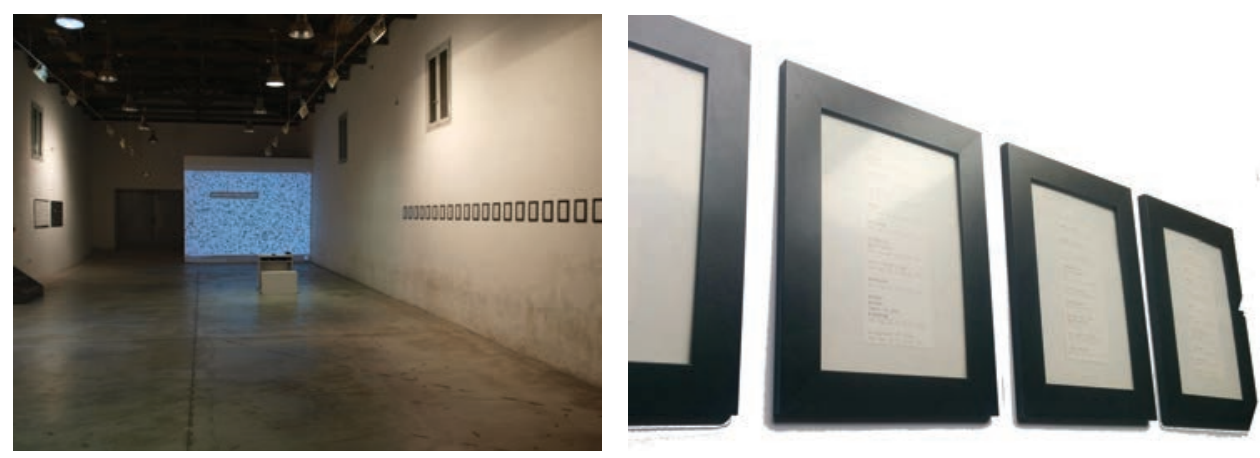

Figure 3. (left) Deletion Process_Only you can see my history, installation at Dialogue \#10: Art, New Technologies and Social Media, November 2015. Interactive installation, URL, server, custom software, Raspberry $\mathrm{Pi}$, thermal mini printer, archival prints mounted on dibond 120 x 67 cm, 20 prints, 17 × 22 cm. (๑ 2015 Kyriaki Goni); (right) my search terms on sale. (๑ 2015 Kyriaki Goni) 
Two eroding processes access this search history and delete one random word forever, turning the respective white square into a black one in the aforementioned webpage. The one process is initiated by the computer and the other is triggered by the viewer. In that way the work develops itself over time without the control of the artist. The computer and the number of viewers interacting with it in situ affect its development in time. There is a synergy between the computer and the viewer, leading to the total deletion of my personal search history. In both cases of the deletion process the deleted search term is printed on paper, turning the digital archive into a physical one. At the end of these processes all terms will have been deleted and the webpage will be completely black. The printed paper will be the only remnant of the personal search history and it will be cut into pieces, exhibited and offered for sale as a playful and provocative comment on the distribution and control of personal data (Figures 4 and 5 ). The continuously growing physical presence of the printed paper is rather intense and provides the work with a performative and material characteristic, almost like a sculpture developing in time (Figure 6).

From an aesthetic point of view, the choices made were the simplest possible, allowing an abstract and therefore almost poetic approach to these extremely complex notions. In my opinion, the facts that the work develops over time, through the joint processes performed by computer and viewer, and that this whole action is presented online, are very important to the aesthetic effect of the project.

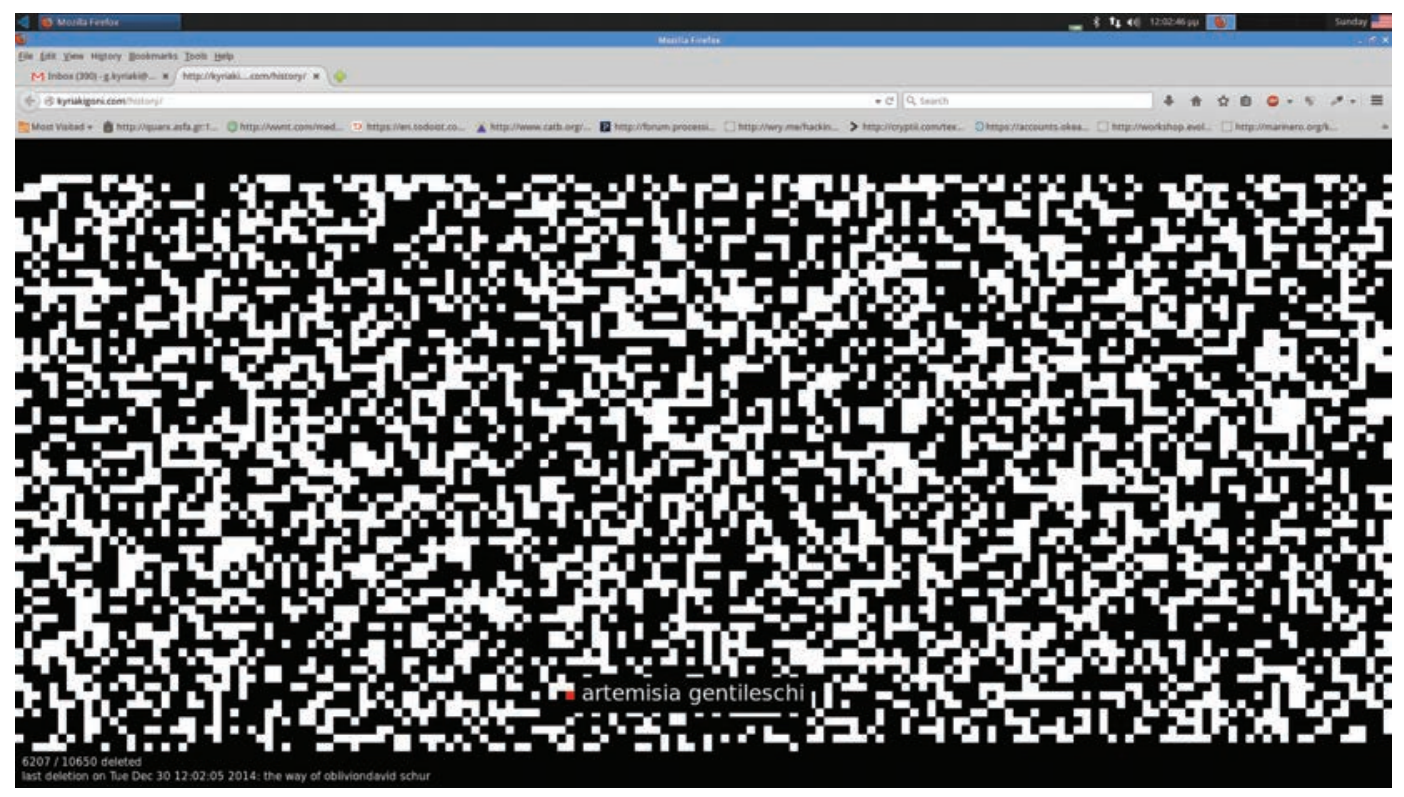

Figure 4. Deletion Process_Only you can see my history. Screenshot from the website. Detail, thermal mini printer and Raspberry Pi. (๑ 2015 Kyriaki Goni)

\section{Thoughts and Reflections}

This project provided me valuable insight into the complex notions of dataveillance, data ownership, and digital oblivion. At the same time it is a physical manifestation of complex processes brought together by the human brain and machine-learning algorithms.

Every time the second version of the work is exhibited, viewers are intensively engaged (Figure 7). Interaction with the work leads to discussion and to further research on the issues the work deals with. 


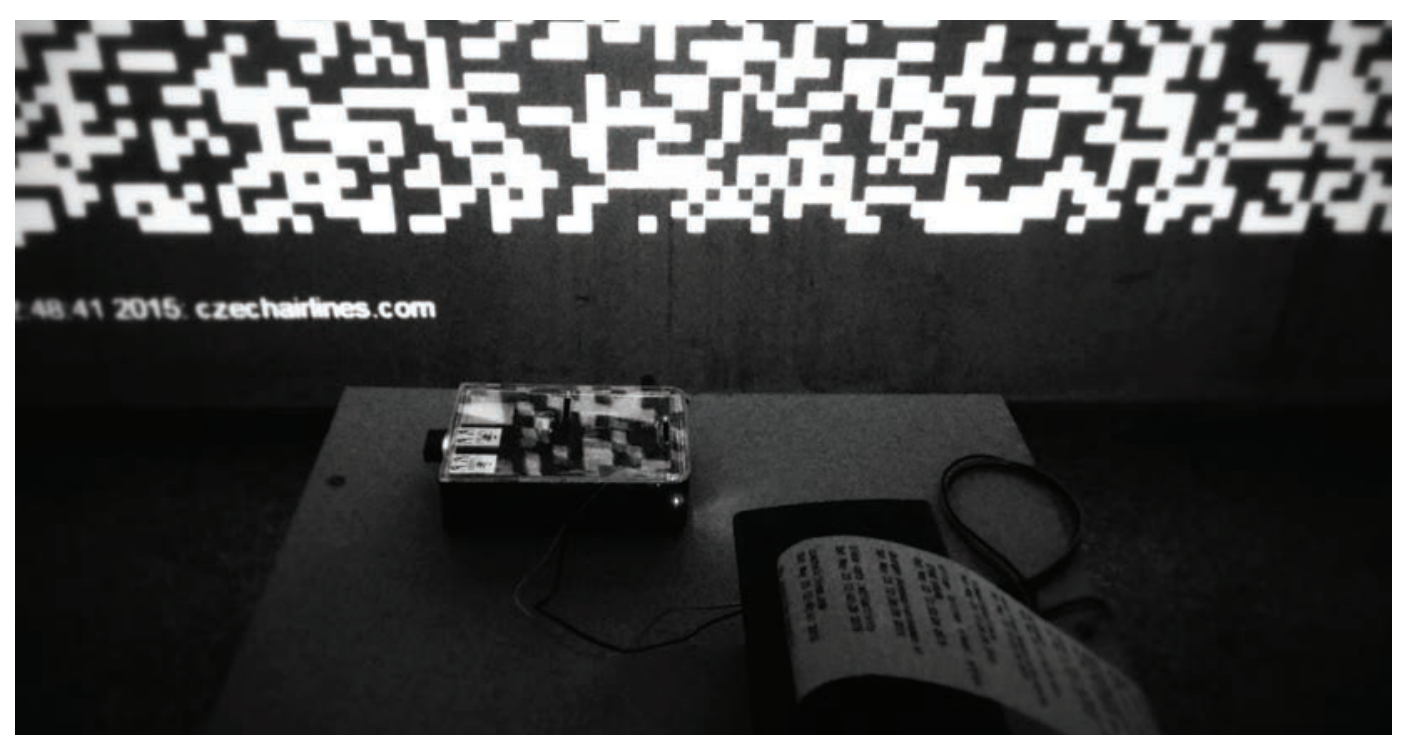

Figure 5. Deletion Process_Only you can see my history, Athens Video Arts Festival, May 2015. Projection of the webpage: Raspberry Pi, mini printer, print. (๑ 2015 Kyriaki Goni)

The intentional iteration of the exact same search history archive adds a further skeptical comment on the control of personal datasets regarding deletion and oblivion.

The possibility exists for a variation on the second version of the work that would make the whole process real-time, with the use of an API and by inviting viewers to watch and delete what I search for in real time. This version would be presented as a short performative piece for two or three days. It is worthwhile to observe that a real-time version would underline the lack of privacy for the artist herself, and emphasize the exhibitionistic and voyeuristic character of the work even more.

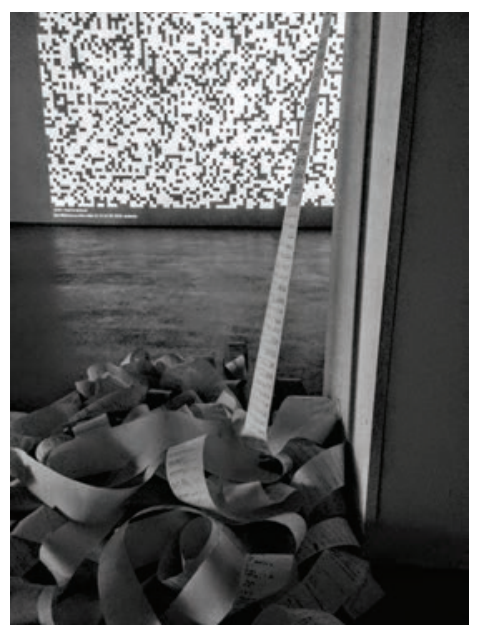

Figure 6. Deletion Process_Only you can see my history, Oddstream Festival, March 2016. Projection of the webpage: Raspberry Pi, mini printer. (๑ 2016 Kyriaki Goni)

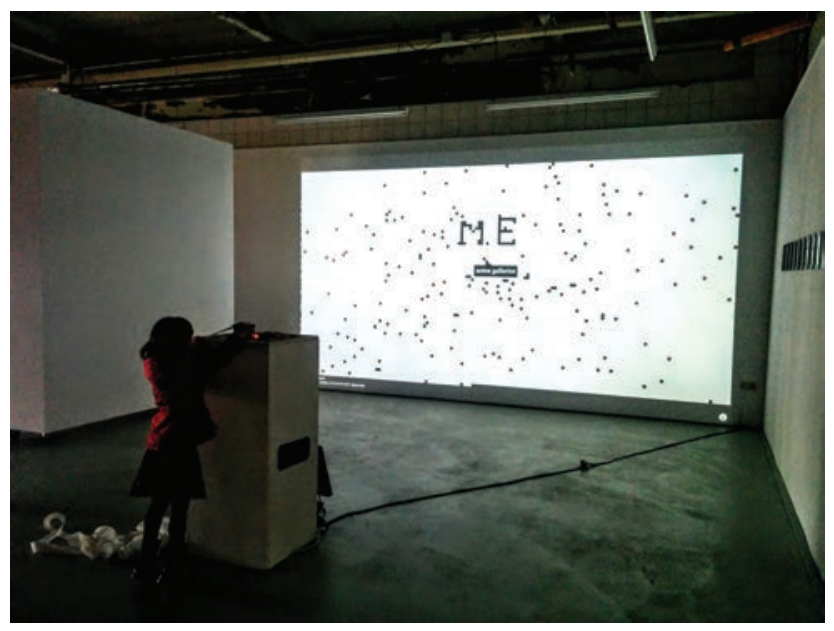

Figure 7. Deletion Process_Only you can see my history, Oddstream Festival, March 2016. Projection of the webpage: Raspberry Pi, mini printer. (๑ 2016 Kyriaki Goni) 


\section{Acknowledgments}

I would like to acknowledge Nikos Roussos and Theodoros Papatheodorou for their technical support.

The installation (version II) has been presented at Oddstream, Nijmegen, Netherlands (March 20I6); Contemporary Art Dialogues_-Dialogue \#IO: Art, New Technologies and Social Media, Athens, Greece (November 20I5); Athens School of Fine Arts (September 20I5); Athens Digital Arts Festival (May 20I5); and the Michalis Cacoyannis Foundation, Athens (November 20I4).

The artist spoke at Oddstream, Nijmegen (March 20I6) and at Hackerspace, Athens, Greece (April 2016).

\section{References and Notes}

I. Surveillance \& Society, <http://library.queensu.ca/ojs/index.php/surveillance-and-society/ about/history>.

2. D. Lyon, The Electronic Eye: The Rise of Surveillance Society (Minneapolis: University of Minnesota Press, 1994), 57-80.

3. G. Deleuze, "Postscript on the Societies of Control," October Vol. 59, 7 (Winter 1997).

4. See, for example, J. Finn, "Surveillance Studies and Visual Art: An Examination of Jill Magid's Evidence Locker," Surveillance \& Society Vol. IO, No. 2, I34-I49 (2012).

5. L.J. Bannon, "Forgetting as a Feature, Not a Bug: the Duality of Memory and Implications for Ubiquitous Computing," CoDesign Journal Vol. 2, No. I, 3-15 (2006).

6. V. Mayer-Schönberger, Delete: The Virtue of Forgetting in the Digital Age (Princeton, NJ: Princeton University Press, 2009) I2.

7. A.R. Luria, The Mind of a Mnemonist: A Little Book About a Vast Memory (New York: Basic Books, I968).

8. Google Gmail, <http://goo.gl/RqD9j>.

9. M. Kuneva, Keynote Speech, Roundtable on Online Data Collection, Targeting and Profiling, Brussels, March 3I, 2009, <http://goo.gl/fmmsB>.

Io. D.J. Solove, “'I've Got Nothing to Hide' and Other Misunderstandings of Privacy," San Diego Law Review Vol. 44, 765 (2007).

II. Ibid., 764 .

I2. European Commision, "Commission Proposes a Comprehensive Reform of the Data Protection Rules," Brussels, January 25, 20I2, <http://goo.gl/Ulekq>.

I3. N. Lawrence, "Why the Ownership of Personal Data in the Hands of a Few Should Worry Us," Alternet, <http://goo.gl/vAs3hk>.

I4. M. Pasquinelli, "Anomaly Detection: The Mathematization of the Abnormal in the Metadata Society," <https:/www.academia.edu/ro369819/ Anomaly_Detection_The_Mathematization_of_the_Abnormal_in_the_Metadata_Society>.

I5. Ibid.

I6. Ibid.

17. P. Maass, "Art in a Time of Surveillance," The Intercept, November 13, 20I4, <https:// theintercept.com/2OI4/II/I3/art-surveillance-explored-artists/>.

I8. CTRL[SPACE], Rhetorics of Surveillance from Bentham to Big Brother, <http://ctrlspace. zkm.de/e/>.

19. E. and F. Mattes, Life Sharing, <http://orooiomioioiroi.org/>.

20. Eva and Franco Mattes co-curated the exhibition Black Chamber, on the theme of surveillance, on display at the Škuc Gallery in Ljubljana, Slovenia, March Io-April I, 2016. $<$ http://aksioma.org/black.chamber/>. 
2I. J. Dawson, “Tracking Himself: 'The Orwell Project'," The Washington Post, May I2, 2007, $<$ http://www.washingtonpost.com/wp-dyn/content/article/2007/05/II/AR2007051102030. html>.

22. H. Elahi, Tracking Transience, <http://trackingtransience.net/>.

23. D. Vasiliev and J. Oliver, "PRISM: The Beacon Frame," < https://criticalengineering.org/ projects/prism-the-beacon-frame/>.

24. Laura Poitras: Astro Noise, an exhibition catalog with chapters by notable contributors, $<$ http//whitney.org/Exhibitions/LauraPoitras $>$.

25. K. Buford, "Data Art vs. Visualization? The Distinction is Unproductive, Says Artist Jer Thorp," Silicon Angle, August 22, 2012, <http://goo.gl/JGhkl>.

26. K. Hillis, M. Petit, and K. Jarrett, Google and the Culture of Search (New York: Routledge, 2012) 27-30.

27. Ibid.

28. Ibid.

29. “Google (verb)," Wikipedia, <https://en.wikipedia.org/wiki/Google_(verb)>.

30. K. Goni, Deletion Process_Only you can see my history, <kyriakigoni.com/history>. The piece runs live online. 


\section{Visual History with Choson Dynasty Annals}

Seong Kuk Park

Eun Ju Lee

Jin Wan Park

Chung-Ang University

Seoul, South Korea

jinpark@cau.ac.kr

See <www.mitpressjournals.org/toc/leon/49/4> for supplemental files associated with this issue.

\author{
Seong Kuk Park, Eun Ju Lee and Jin Wan Park
}

\begin{abstract}
A B S T R A C T
For this paper, the authors selected three historical events taken from the Annals of the Choson Dynasty that represent dramatic and tragic stories about parents and their sons for data visualization. By connecting names with entities indicating conductions from history books, they found interesting patterns that tell stories with embedded relations. The visualized images in this paper were mainly code-generated, based on the data of the Annals, with some graphic embellishment added.
\end{abstract}

There Is No Passive Recording

At the 2006 and 2009 SIGGRAPH Art Gallery, we presented serial information visualizations of two generative artworks based on family tree, or "Jokbo," data, entitled Visual Genealogy [I]. Jokbo is a Korean family tree record usually kept for more than 30 generations. A list of names like this without any commentary might at first appear meaningless, but when the data and visualization were examined, interesting stories about various family histories were revealed [2]. While the data is simple, the stories are profound; although the data consists of simple proper nouns_-individuals' names_each name represents the dense abstraction of a human life.

The desire to further investigate these complex historical stories inspired this current study. Searching the historical data was fairly straightforward [3]. What proved to be the most difficult aspect of this investigation was establishing pure, unbiased records for illustrating the subject because historical data is frequently distorted or at least filtered by the historian's point of view or prejudice towards a certain belief, or due to external political-social pressure. History books are sometimes more like fact-inspired literature in which the truth is hidden between the lines. This is inevitable because history is written by humans, not by recording automata [4], with the exception of some extraordinary cases, such as the 500 account books and 50,000 businessrelated papers recorded by Francesco Datini who, incidentally, had not intended for them to be viewed by the general public [5].

\section{Annals of the Choson Dynasty}

The Annals of the Choson Dynasty is a collection of historical documents that were recorded with unusual strictness and objectivity. This heritage contains daily records in chronological form [6] and mainly consists of news and events from the conversations between a king and his vassals over the course of the 500 years of Korea's Choson dynasty. It consists of a total of 1,967 books, which if stacked up would be taller than a Io-story building. Such is their importance and authenticity that, in 1997, UNESCO registered the Annals of the Choson Dynasty as a "Memory of the World" [7].

While the sheer volume of the collection is impressive, the credibility of its information is significant. The fairness and objectivity of the records, which span 500 years, are due to the strict rules protected by official historiographers. The affairs of a king, whether positive or negative, were recorded every day without exception, and the officers writing the records were not allowed 
to be influenced by anyone, including the king himself. In fact, the annals of a king could only be opened after his death. In short, a king was not able to view his own annals while he was alive.

Undoubtedly, with its many interesting hidden stories, this type of detailed and credible data is a valuable source for data visualization. One such story reveals the credibility of these records: In I404, the second king, King Taejong, fell from his horse in an accident. He was so embarrassed that he asked the historiographers not to record his mistake. However, the information about this event is available to us today, because the historiographers not only recorded that the king fell from his horse, but also recorded that he pleaded for the event to be omitted from the annals [8].

\section{Computational History Mining}

While investigating the annals is an interesting process, it is time-consuming and difficult work. While the annals describe many historical events and reveal the causes and effects of incidents, the format is such that the path of any single story can easily be lost. Additionally, in terms of names, the structure of the annals is closer to social network visualization than to traditional narrative storytelling [9].

Fortunately, the Annals of the Choson Dynasty has already been digitized by the National History Compilation Committee of Korea (with Korean and Chinese characters) [Io]. In fact, this current project would otherwise not have been possible, as it would have required a team of researchers.

For this project, the names from the Annals were parsed, extracted, and categorized. Various methods were then used to connect or trace them according to subject. This was not always a simple task, because of homonyms, bynames, pseudonyms, and various titles; for example, a king's mother can be referred to in various ways: by her actual family name (e.g. Chang), the title of the previous king's wife (e.g. Bin), the title of the new king's mother (e.g. Dae Bin), or in other ways (e.g. Hee Bin Chang).

After data-mining more than I0o,ooo HTML pages and connecting names with words indicating conductions (e.g. compliments, reward as positive words, exile, execution as negative words), we found interesting patterns that tell stories with embedded relations.

The visualized images in this paper were mostly code-generated, with some graphic embellishment added. Therefore, the images could be considered hybrid data visualizations.

In this paper, we selected three historical events taken from the Annals that represent dramatic and tragic stories about parents and their sons. These stories are described below.

\section{Father, I Will Finish What You Started: Taejong "Bang Won Yi" (1367-1422) [11]}

The Goryeo dynasty (918-I392) preceded the Choson dynasty (I392-I9IO); apparently, Korea is named after old Goryeo, which Marco Polo recorded as "Cauli" (Italian) [I2]. Seong-gye Yi (I335-I408) was one of Goryeo's powerful generals and a national hero who was never defeated in numerous wars lasting over 30 years. As the hero's power increased, the might of his followers also increased, eventually resulting in an uprising.

In 1388, General Yi disobeyed King Goryeo's order to send his army to attack the large neighboring country of Ming (old China: Ming dynasty, I368-I644). The uprising against the old aristocrat's orders, at that time, was probably spurred by the common people's will, since they could not endure another war. Instead of instigating war as ordered by the king, the general had 
his army retreat into the king's castle and soon became the new king. Many such empires in world history have fallen through such revolts from within. For example, nepotism corrupted the Ottoman Empire, while the Praetorian Guard's absolute power eventually led to the demise of the Roman Empire. The Roman Praetorians controlled powerful private troops and eventually became the authority as to whether an emperor should be overthrown and who would be the new emperor.

In this visualization (Figure I), we traced the names and incidents in the first three books of the Annals. This time-series visualization distinguishes between two parties based on vector directions (upward lines for the new country vs. downward lines for the old country). Each vector line of a man was generated by a computational connection of each record about him in the annals with spline interpolation. The scatter dots around the entire timeline are notable records in the annals; we manually applied colors and particles based on the frequency of homicide for a dramatic presentation, such as bloody scattered lines on the right side of the picture. The fading of the bright lines in the visualization represents the deaths during the founding time of the Choson dynasty (1392), when the purging of the rulers began, mainly by the new king's fifth son, Bang Won Yi (1367-I422) [I3].

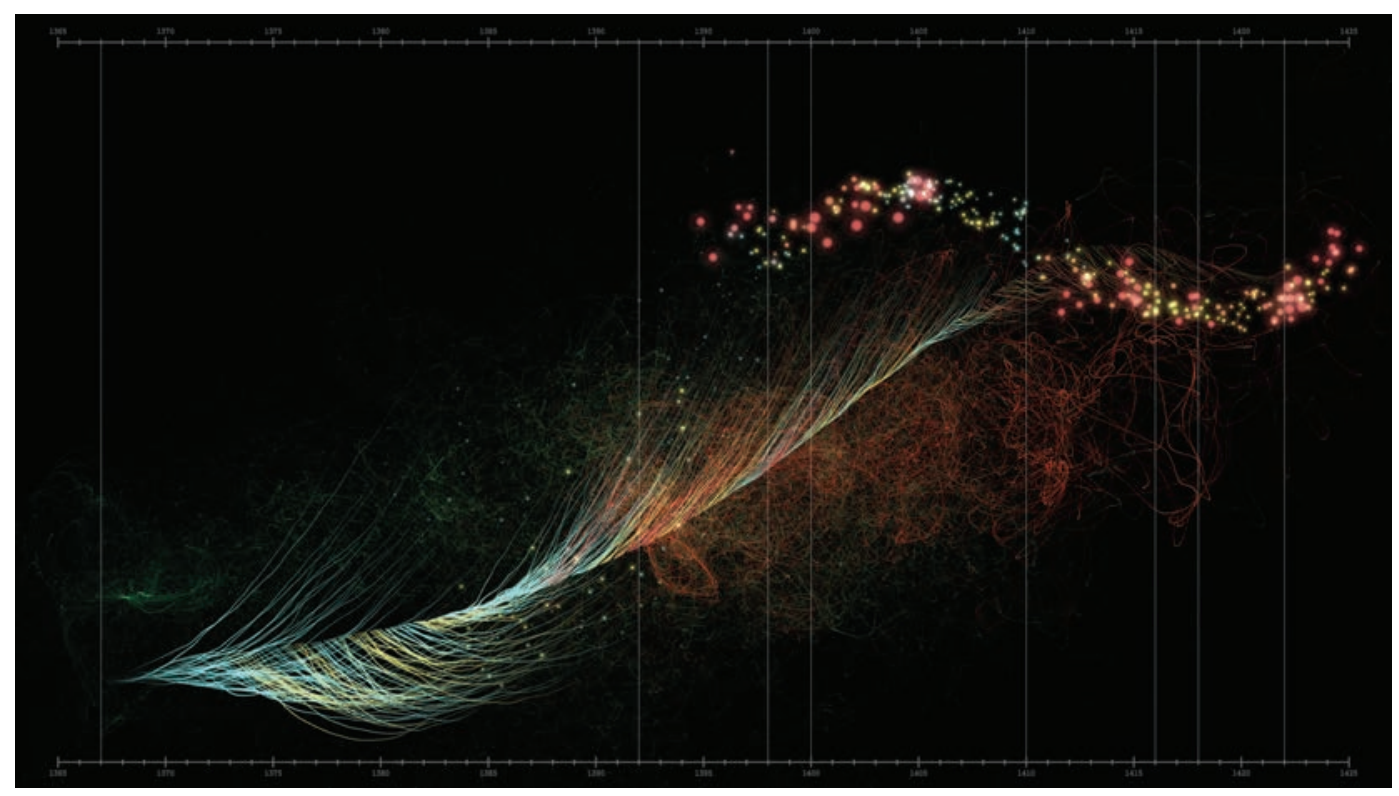

Figure 1. The beginning of Choson dynasty: The Purging (1388-1420). (๑ 2016 Jin Wan Park)

After the new dynasty was brought into existence, King Taejo the First (posthumously named Seong-gye Yi) announced his last (eighth) son would be his successor, because many of the lieges (feudal superiors) of the founding contributor believed Bang Won Yi (the fifth son, highly influential as a contributor to the new dynasty) was uncontrollable and not fit to be a king. In 1398, during the king's brief absence, Bang Won Yi assaulted the palace and killed his political enemies, including his brother the crown prince. The king was filled with anger and sorrow. He enthroned his second son (King Jungjong the Second) and left the castle.

A few years later, in I400, Bang Won initiated the second Strife of Princes. Many of his rivals (especially his brothers) and followers were executed or exiled. In this intimidating situation, Jungjong gave up his crown to Bang Won, and the fifth son finally became king (King Taejong the Third). King Taejong then eliminated potential political enemies who might jeopardize his 
reign, including his wife's family, who had tried to take a consort clan's power [I4]. The end of the visualization shows all of the thin lines disappearing with bloody tips, representing the massacre; it also depicts this fratricide as a dark splatter of a deeper red color.

This visualization depicts the intense bloodshed that occurred; indeed, how much blood needed to be shed for the sake of obtaining the throne? The slain were not always enemies, but were once friends, blood allies, in-laws, and even King Taejong's own blood! While this appears to be a very cruel story, King Taejong, by eliminating all the private forces, stabilized Choson in a very short period of time so that the common people could finally live without war and hunger. $\mathrm{He}$ established a new, peaceful and robust dynasty, which his father had only dreamed of, even though he did not follow in his father's footsteps—-because he believed his was the only way.

Historical writers usually record more spectacular events and, unlike the Choson annals, they did not necessarily record all of the cruel, shameful, and controversial facts. The truth is sometimes rather ugly or even inexplicable. Even today, before undertaking a military coup d'état, many dictators and generals will first attempt to control the media and education. Indeed, while the span of time between Hitler and King Qin Shi Huang (BC 259-BC 210) was more than 2,000 years, the followers of both of these leaders burned books.

\section{Mother, They Will Pay with Blood: "Yeonsan-gun" (1476-1506)}

This tragic story centers on a mother and her son. Yeonsan-gun (1476-1506) was one of the most infamous kings in Choson history, carrying out many bloody purges of his political and personal enemies.

Mary I, the Queen of England, executed countless Protestants and was named "Bloody Mary" for her reign of terror [I5]. She had an unhappy childhood due to her mother's exile when she divorced Mary I's father, Henry VIII [I6]. While not always the case, an unhappy childhood can be the root of the later development of a twisted mind, although in many cases a specific moment can also trigger psychological damage—-this was especially the case for Yeonsan-gun, whose mother was deposed and executed.

Yeonsan-gun's mother, Queen Yoon (?-I482), was chosen for her beauty as the second wife of his father (Seongjong, the ninth king of Choson, I469-I494). For various reasons, but mostly jealousy, she committed misdeeds such as poisoning other concubines and cursing them with puppets (similar to voodoo hexing), and later even scratched the king's face with her nails. The queen was deposed in I479. In addition, Yeonsan-gun's grandmother, Grand Queen Insu (Yoon's mother-in-law), and her party abetted Yoon with a frameset. Yoon was finally poisoned to death by the king in I482, when Yeonsan-gun, the crown prince, was only six years old.

In I494, when he was I2 years old, Yeonsan-gun became king. There were periods when the new king governed wisely, during the beginning of his reign. Five years later, in I504, a rusticated privy councelor (Sa-hongIm) revealed to Yeonsan-gun the details of his mother's death by showing him an old cloth that was stained with blood - the cruel vestiges of his mother's execution by poisoning; the son became obsessed with vengeance.

Yeonsan-gun began to take revenge against everyone who was responsible for his mother's death. First, he beat two of his father's concubines to death and threw their bodies into the wilderness. The concubines' sons, his step-brothers, were exiled and their death by self-poisoning was later ordered. Yeonsan-gun's grandmother (Grand Queen Insu) died from shock immediately after he 
violently pushed her during an argument. Exacting brutal punishment, he then executed and condemned everyone he deemed responsible for his mother's death, which haunted him until the end of his reign.

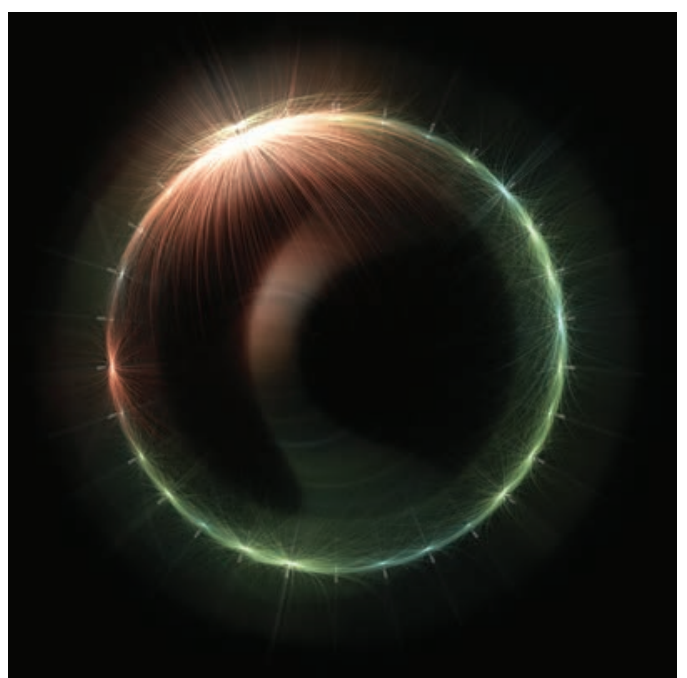

Figure 2. Yeonsan-gun (1476-1506) and posthumous execution. (๑) 2016 Jin Wan Park)
This visualization (Figure 2) is generated by the circular layout algorithm (one year is PI/I5), with cross-reference line connections. The bright lines at the top of the image (depicting the years I498-I504) indicate the cruelty of the terror. The visualization also shows interesting ghostly trails, referring to the record in the annals describing dead people who were figuratively resurrected to be killed again. To emphasize the lines representing posthumous execution, contrast and glare effects were applied to the image. One of these ghosts was Myeong-hoi Han, who wielded absolute power in the previous king's era and died in 1487 . His name appears suddenly in $\mathrm{I} 5 \mathrm{O} 4$, the year of the purging, when Yeonsan-gun took revenge against Myeong-hoi Han with a posthumous execution: he excavated the dead body, cut off the head, and displayed it in the street [I7].

Antagonism towards the tyrannical king grew each day. Two years later (I506), he was overthrown and replaced by his step-brother, Jungjong, through an uprising. When Yeonsangun's vengeance was assuaged, he possibly also lost his reason for living. Two months later, he died from an illness while in exile [I8].

All I Ever Wanted Was One Loving Gaze, One Kind Word from My Father: Prince Sado (1735-1762) [19] This visualization illustrates the story of a relationship between a father and his son, who longed only to be loved by his father. The father expected his son to be greater than him. Despite the son's efforts, he never satisfied his father. The son began to feel unworthy and soon became destructive. This conflict between father and son is a common phenomenon and still occurs today in most societies.

Yeongjo (I694-I776) was the strictest king, in terms of self-discipline, among all the kings of the Choson dynasty, due to controversy over the legitimacy of his succession. He struggled to be perfect in every way-in his studies, his reputation, and his politics. He lived to the age of 83 , and thus reigned for the longest period of all the Choson kings [20].

At the age of 4I, Yeongjo fathered a son, Prince Sado (I735-I762), whom he favored and loved in Sado's youth, and he had great expectations of his son. Crown Prince Sado became a joy for the king because of his remarkable brightness. Although Yeongjo wanted him to study, Sado, unlike his father, was more interested in painting and martial arts, and showed a free-spirited nature while he was growing up.

The king pushed his son to be the perfect crown prince he desired, and he behaved in a coercive and strict manner toward his son; this treatment resulted in the confident and cheerful son 
developing aphasia (language impairment). Due to the gradually increasing and ongoing stress, Sado also developed and suffered from a mental disorder which resulted in his causing harm to other people. Political conflict ensued when he went insane and warned that he would even kill his father.

When the tension between father and son was mentioned in the court, the party in opposition to the king transformed the family conflict into a political confrontation. The king was fearful that the outbreak of political conflict would lead to usurpation of the throne. To protect the royal family, including the king's grandson (Sado's son), the king needed Prince Sado to die. However, King Yeongjo could not bring himself to kill his son with his own hands. So he ordered Sado to be locked in a large sealed wooden rice chest on a hot July day in 1762 . After eight days, Sado died.

They were connected as king and crown prince, but they never really developed a father-son relationship. The visualization (Figure 3) represents the tragedy as three distinctive parallel twisted lines that never meet: Yeongjo, Sado, and Sado's son Jungjo. The color and length of the lines are determined by computation, but the arrangement of the lines is based on our impression of the story. The underlying image filled with nodes is not from Yeongjo's annals, but Taejong's. Surprisingly, although the eras are separated by 300 years, they matched well visually. After all, history is recursive.

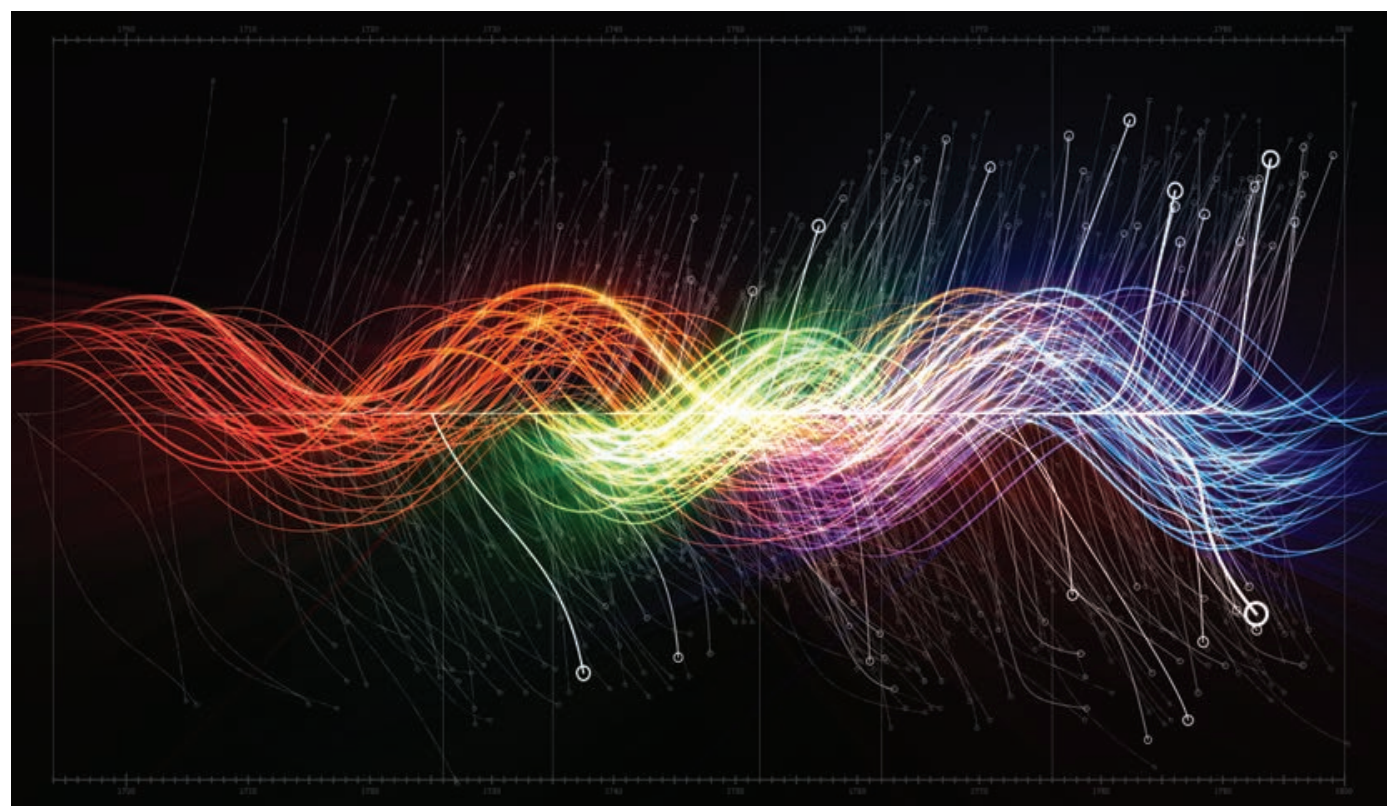

Figure 3. The king, the son, and the grandson. (๑ 2016 Jin Wan Park)

\section{History Flows Concurrently}

While the Annals consist of I,967 volumes, only a small fraction of the vast number of episodes has been presented here. Although the data in the annals is very credible, imagination is still required to weave the facts together to recreate a story; we therefore cannot guarantee that the suggested stories are the only possible interpretation. However, these three stories are believable because they describe plausible family relationships; even today, we can still sympathize with the struggles of the individuals involved in these tragic events. Maybe people basically never change.

The overall flow of history as seen through the results of the visualization of the Annals is akin to a series of unpredictable waves. Meanwhile, just as the weather and the sea eventually become 
silent after a storm, there were periods where connections could be made. A pattern in the long 500-year history was identified. In the Choson dynasty, the same mistakes were often repeated, suggesting that history often repeats itself, with variations.

Finally, in this study, while we encountered precious data and visualized it with passion as an interdisciplinary artist and engineer group, we still have a long way to go. We expect to conduct further studies through detailed analysis and visualization for each period of the Choson dynasty through the annals, with the expectation that the concerns of a single family will reflect widespread human concerns.

\section{Acknowledgment}

This research was supported by the Chung-Ang University Excellent Student Scholarship in 20I5.

\section{References and Notes}

I. J.W. Park, Visual Genealogy, ACM SIGGRAPH 2007 Art Gallery, San Diego, California, 2007; J.W. Park, Visual Genealogy: MR. Park, Myrang-Hwarok Clan, ACM SIGGRAPH 2009 Information Aesthetics, New Orleans, Louisiana, 2009.

2. J.W. Park, "Information Aesthetics with Visual Genealogy Project," Leonardo Vol. 44, No. 5 , 464-465 (20II).

3. Unlike static historical data, contemporary data grows and becomes big data, which makes it hard to mine and analyze. A good example of computer-based visual analysis for contemporary data is Lev Manovich's cultural analytics, which covers films, animations, video games, comics, magazines, books and other media. <http://lab.softwarestudies.com/p/ cultural-analytics.html>.

4. Carr argues that viewing history as accurate (and independent of human opinion) is improper, because historians selectively choose facts based on particular interests. E.H. Carr, What is history?, 3rd Revised ed. (Basingstoke, UK: Palgrave Macmillan, 2002). Hayden White also points to the problem of historical representation, which recounts not merely a neutral real event, but entails an ontological and epistemic choice with distinct ideological and even specific political implications. H. White, The Content of the Form: Narrative Discourse and Historical Representation (Baltimore: Johns Hopkins University Press, 1990).

5. In I870, Francesco Datini's business records were found in Prato. These private records provide insight into the medieval-renascent merchant class in the I4th and 15 th centuries.

6. Historical facts recorded by day, month, and year, which is the most common and traditional way of recording history in Eastern Asia.

7. The Annals was listed in UNESCO's Memory of the World Register, and despite the existence of other annals around the world, this is the first and only case of annals being listed.

8. Annals of Taejong, fourth year (I4O4), February 8th, fourth article. "After the king fell from a horse, he looked left and right, and he asked, 'Do not let historiographers know this."'

9. A similar structure can be found in "Saga" or in the epic novel. A. Cappelli et al., "The Social Network of Dante's Inferno," Leonardo Vol. 44, No. 3, 246-247 (June 20II).

IO. The Annals of the Joseon Dynasty, <http://sillok.history.go.kr/main/main.do>.

II. From the movie Star Wars: The Force Awakens (2015): "Nothing will stand in our way. I will finish what you started." The father and son relationship is the same in this epic contemporary fictional saga as the one recorded in the Annals.

I2. J. Brown and J. Brown, China, Japan, Korea: Culture and Customs (Seattle: Book Surge Publishing, 2006).

13. "Taejong" is Bang Won Yi's posthumous royal name.

I4. H. Park, "King Taejong as Statesman: From Power to Authority," Korea Journal, 207 (Winter 2006). 
15. M. Waller, Sovereign Ladies: The Six Reigning Queens of England (New York: St. Martin's Press, 2006) in6.

16. A. Whitelock, Mary Tudor: England's First Queen (London: Bloomsbury, 2009).

I7. On executing people whose cardinal sins are exposed after death: Records show that Oliver Cromwell of England was also sentenced to a posthumous execution by Charles II. R.L. Bradshaw, God's Battleaxe (Bloomington, IN: Xlibris, 2010) 379-38I.

I8. Although the king's revenge was the only motive that had been recognized, the political confrontation between the two parties of courtiers might also be a plausible reason. His opponents used the king's fury to gain political leverage.

19. Quotation from the movie Sado (2015), directed by Joon-ik Lee.

20. Yeongjo created a policy with the intention of adjusting the balance between political parties to prevent conflicts. 


\section{Raised On YouTube: Cultural Data Materialization Using Plants}

Misha Rabinovich

Artist, Developer and Educator

155 Middlesex Street, Apt 3A

Lowell, MA 01852

mishawagon@gmail.com

See $<$ www.mitpressjournals.org/toc/leon/49/4> for supplemental files associated with this issue.

\author{
Misha Rabinovich
}

\begin{abstract}
A B S T R A C T
Raised on YouTube is an installation and game that grows plants using only the light of projected video and makes ecology legible as a multiplayer game. The challenge of finding the most nurturing video is crowdsourced online. As players watch a webcam feed of the plants surrounded by two-way mirrors, their computer power is diverted to photosynthetic video analysis. The system calculates the photosynthetic score for each video using a basic botanical model. The resulting shape and density of the plant grow bed serves as a data visualization of the energy patterns in the cultural stream. The system provides opportunities to reflect on the effects of long-term exposure to contemporary media and to imagine ecological possibilities of participatory culture.
\end{abstract}

\section{Living Off of Video}

In 2012 I was working with the Everson Museum and the City of Syracuse to create a public art sculpture, which featured an aquaponics fish and vegetable garden in a shipping container. Research into grow lights led me to the realization that plants grow differently under different colors of light. This is due to two different types of chlorophyll; Chlorophyll A is mostly stimulated by purple and red light, and Chlorophyll B by blue and orange light [I]. Plants that are leggy or losing green leaves are not getting enough blue light, while plants that don't bloom are not getting enough red [2]. Witnessing the sunset or sunrise indicates that daylight color temperature changes throughout the day. Plants evolved to respond to the length of the day because it is a "reliable indicator of the time of year, enabling developmental events to be scheduled to coincide with particular environmental conditions" [3]. A calibrated light-and-dark cycle can kick plants into the reproductive stage. Plants evolved under a dynamic light source and developed phototropism (they move to follow the sun). It seems that lights flashing at specific frequencies can create higher plant yields [4]. "Electro-culture" gardening is replete with anecdotal evidence of gardening interventions using various energy waves. In 1992 Patrick Ready's installation Radio and Beans acknowledged radio as a material and not just a communication medium by showing the effects of media transmissions on the germination of beans. By situating the plants around a radio, television set, and other devices, the work reminds us of the "utopian desire to ... harmonize relationships within the earth's ecosystem" [5]. Eventually it became clear to me that fostering an environment for the plants with this type of equilibrium was dependent on getting the frequencies right, especially the light frequencies. A r:6 blue to red ratio worked well enough for the installation. However, after the basil shot up and flowered it became clear that the light was too red.

Calculating the ratios of light frequencies became the recipe for a sort of filter. This led me to an investigation of the effects on plants of different ratios of blue to red light using custom-made LED grow jars (Figure I). Could we communicate with plants by feeding them light patterns over time and evolve the best patterns by trial and error? The $1995 \mathrm{TV}+$ Beans installation by Garnet Hertz shed light on this question by exposing beans directly to the glow of a television suspended overhead (while also including a control group under more traditional lighting) [6]. 


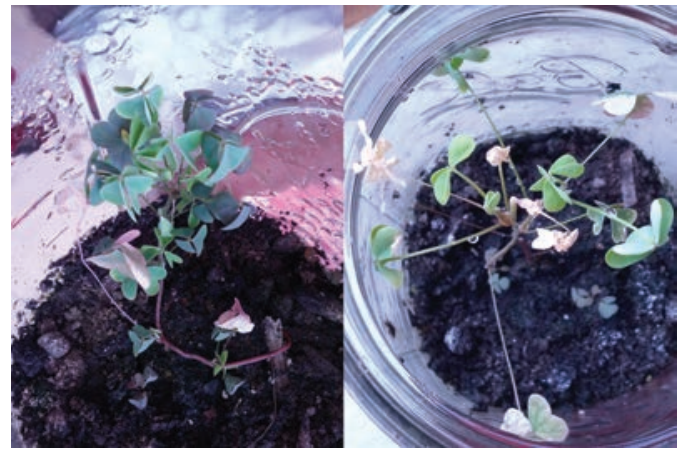

Figure 1. Two clover plants, originally the same size, were grown for 16 days in the summer of 2014. The left image shows the blue LED clover, bushy with short internodal distances. The red light clover on the right is spidery. (๑ 2013 Misha Rabinovich)
I restaged a version of this experiment by splitting a store-bought basil plant in half and putting one half under a window.

I isolated the other half from external light and projected my cell phone videos onto it using a 2,500 lumen projector. After two weeks the experimental basil seemed as healthy as—or maybe even more alive than-the control. Eduardo Kac's 1994 installation Teleporting an Unknown State [7] used a projector to germinate bean seeds using video streams of people pointing their webcams to the sky. Video has continued to evolve to become an efficient format for organizing light color information over time. Variegated video is available all across the internet, but what better source for video than YouTube, which is already ingesting hundreds of hours of video per minute [8] and pooling it all under a standard Application Programming Interface (API)?

\section{Alchemy and Ethnobotany}

Internet traffic is growing exponentially. Cisco Systems predicted that this year we will enter the Zettabyte era. Most of this traffic is video: millions of years of video are transmitted over the internet every month [9]. As an artist in residence at McGill University's Centre for Intelligent Machines, I collaborated with data scientist Yogesh Girdhar to use machine learning to distill films into summary montages [ro]. Curating video for plants is decidedly simpler: it is enough to measure the amount of blue and red energy and subtract the green (Figure 2). Green light is reflected away by green plants because they have no use for it and producing it is a waste of energy. The difference between frames indicates motion and is also a good metric of light
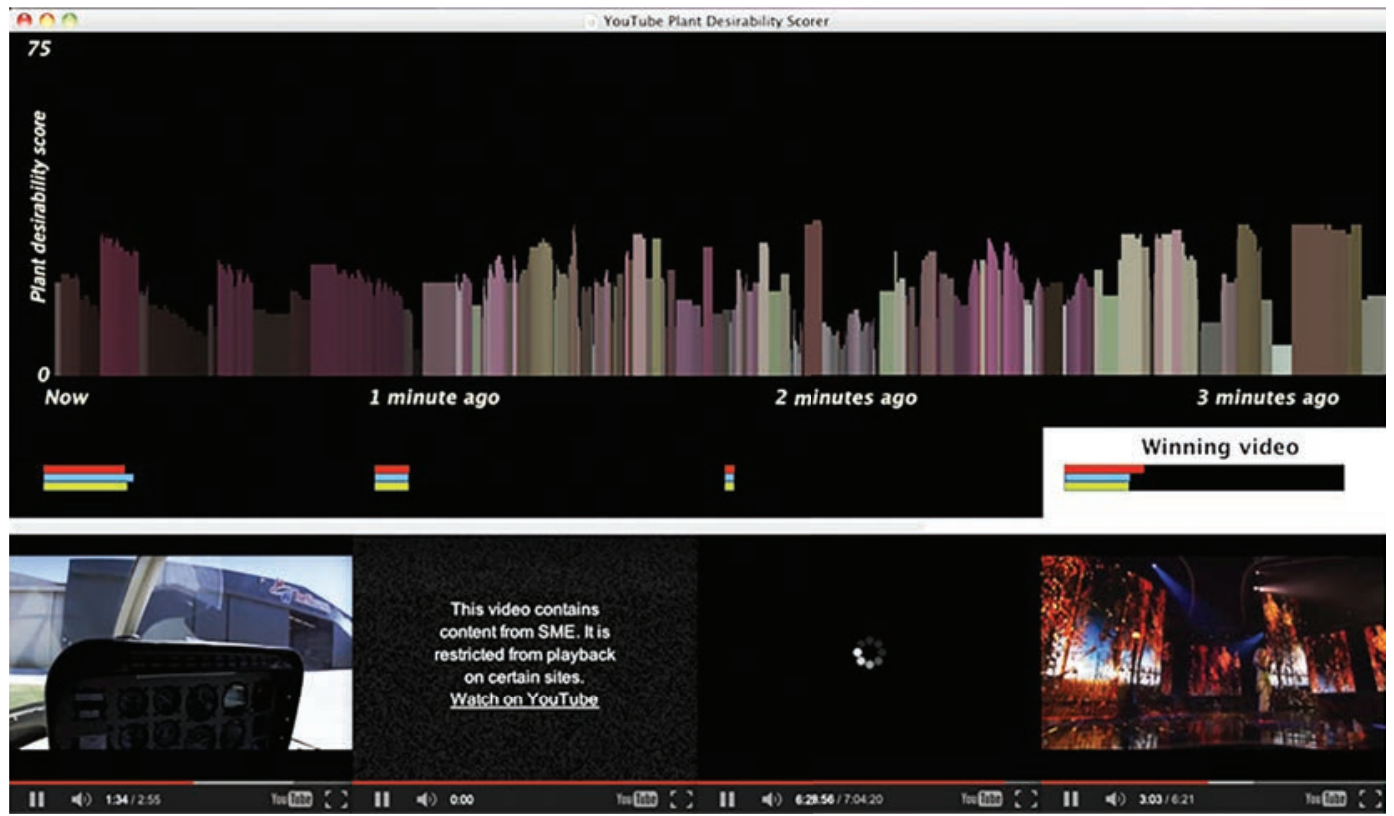

Figure 2. In the earlier version of the installation, four videos were evaluated in real time to create a projected remix. A graph displays the winning scores of the past three minutes. (๑ 2013 Misha Rabinovich) 
dynamism, which seems to increase plant stimulation. It is best to normalize the score from o to Ioo for readability.

$$
\text { Photosynthetic Score }=(\text { Red }+ \text { Blue }- \text { Green })^{*} \text { Motion }
$$

As food, as medicine, as material, plants shaped the development of humankind. Humans have also shaped the development of plants. George Gessert describes the resulting variety of domesticated plants_-from the ornamental to the mind-altering — as a "vast unacknowledged genetic folk art with a history stretching back a thousand years" [II]. However the Anthropocene is characterized by many other indirect and unintentional influences of humanity on plants. Artist Brigitta Zics has written about "instant affection technologies" which help people "achieve immersive states by self-observation and reflection." She used what I argue is an ecological approach of leveraging the "aesthetic linkage between the bodily state and the visual representation" in order to "produce a new body-awareness in the participant" [I2]. Because ecology is so complex, it was important for me to pare down the inputs and outputs and tie the display to the plant bodies. The poetic juxtaposition of plants and YouTube video (yet another

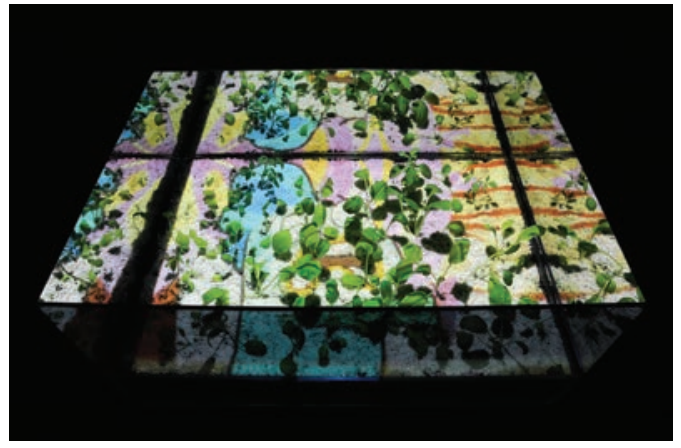

Figure 3. Basil and white-stemmed pak choi are grown with video as the only source of light. The two-way mirror box and white Perlite soil cover recycle the light from the projector and enhance the display. (๑) 2013 Misha Rabinovich)

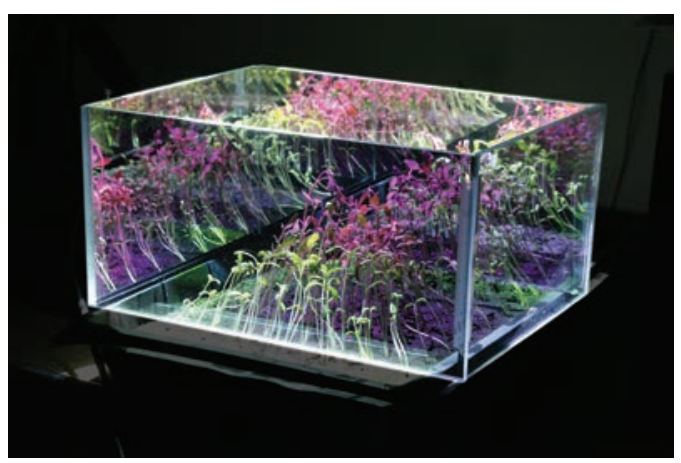

Figure 4. Tomato sprouts bend toward the center after being exposed to weeks of talking head videos from YouTube's educational recesses. (๑ 2013 Misha Rabinovich) form of folk art) is an affectation technique that aims to produce a new ecological awareness. I started growing basil and white-stemmed pak choi using projected YouTube videos as the only source of light. It turns out that plants can be programmed by light patterns over time. Tiny seeds materialize into living data realizations. The shape of the grow bed coalesces over time to reflect the videos the plants have been "watching" (Figure 3). Videos that deviate from the default YouTube aspect ratio have black bars on the top and bottom or on the sides. The black bars of aspect ratio mismatches dwarfed the plants at the edges of the grow bed, and sometimes killed them. If most of the video is of talking heads, then the energy will be concentrated in the middle of the grow bed because central faces are well lit at the expense of a dim background. In this case, the grow bed will be tallest in the middle (Figure 4). Andrés Ramírez Gaviria wrote that functional data visualization communicates a message, while a data visualization artwork aims for a gut-level reaction [13]. Raised on YouTube doesn't just function as a visualization of video light frequencies and energy concentrations, but creates an emotional response in the viewers witnessing plants on video life-support.

\section{Creating the Installation}

Stephanie Rothenberg's installation Reversal of Fortune: Garden of Virtual Kinship grows plants in a map-shaped grow bed and uses "water to visualize the flow of money" [I4]. The project's activist bent is helped along by a correlation: money and water are two essential resources. The clarity of the relationship underscores the importance of a flowing economy. The project is 
another example of what Wim van Eck and Maarten H. Lamers describe as "digitally controlled nurture of biological systems" that relates "external factors to nurture conditions" [I5]. Raised on YouTube reveals the latent power in a subset of visual culture using more ambiguous mappings of inputs to outcomes. Artist Lindsey French's projects Concert for Plants by Plants and Phytovision: Road Trip connect people and plants to "produce stimulating effects that do not have to result in explicit understanding to constitute engaged cross-species interactions" [I6]. In Concert for Plants by Plants, French used vibration sensors and WiFi to transmit the physical vibrations of a tree in Massachusetts into houseplants situated in a Chicago performance space. People sharing the space were left to speculate on what the plants were experiencing only from their perception of the barely audible vibrations. In Phytovision: Road Trip, French took a tree on the road and created a speculative video installation conveying what the tree might have "seen" during the ride. Similarly to how French demonstrates that "multiple ways of sensing or experiencing are both possible and valuable" [I7], Raised on YouTube creates an opportunity to imagine the cultural experience from the perspective of non-human alterity.

Two-way mirrors helped me recycle the light of the projector and also created the illusion of a larger grow bed. A two-way mirror works by letting only enough light through for people to see inside (Figure 5). In a dark room, a projector shining into an open box made of two-way mirrors creates several arresting visual effects. The first is the infinity mirror effect caused by enough light being trapped and reflected inside the box. The plants appear to extend outward in all directions, inviting speculation on the use of projection farming on an industrial scale as a thought experiment on future ecologies. To quote Gaviria, an artistic information visualization "aspires to be conceptually transgressive, to reframe canonized structures.... [The] task is...not to resolve but to question or restructure issues...in a manner that is not possible through any

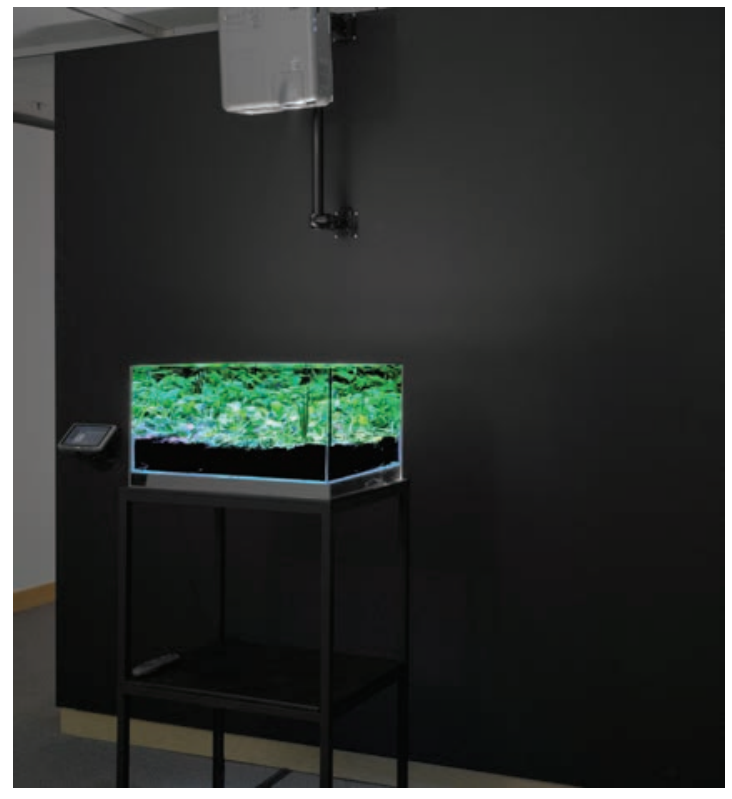
Figure 5. Raised on YouTube: living plants, video projection, custom software, two-way mirrors, 10' x 2.5' x 1.5.' (๑ 2013 Misha Rabinovich. Photo: David Broda.) other means, medium or cultural artifact" [18]. Jussi Parikka wrote that during the Anthropocene the "environmental expands from a focus on the natural ecology to an entanglement with technological questions" [I9]. I used white perlite to blanket the soil and enhance the grow bed's capability of functioning as a video screen technology. David Latimer sealed an azalea garden in a glass bottle for 50 years and the plant survived [20]. His project removed all ecological inputs except light. Raised on YouTube deprioritizes all inputs except light, and goes further by repositioning "waste" videos often considered to be spam as potent energy sources. Even something as seemingly distant from "nature" as YouTube is subsumed into the ecological cycle, which can be read as a utopian act of erasing the concept of "waste." Arguably there was no such thing as waste before humankind. It was human culture that invented waste as something externalized from the life and death cycle, not biodegradable, something to be cordoned off due to poisonous effects. Growing plants with user-generated videos reveals the corporeality of data, or at least demonstrates that data has a direct influence over the material world. Raised on 
YouTube manifests this influence and short-circuits the separation between information and material as well as "nature" and "culture."

\section{Making the Installation Telematic}

Ecology is hard to circumscribe because the connections keep extending outward. Influenced by an artistic and theoretical thrust toward the dematerialization of the art object, I yearned to have the system transcend physical space and extend outward through the internet. At first, the system was seeded with four starting videos and programmed to use the YouTube API's "related" feature to automatically spider out through user-defined folksonomies and find new videos. Several visitors to the Red Roots gallery in New York City who saw the installation wanted to try their hand at choosing the videos, so I decided to allow participants to submit YouTube links themselves. Eduardo Kac described the ability of telepresence art to reconcile cyberspace and physical space, to bridge the gap between "carbon and silicon" [2I]. When it comes to elucidating ecology, some active participation is essential for demonstrating the power of human choice. Artistic telepresence, especially the type achieved by Ken Goldberg's Telegarden project from the mid-I990s was instructive here. "The user's control over 'what' and 'how' to see over the Web becomes more important than the image that mediates a glimpse and/or an action. This low resolution image becomes secondary compared to the definition of or access to other realities" [22]. Lacking the servers or budget to evaluate all of the potential submissions for their photosynthetic scores, I chose to crowdsource the evaluation.

The Search for Extraterrestrial Intelligence at Home (SETI@Home) is an excellent model for crowdsourcing processing because it entices users with fun graphics and a noble cause at practically no cost to said users. This is not some malware that runs in the background, slowing down the user experience, but a screensaver installed voluntarily by the user. Screensavers run when the computer is not being used. This is when SETI@Home downloads telescope data and looks for patterns which can be sent back to research headquarters. Similarly, Folding@home

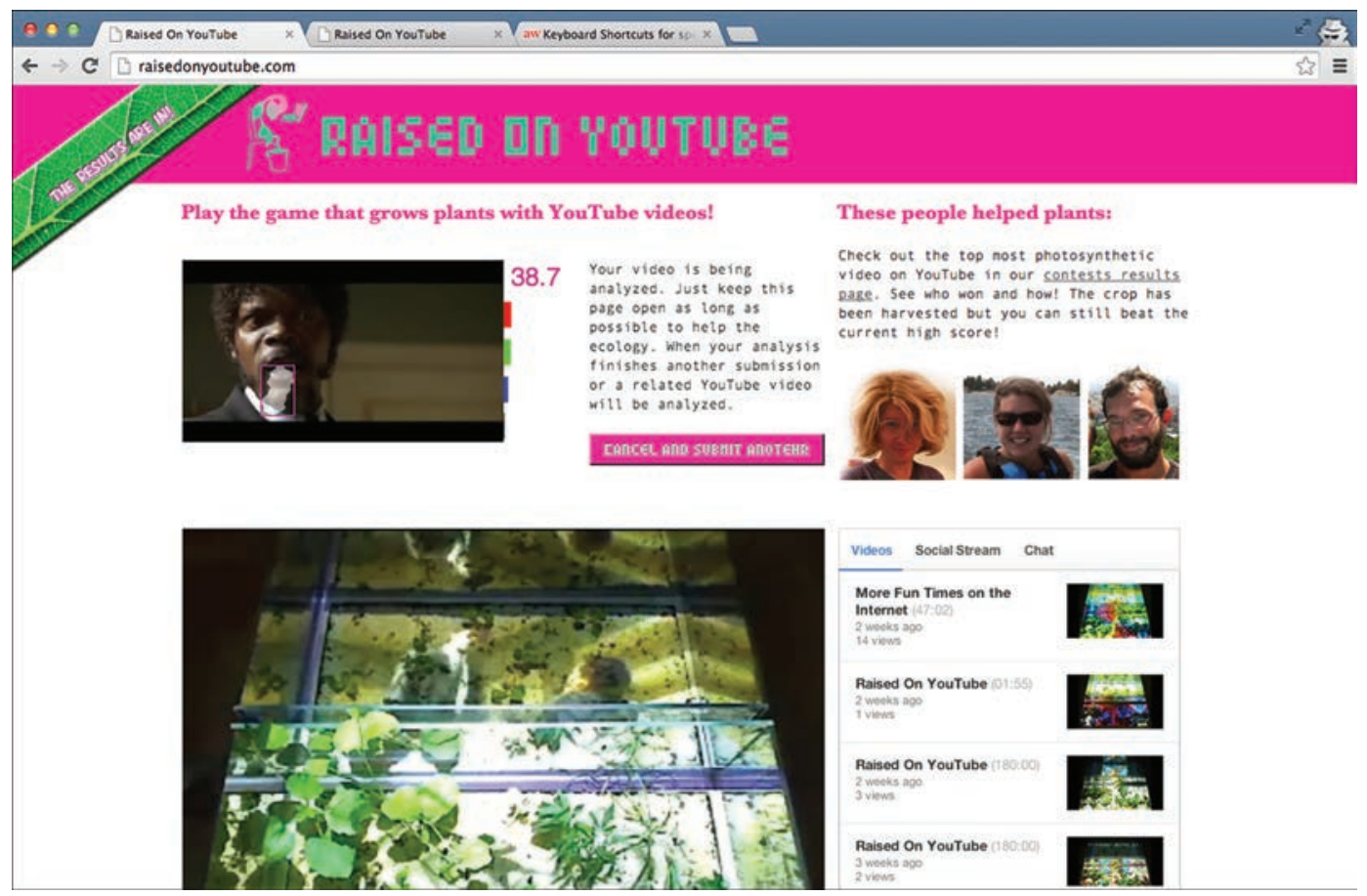

Figure 6. Players pasted YouTube video links directly into the website. To be eligible to win a prize, a player had to contribute computing power toward crowdsourced video analysis. (๑ 2014 Misha Rabinovich) 
crowdsources the process of understanding protein folding. In the same way, Raised on YouTube gives people the chance to play ecology in exchange for making their processing power available as a shared resource. Users gave up some of their processing power only while the website was open (Figure 6), and they were incentivized to do so in several ways. Firstly, the website offered up a live feed of the rows of crops dancing under the dynamic light and sound of digital culture. Secondly, the players were not eligible to win until their submitted video was fully processed on the client side and score posted back to the server. Once their submission was processed and the score was sent to the database, they were also served previous video submissions that had not yet been scored (e.g. because the original submitter left the page too early). This amplified the network effect of processing so that the more people who visited the site, the faster submissions were analyzed, allowing the plants to receive better video more quickly. The system doesn't require installation of custom software but takes advantage of existing browser-based technologies, such as JavaScript and Flash, to run analysis in the background. The ActionScript Bitmap class

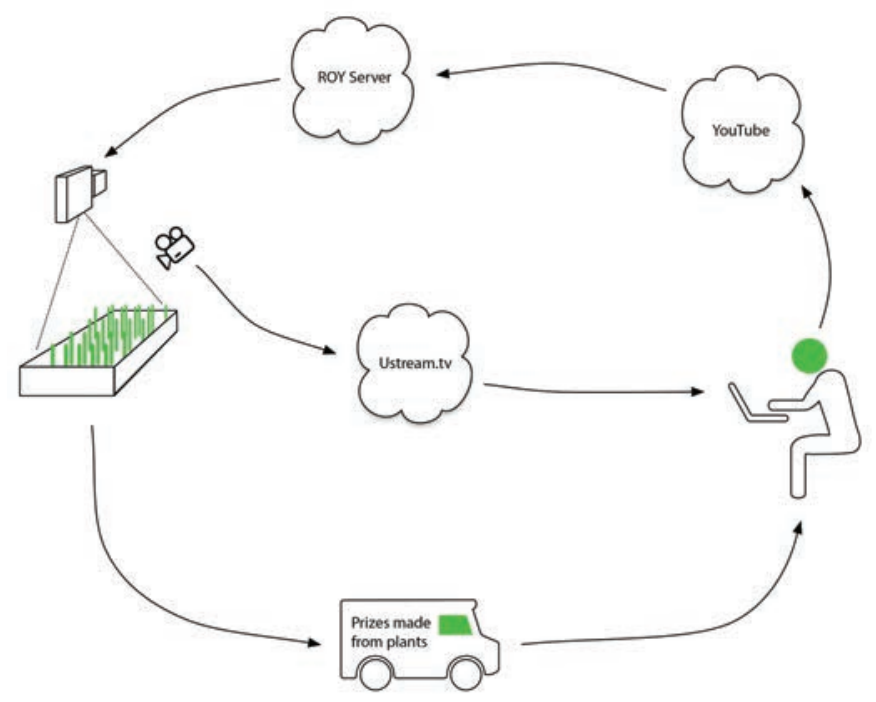

Figure 7. Raised on YouTube ecology diagram shown with a single user. (๑) 2016 Misha Rabinovich) opens up the access to the pixel data of each individual frame of video, which allowed for programmatic measurement of color energy and motion. I also created a custom Ruby on Rails backend and coupled it with the open-source youtube-dl Python library, which provides access to the raw video data syphoned off of Google's YouTube servers (Figure 7). The ROY server kept a live tally of submissions and showed the top videos ranked by photosynthetic score. Because the website compared submissions to one another, people could learn from each other.

To bring the contest into the aesthetic dimension, I added a second identical grow bed which housed the same types of plants. The first grow bed was illuminated by the latest submitted video to date. The second grow bed was illuminated by a playlist of the top 40 hits submitted to date. The game experience benefited from this for a couple of reasons. The first was that a player had a high chance of seeing his or her submission appear on at least one grow bed almost immediately - even if the video was not well scored - which served as an instant reward to encourage further engagement. The second reason was to show what a difference highly photosynthetic videos made: the top 40 grow bed plants were bigger.

\section{Outcomes}

The telepresence version of the project was exhibited at the Arcade Gallery in the Los Angeles neighborhood of San Pedro in 20I4, while also being broadcast via the internet. I received about I,O०o video submissions during the two-month run of the contest. The photosynthetic scores increased in bursts as players discovered whole genres of well-performing videos, with scores peaking in the mid-7os. Psychedelic eye-candy videos with lots of changing colors did well. Documentary videos of commercial grow rooms also did well, which is unsurprising considering how much time horticulturalists put into calibrating their grow lights. I continued to operate the website even after the main run of the contest was over and winners were chosen. In the spring 
of 20I5 I presented the project at the University of California San Diego and held a workshop with students. It was during this event that the most photosynthetic video to date (score of 79) was found: the video is called My Girl's Reaction to Harvard Acceptance. It is important to note that by this point the system ignored black bars during evaluation. This vertical video has a lot of excited movement and the reddish brick wall background surely boosts the score. I published the top 40 photosynthetic videos as a YouTube playlist to help people try this at home (Figure 8). One future direction for this research is the incorporation of sound analysis into the photosynthetic score. Research shows that specific genres of music [23] and sound frequencies of wavelengths similar to average leaf sizes can have serious effects on transpiration (plant "breathing") [24]. The Bemis Contemporary Art Center has invited me to continue this research in the summer of 2016 for their "Future of Food" theme.

\section{Average Video Frame Color of the Top 40 Playlist}
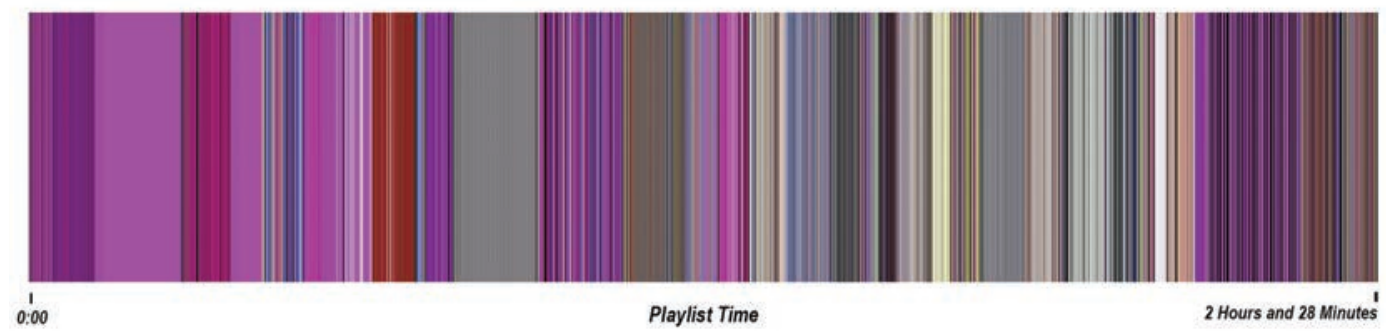

Figure 8. Visualization of the average video frame color over the running time of the Top 40 playlist as it stood at the end of the contest. (๑) 2015 Misha Rabinovich)

The ability of the grow beds to function as data visualizations creates opportunities to reflect on our exposure to user-generated culture. People relate to plants as living beings, and watching them become changed by this artificial light invites contemplation about the effects this culture is having on us. How are we changing under the influence of so much content? I hope that by making tangible these rather abstract data flows, the project stimulates appreciation for nonhuman players and provides an opportunity for reimagining ecology as an interspecies game.

\section{Acknowledgment}

This project was made possible with the support of Marylyn Ginsburg and Chuck Klaus and the help of Andrew Andkjar, Cooper Battersby, Caitlin Foley, Sunil Buster Kapila, Boryana Rossa, $R O Y$ Players, and Tom Sherman.

\section{References}

I. A.W.D. Larkum, S.E. Douglas, and J.A. Raven, eds., Photosynthesis in Algae (Dordrecht, Netherlands: Kluwer Academic Publishers, 2003), I20.

2. L. Baessler, "Red Light vs. Blue Light: Which Light Color Is Better For Plant Growth," Gardening Know How (20I5), <www.gardeningknowhow.com/garden-how-to/info/red-lightvs-blue-light.htm>. Accessed June 3, 2015.

3. S.D. Jackson, "Plant Responses to Photoperiod," New Phytologist Vol. 181, No. 3, 517 (2009).

4. R.A. Nelson, "Chapter 5: Electro-Culture," Hemp Husbandry, internet edition (2000), <www.rexresearch.com/hhusb/hhselc.htm>. Accessed January II, 2014.

5. D. Augaitis and D. Lander, eds., Radio Rethink: Art, Sound and Transmission (Banff: Banff Centre Press, 1994), 72.

6. G. Hertz, TV + Beans (1995), <http://www.conceptlab.com/tvbeans/index.html>. Accessed March 19, 2016.

7. E. Kac, Teleporting an Unknown State (1994), <www.ekac.org/teleporting.html>. Accessed January I5, 20I5. 
8. M.R. Robertson, “30o+ Hours of Video Uploaded to YouTube Every Minute,” Reelseo (20I4), <www.reelseo.com/youtube-300-hours/>. Accessed December IO, 20I5.

9. Cisco, "The Zettabyte Era: Trends and Analysis" (May 20I5), <www.cisco.com/c/en/us/ solutions/collateral/service-provider/visual-networking-index-vni/VNI_Hyperconnectivity_ WP.pdf>. Accessed July 24, 2015.

IO. M. Rabinovich and Y. Girdhar, "Gaining Insight Into Films Via Topic Modeling \& Visualization," Parsons Journal of Information Mapping Vol. 7, No. I, 3-5 (Spring 2015).

II. G. Gessert, "Notes on Genetic Art," Leonardo Vol. 26, No. 3, 205 (1993).

I2. B. Zics, "Toward an Affective Aesthetics: Cognitive-Driven Interaction in the Affective Environment of the Mind Cupola," Leonardo Vol. 44, No. I, 3I-37 (20II).

13. A. Ramírez Gaviria, "When Is Information Visualization Art?: Determining the Critical Criteria," Leonardo Vol. 4I, No. 5, 479-482 (2008).

I4. C. Voon, "Growing a Garden According to the Economics of Philanthropic Crowdfunding," Hyperallergic (20I6), <hyperallergic.com/26I458/growing-a-garden-according-to-theeconomics-of-philanthropic-crowdfunding>. Accessed January I2, 2016.

I5. W. van Eck and M.H. Lamers, "Hybrid Biological-Digital Systems in Artistic and Entertainment Computing," Leonardo Vol. 46, No. 2, I54 (2013)

I6. K. Anderson, "Object Intermediaries: How New Media Artists Translate the Language of Things," Leonardo Vol. 47, No. 4, 357 (2014).

I7. Ibid., 356.

I8. A. Ramírez Gaviria, "When Is Information Visualization Art?: Determining the Critical Criteria," Leonardo Vol. 4I, No. 5, 482 (2008).

19. J. Parikka, The Anthrobscene (Minneapolis: University of Minnesota Press, 20I4), 35.

20. D. Wilkes, "Thriving Since 1960, my Garden in a Bottle: Seedling Sealed in its Own Ecosystem and Watered Just Once in 53 Years," The Daily Mail (January 24, 20I3), <http:// www.dailymail.co.uk/sciencetech/article-2267504/The-sealed-bottle-garden-thriving-40years-fresh-air-water.html>. Accessed April i3, 2016.

2I. K. Goldberg, ed., The Robot in the Garden: Telerobotics and Telepistemology in the Age of the Internet (Cambridge, MA: MIT Press, 200I), I82.

22. L. Paraguai Donati and G. Prado, "Artistic Environments of Telepresence on the World Wide Web," Leonardo Vol. 34, No. 5, 438 (200I).

23. V. Chivukula and S. Ramaswamy, "Effect of Different Types of Music on Rosa Chinensis Plants," International Journal of Environmental Science and Development Vol. 5, No. 5, 43I-434 (20I4).

24. M.E. Collins and J.E.K. Foreman, "The Effect of Sound on the Growth of Plants," Canadian Acoustics Vol. 29, No. 2, I-8 (200I). 


\section{Jonah Brucker-Cohen}

Jonah Brucker-Cohen, $\mathrm{PhD}$, is an award-winning researcher, artist, writer, and full-time faculty member at Lehman College, City University of New York. He received his PhD from the Disruptive Design Team in the Department of Electronic and Electrical Engineering at Trinity College Dublin. His work focuses on the theme of "deconstructing networks," with projects that critically challenge and subvert accepted perceptions of network interaction and experience. His work has been exhibited and showcased at venues such as the San Francisco Museum of Modern Art, MOMA New York, ICA London, Palais du Tokyo, Tate Modern, Ars Electronica, and Transmediale. His project BumpList is included in the permanent collection of the Whitney Museum of American Art. His writing has appeared in WIRED, Make, Gizmodo, Neural, and other publications. His Scrapyard Challenge workshops have been held in more than 14 countries in Europe, South America, North America, Asia, and Australia since 2003. He is the curator of the SIGGRAPH 2016 Art Gallery. 
Data Materialities Art Gallery 


\title{
Introduction
}

\author{
Jonah Brucker-Cohen
}

The theme of the SIGGRAPH 2016 Art Gallery is "data materialities," which centers on the premise that we are surrounded daily by networks, information, and data. Data sources range from public to private profiles, wired to wireless networks, and social and mediated realities. Whether the signals consist of radio frequencies or physical, wired connections, networks are always around us, permeating and consuming our offices, homes, schools, and public indoor and outdoor spaces. Their various incarnations include social networks, transportation and sustenance networks, and networks that enable the distribution of electricity, data, water, and more. As Dr. Anna Nagurney explains in "Networks_-The Science-Spanning Disciplines," network complexity is entrenched in the concept of layered "super networks" comprising multiple networks layered on top of each other to complement each other's strengths and weaknesses. Nagurney ultimately describes networks as interpersonal technologies that simply connect people to each other: "Networks have served many purposes but their main goal is: Connecting humans to one another and their activities" [I].

The SIGGRAPH 2016 Art Gallery begins from this premise and goes further to expose the plethora of data we encounter daily by transforming it into tangible incarnations that not only showcase its complexity, but also allow us to relate to it on a human scale. Whether by injecting humor into the portrayal or kinetic energy into the exposition, the goal of the Art Gallery is to shed light on these data platforms and showcase them on a grand scale, in order to make the audience more aware of the data they carry with them daily (and presumably keep private). Visitors will not only be able to experience these data flows, they will also be able to interact with them through both their presence and unique preferences.

Works in the exhibition range from software simulations to large-scale interactive installations that fully engage with audience members, from providing visceral encounters to revealing unexpected connections. From Squidsoup's enveloping LED cube space of Submergence, which transports visitors into an immersive datascape, to Tine Bech's playful social media swing sets in The Kinetic Storyteller, the range and scope of information being generated and consumed is both varied and divergent. Mogens Jacobsen's Crime Scene displays two computers in the act of swapping copyrighted material, highlighting the component of illegality by surrounding them with yellow police tape. Benjamin Grosser's Facebook Demetricator alerts us to the numbers that consume and rank our daily lives on social media sites by removing them from these environments and allowing us to enjoy our social relationships in virtual space as we would in physical space. Deqing Sun and Peiqi Su's Plinko Poetry plays with the abundance of data 


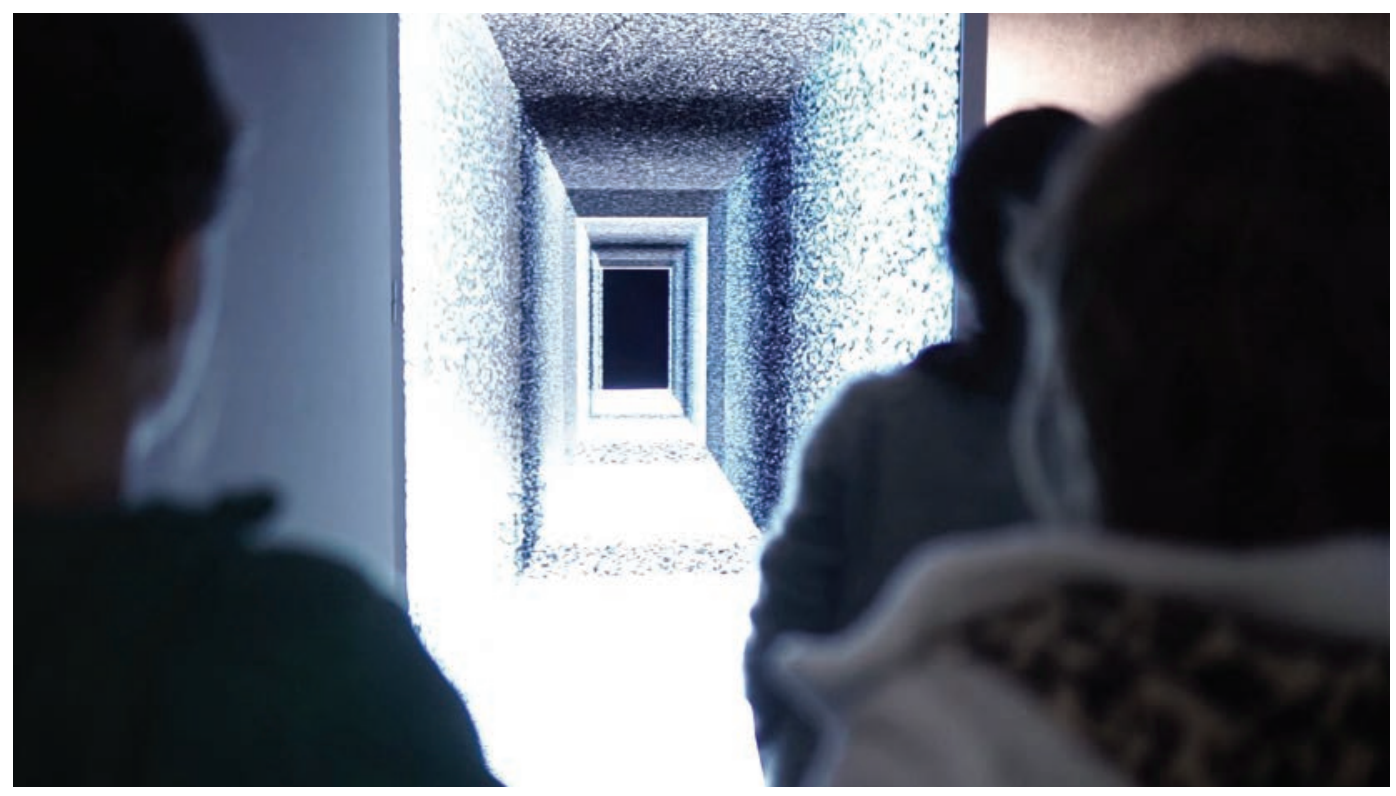

Doors. (C) 2015 THÉORIZ Studio, David-Alexandre Chanel and Romain Constant)

traveling through social networks like Twitter by giving visitors a chance to remix this data into poetry, which is randomly generated by dropping a Plinko token onto a game board. THÉORIZ Studio's Doors invites people to change their perspective of a virtual landscape simply by moving their bodies through space and peering inward.

The works in the Art Gallery fit into three distinct categories: I) Social Media, 2) Data from Natural Sources, and 3) Simulations. Although they are all very different, they share the theme of managing and representing data in novel or unexpected ways, manifesting data and the natural world on both massive and human scales. Works in the Social Media category, including Crime Scene, The Kinetic Storyteller, Plinko Poetry, and Facebook Demetricator, connect visitors' actions to social media streams; they mine data from the audience and from across the internet in real time and remix it live in public space. The second category, Data from Natural Sources, includes Metaphase Sound Machine and Submergence, works that tap into the live data streams that surround us from the earth and from man-made objects. Finally, the category of Simulations explores how data can be envisioned very differently from how their original creators envisioned them. Works in this category include Doors, Grafikdemo, Pixelbots, and Flower. Overall, the works selected for the 2016 Art Gallery speak to the intensity of data gathering, manipulation, and engagement through the interactive process of creating unexpected and beautiful art. 


\section{The Kinetic Storyteller 2016}

\section{Tine Bech}

University of Copenhagen

Denmark

mail@tinebech.com
Light Bug (2015), an interactive swing (C) 2016 Tine Bech. Photo: Paul Blakemore.)

\section{Tine Bech}

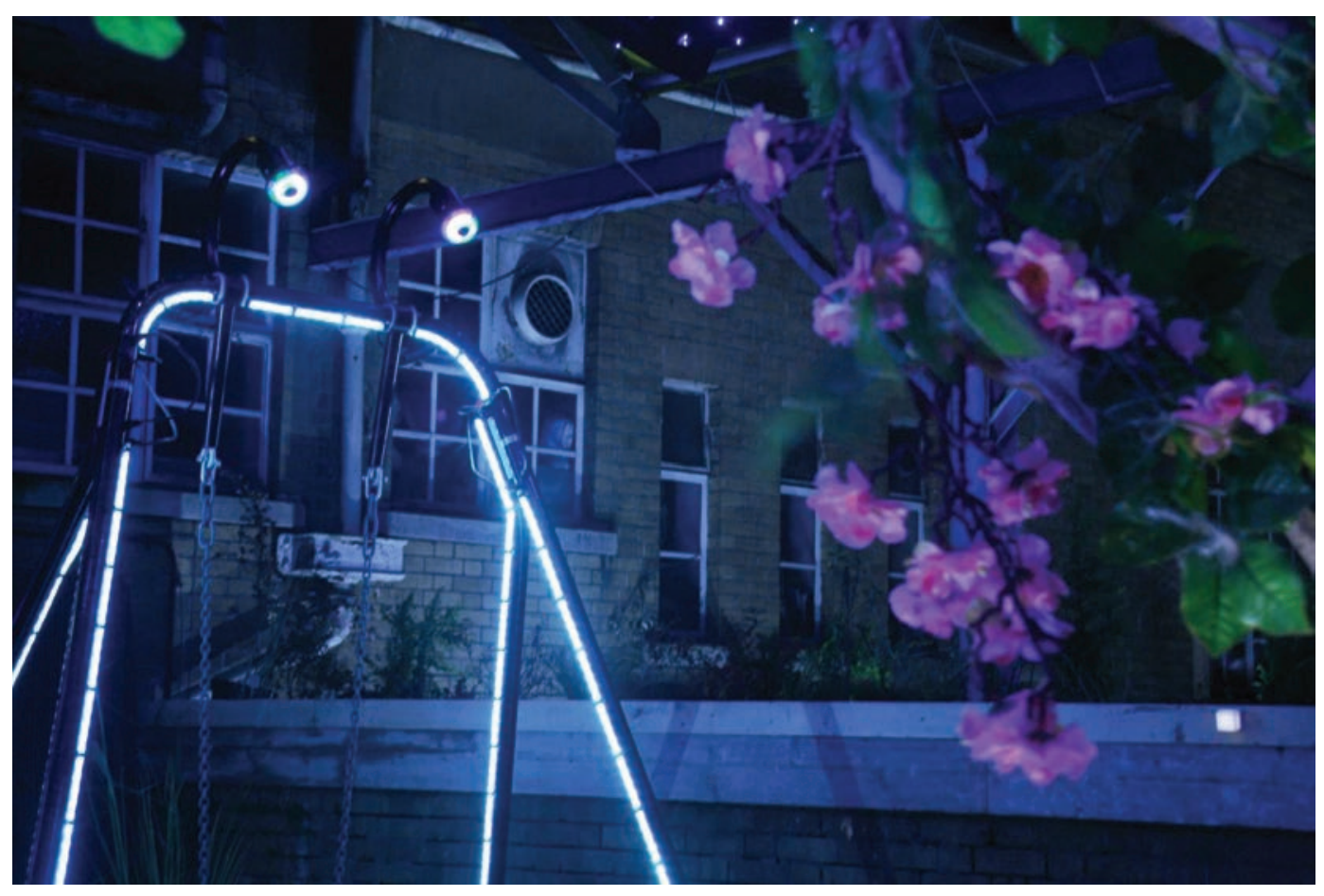

Social engagement in public space can be an awkward, challenging, and often difficult experience for people unfamiliar with each other or their surroundings. The need for an impartial mediator to connect people is something that artists have been tackling with their work for many years and is still being readdressed daily. This form of intervention allows for people occupying a space to engage in playful and anonymous interaction with others. Creatively speaking, this can take the form of a simple note on the wall that reminds people that others exist around them or a full-scale interactive experience that encourages interaction between people as well as inviting them to play with a system.

The Kinetic Storyteller is a playful environment for social interaction consisting of a pair of illuminated swings next to each other. As participants swing on the structure, they are connected to a data stream of the networked landscape around them, specifically the social media banter of Twitter. With each kinetic swing rotation, a game of color is played out on screens situated in front of the swings. Each swing generates different colors and takes over different pixels. The social interaction is not only a game of gaining pixels; here each player can see their kinetic movement and battle to show the most data or swing in sync to reveal hidden stories. Thus the motion of the swings drives the data stream, illuminating the lost connection between our physical movement and the information that we generate and carry 

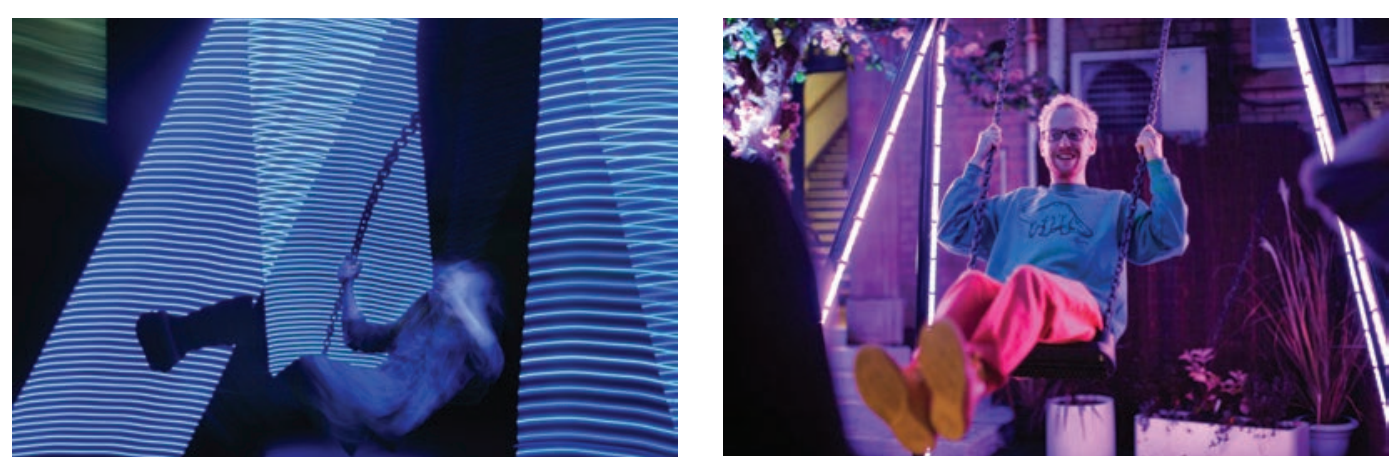

Light Bug (2015), an interactive swing. (C) 2016 Tine Bech. Photo: Paul Blakemore.)
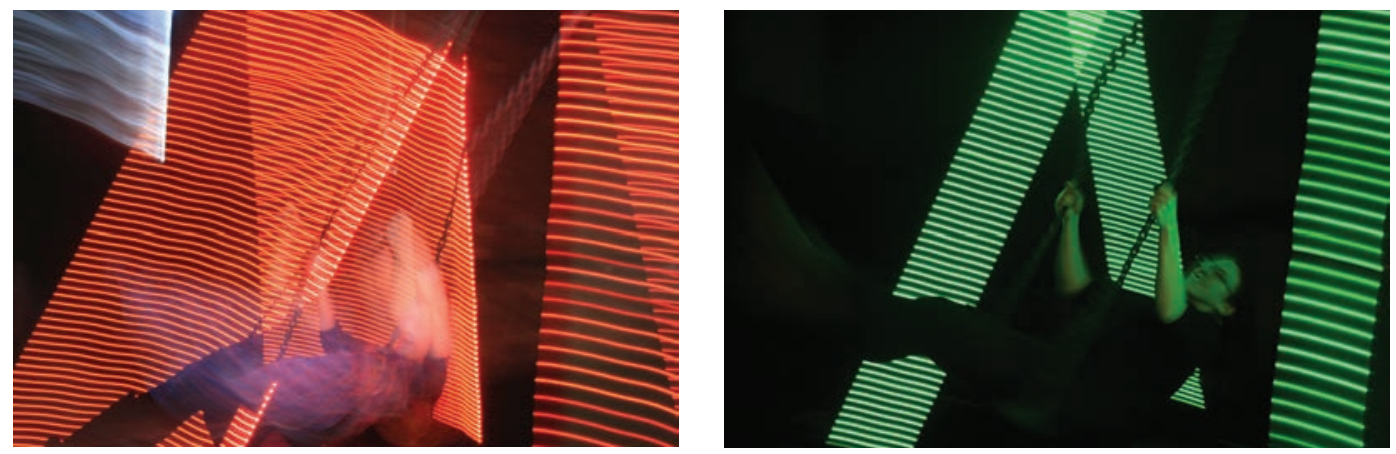

with us daily in our mobile devices. Participants' interaction with the swings materializes the data moving invisibly through their immediate spaces through play.

The playground swing is one of life's simplest pleasures. Feeling your suspended body move through space, rising and falling in a fixed arc that flows first with, then against, the pull of gravity, is both thrilling and reassuring. It remains a peerless, timeless invention and an open invitation to play, for children and adults alike.

The Kinetic Storyteller is a magical, interactive reinvention of the swing that brings additional dimensions to data materialization. By imbuing the intuitive, classic structure with facets of new digital and interactive technologies, the swing takes on a character and personality that can be developed by the "swinger." Using sensors embedded in the structure which respond to presence, modes of use, and methods of play, and using game designs developed by the artist, Kinetic Storyteller takes the art of the swing to the next level to show us a glimpse of the future of the creative playground and creates a truly immersive and mesmerizing experience. It brings the joy of the swing into the digital age; not through touchscreens and game controllers, but through interactivity, game mechanics, and light. 


\section{Submergence 2013}

Anthony Rowe

Squidsoup

United Kingdom

ant@squidsoup.org

Gaz Bushell

Squidsoup

United Kingdom

Liam Birtles

Squidsoup

United Kingdom

Ibirtles@aucb.ac.uk

Chris Bennewith

Squidsoup

United Kingdom

c.bennewith@massey.ac.nz

Oliver Bown

Squidsoup

United Kingdom

\section{Squidsoup}

In a media landscape filled with touchscreens, flat displays, projections, and virtual reality goggles, immersion in a data landscape is a fairly common experience. Simply put on a headset with some form of VR software, and magically be transported to a 360-degree virtual landscape of your choosing. Whether it is a gaming environment, or a virtual instruction manualcomplete with technician-to help fix your kitchen sink, virtual spaces are growing daily, along with our ability to engage with them.

Submergence, a large-scale LED sculpture and immersive space by U.K.-based collective Squidsoup, brings virtuality into physical space in the form of a walkthrough environment consisting of 8,064 individually addressable LEDs suspended from a ceiling. Submergence is intended to create feelings of presence, movement, and envelopment as one interacts with it. Contrary to the VR headset, the physicality of this environment challenges the ways in which we experience data and makes us think more creatively about how information could be represented in tangible spaces. Going beyond the ways in which we experience data on a daily basis, the ability to visualize the presence of data on a scale larger than our own bodies is important for our understanding of its immensity.

Submergence utilizes widely available electronics boards, inexpensive LED lights, and opensource software platforms to create a lively and immersive installation that envelops its users in continually changing data representations. The installation's form of display not only fills a space with emanating data flows and information pathways, but also illuminates potential pathways for users to meet midway through the structure. Thus the work functions as both a data sculpture and a social space for candid public interaction. Submergence is both a reflective space and a fluid space for data retrieval, giving presence to the reflective nature of our social and technological worlds as they intersect. 


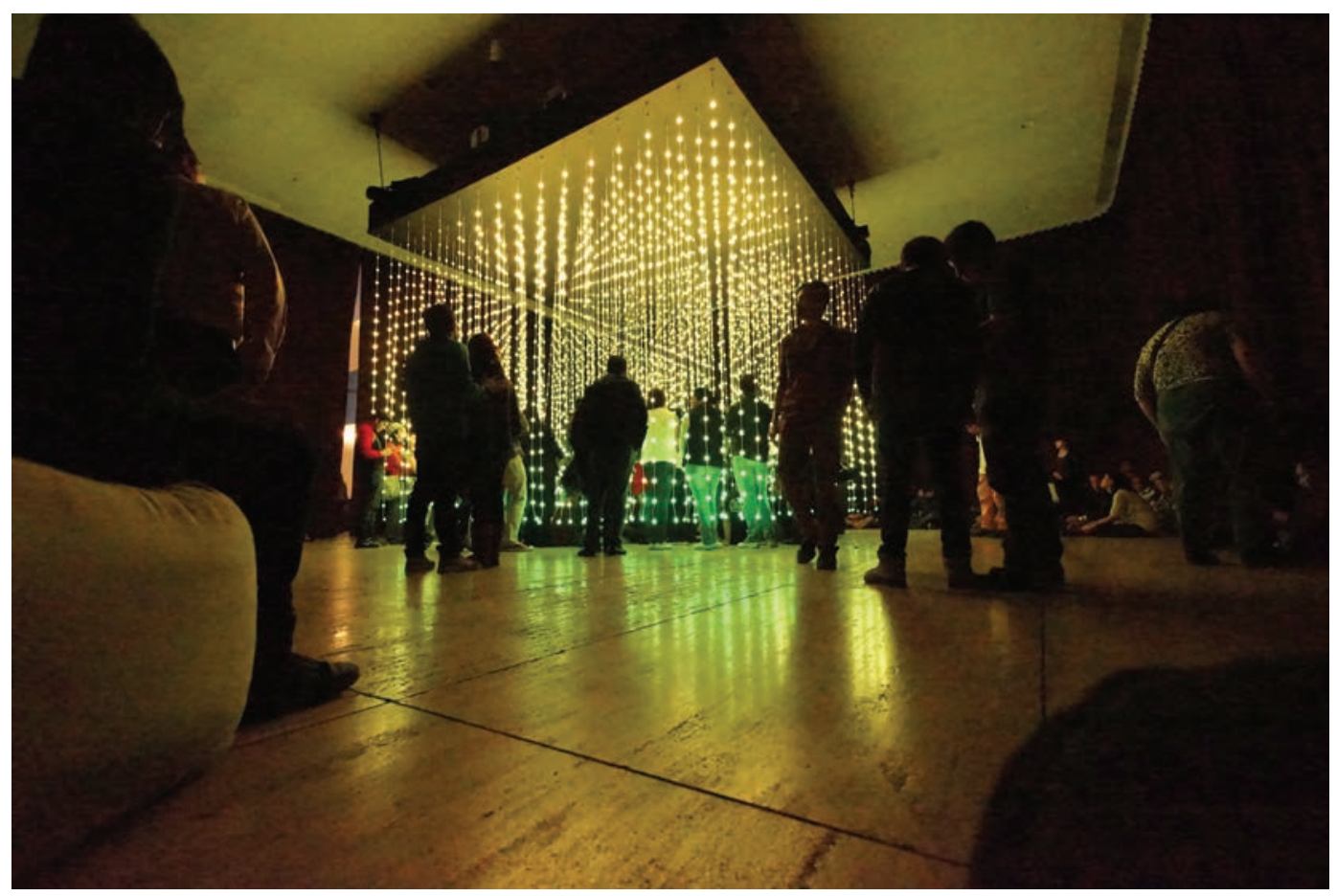

Submergence. (๑) 2013 Squidsoup.org. Photo: Paul Blakemore.)

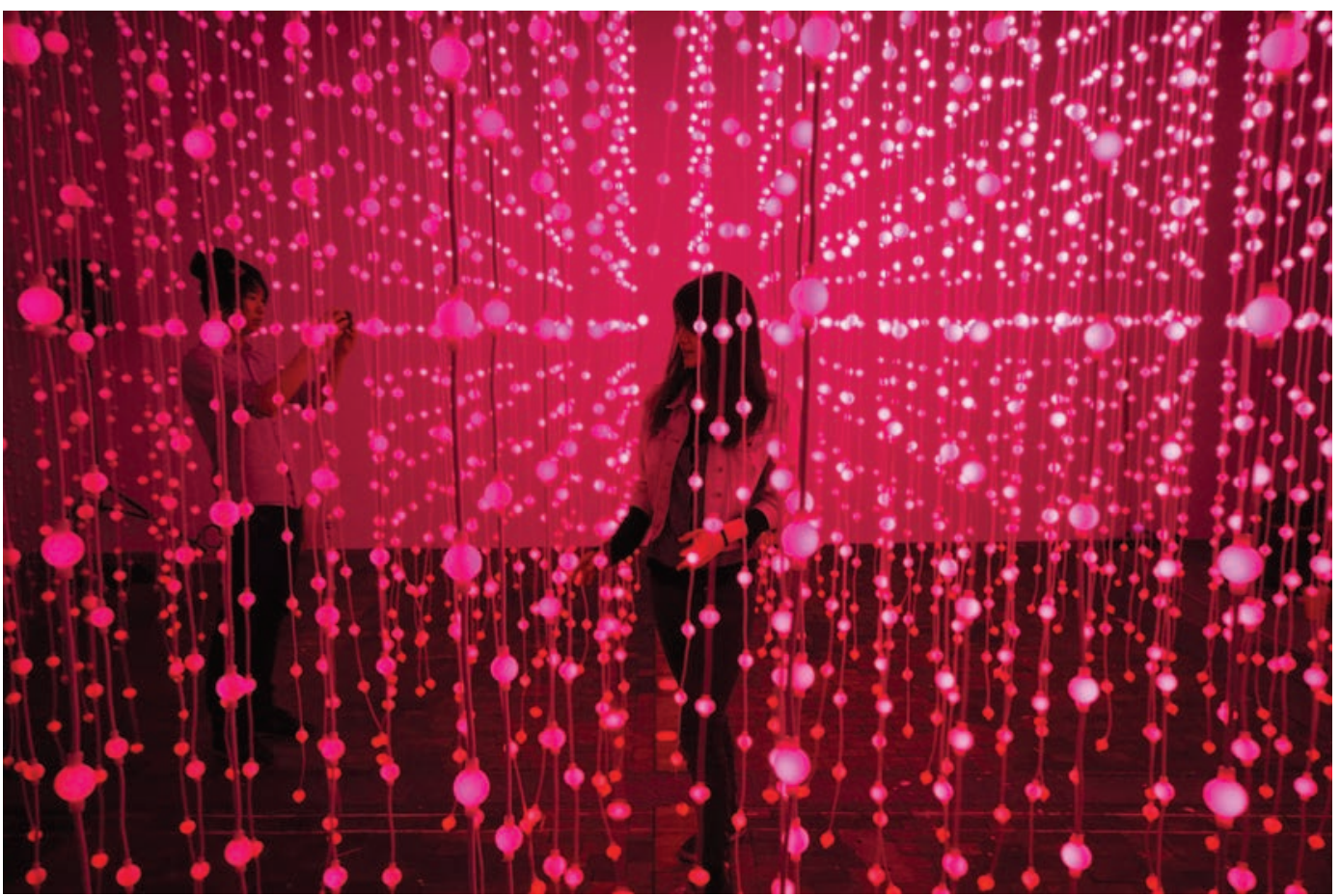

Submergence (Aeolian Light) at Salford Quays, Greater Manchester, U.K.

(C) 2014 Squidsoup.org. Photo: Quays Culture.) 


\section{Plinko Poetry 2012}

\section{Deqing Sun}

New York University

United States

ds3457@nyu.edu

Peiqi Su

New York University

United States

supeiqi.design@gmail.com

Plinko Poetry. (@ 2012 Deqing Sun and Peiqi Su)

\section{Deqing Sun and Peiqi Su}
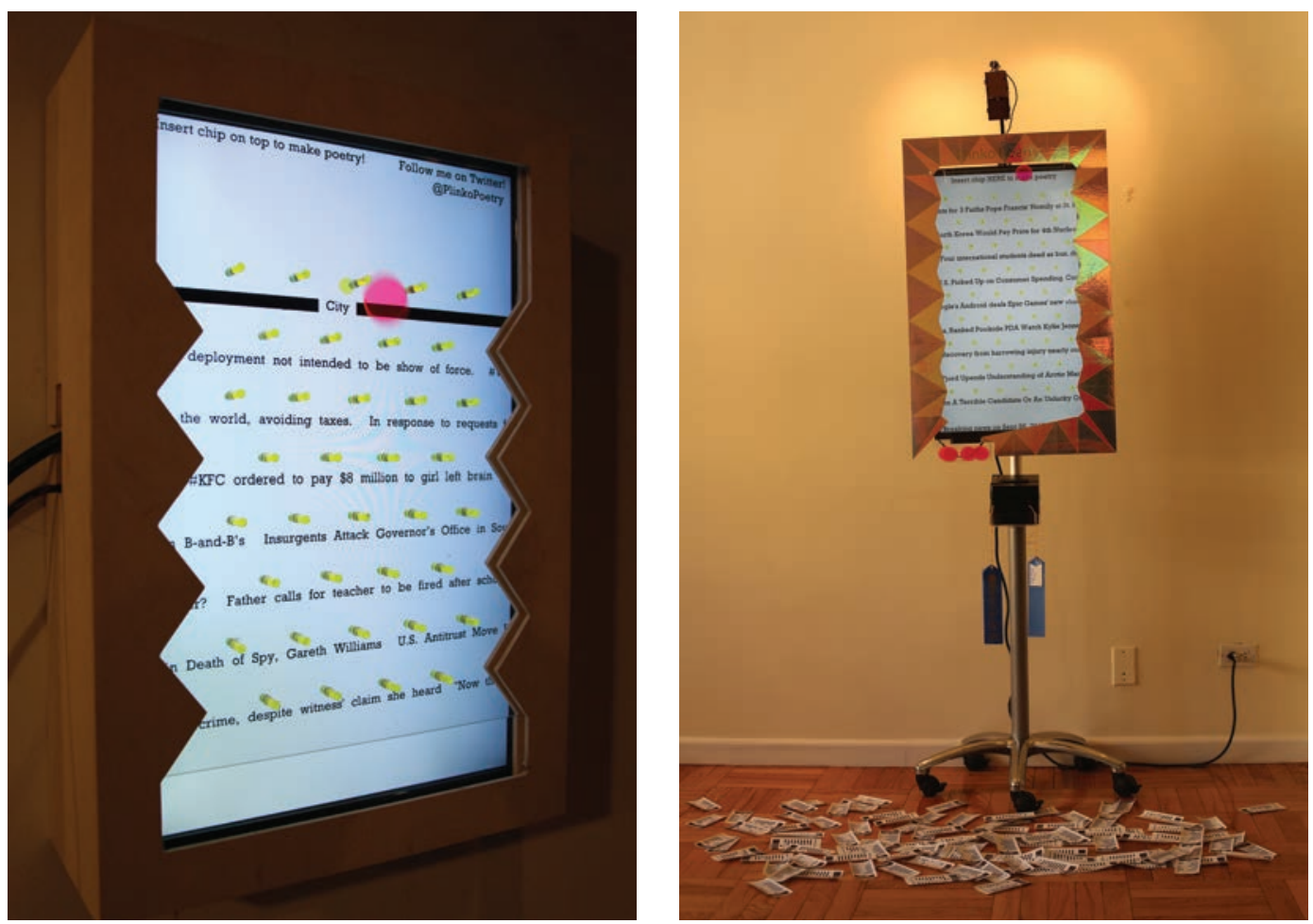

With the plethora of real-time information and news coming from both commercial news sources and individual broadcasters using the internet and Twitter to get their messages across, we seem to have arrived at a backlog of data chaos that is clamoring for order. Plinko Poetry, by Deqing Sun and Peiqi Su, playfully recontextualizes this heavy onslaught of information. The project gets its name from the game of Plinko, introduced in 1983 on the hit American television game show The Price Is Right. In the original game, contestants climbed a staircase and dropped large chips into a game board fitted with hundreds of pegs. The chips would hit the pegs as they fell, sending them off in different directions until they landed at the bottom of the board into one of several slots assigned with different dollar values. 


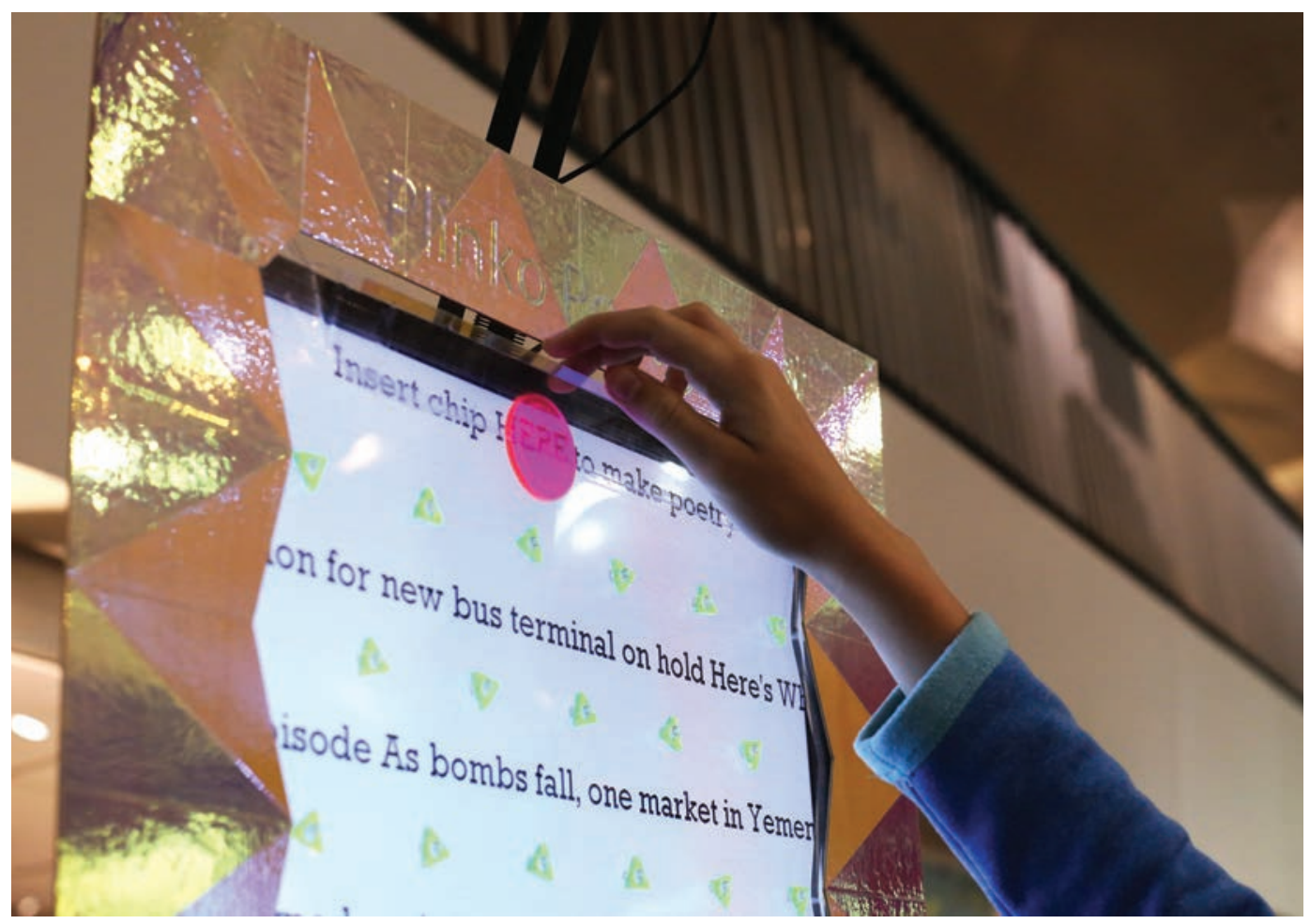

Plinko Poetry. (C) 2012 Deqing Sun and Peiqi Su)

Bringing the aesthetic of the original game of Plinko into the digital era, Plinko Poetry retains the chip and pegs convention, but instead of waiting for the chip to drop to the bottom of the board to arrive at a result, the chip creates a poem out of scrolling Twitter feeds on a screen: Each peg hit by the chip stops the Twitter feed on a word, collecting the words into a poem that is printed on a piece of paper and given to the participant. The resulting poem is also live-tweeted to the @PlinkoPoetry Twitter account. The result is a live poetry engine, powered by people, that constantly broadcasts its poems as the installation is used. The installation feeds off of the seemingly useless number of messages that are sent daily by celebrities, political leaders, ordinary citizens, and media outlets. Ultimately, it makes light of the fact that we are living in such an information-rich landscape, from social media to traditional news media, that the amount of data produced daily often outlives its usefulness to the general public. 


\section{Grafikdemo 2004}

Niklas Roy

Freelancer

Germany

nik|@s-roy.de

\section{Niklas Roy}

Virtual spaces and $3 \mathrm{D}$-rendered objects can both be manipulated in on-screen environments and modified by designers in real time. We are now so accustomed to our ability to "fly through" these rendered spaces with computer mice or handheld controllers that they have become commonplace. In today's oversaturated media landscape, we often take for granted the fact that virtual objects can coexist with our physical spaces through head-mounted displays. Increasingly, these devices also allow for augmented reality (AR) such as Microsoft's HoloLens [2], Google's Glass [3], and the countless other VR viewers on the market.

Materializing this theme of virtual reality and object manipulation outside the virtual space of a headset or screen and bringing it into the physical world is Niklas Roy's Grafikdemo, which consists of a physical wireframe of the quintessential ${ }_{3} \mathrm{D}$ model, the standard teapot, built inside the frame of a classic Commodore CBM, a computer originally produced in 1977. At the time, the CBM was Commodore's top-selling computer in North America and was Commodore's first full-featured machine, a predecessor of the classic Commodore 64. Looking back at the historical value of such a machine's physical attributes and processing power, the inability to render anything useful is contrasted with an analog version of the teapot that sits atop a system of motors and a frame that allows the teapot to be rotated in ${ }_{3} \mathrm{D}$ space in the same way that a traditional $3 \mathrm{D}$ model could be manipulated to show it from all angles. The difference in Roy's adaptation is that the entire process takes place through physical means. There is no mouse on this computer; only the analog keys of the antiquated keyboard allow visitors to manipulate the object inside, thus exposing the mechanical aspects of the project. 

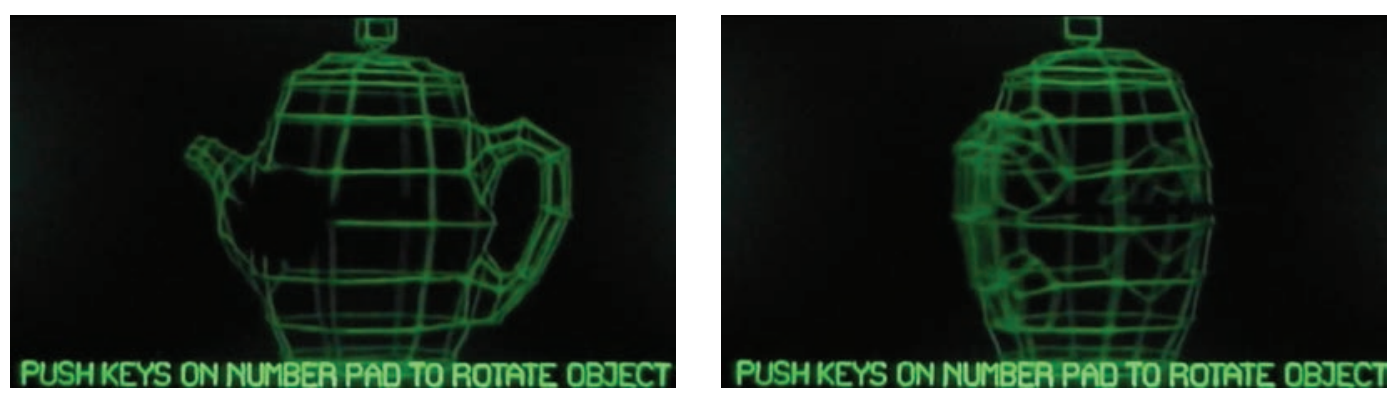

Grafikdemo. (๑ 2004 Niklas Roy)

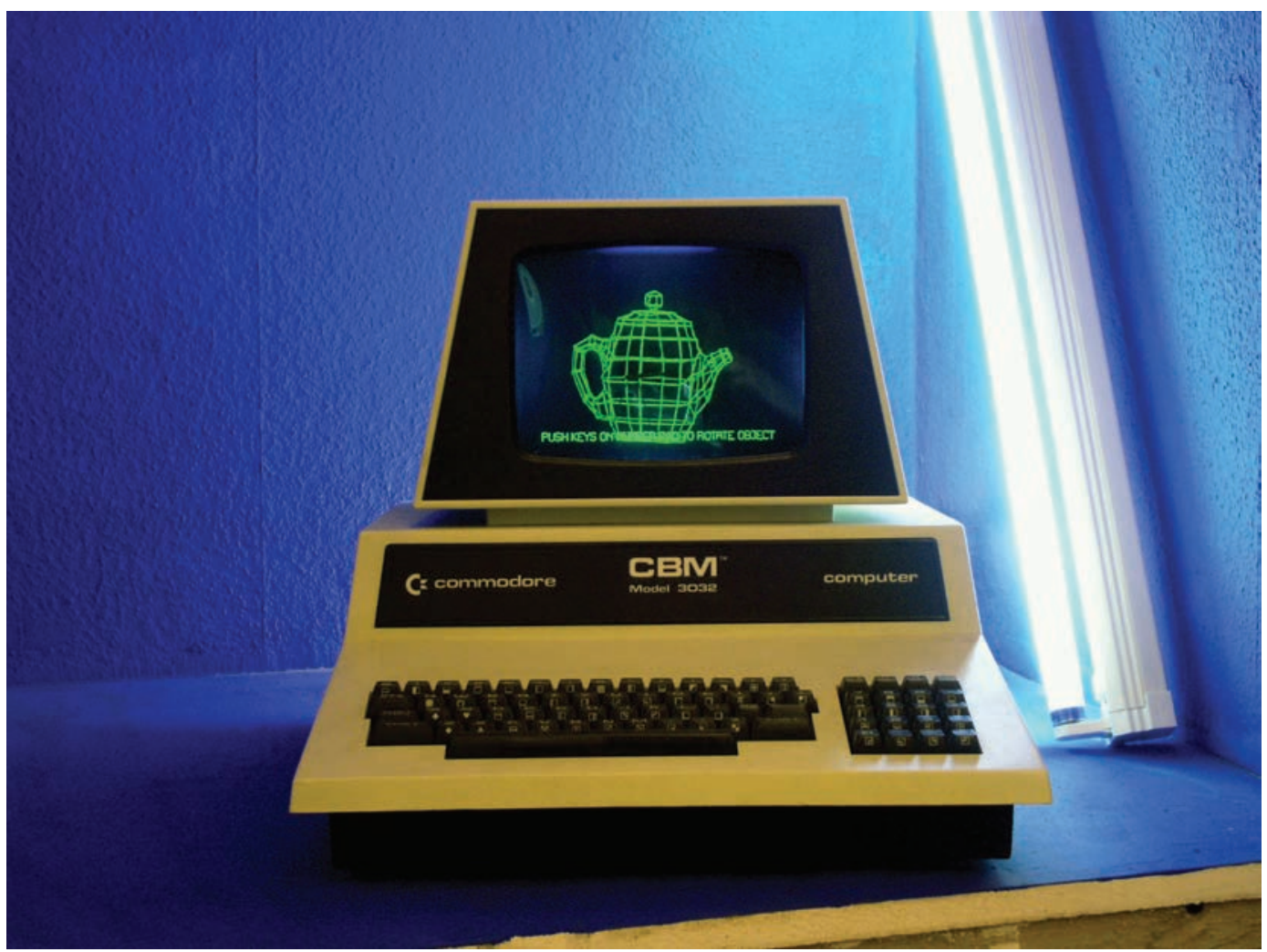

Grafikdemo. (@ 2004 Niklas Roy) 


\section{Flower 2014}

Viktor Jan

Freelancer

South Korea

viktography@me.com

\section{Viktor Jan}

Although Viktor Jan's Flower may seem like an interloper among the many data sculptures and media representations appearing in this exhibition, it provides a contrast from the other works by focusing on how data can spur the creation and loss of natural entities. Inspired by the poem "Flower," by one of South Korea's leading poets of the late 2 oth century (Kim Ch'un-Su), the flower "blooms" or comes to life in a dark environment, when visitors whisper into its microphone, or when it senses data streams on local networks. Unlike a natural flower, Jan's flower awakens in the evening and will never come to life unless someone calls its name. Flower reacts to the idea of "the gaze" in digital space, where people online are always vying for more views, likes, and mentions.

Until I spoke his name, he had been no more than a mere gesture.

When I spoke his name,

he came to me and became a flower.

Now speak my name, one fitting this colour and odour of mine, as I spoke his name, so that I may go to him and become his flower.

We all wish to become something. You to me and I to you wish to become an unforgettable gaze [4].

The work operates in a similar fashion to internet chat rooms, which are often most active in the evening hours when people are up late at night or home from a busy day at work and can finally contribute to the global online discussions. Flower, in effect, directly correlates to the variety of activities that take place online and out of sight. Flower only comes to life when people interact with it, which is similar to the phenomenon of Web 2.0, where databases and interfaces for cataloguing large amounts of data are created, and then wait for the general public to populate them with everything from personal photos to endless chatter. Maybe it is precisely this seemingly endless amount of data that either encourages us to be more creative or inspires us to challenge its use and purpose. 

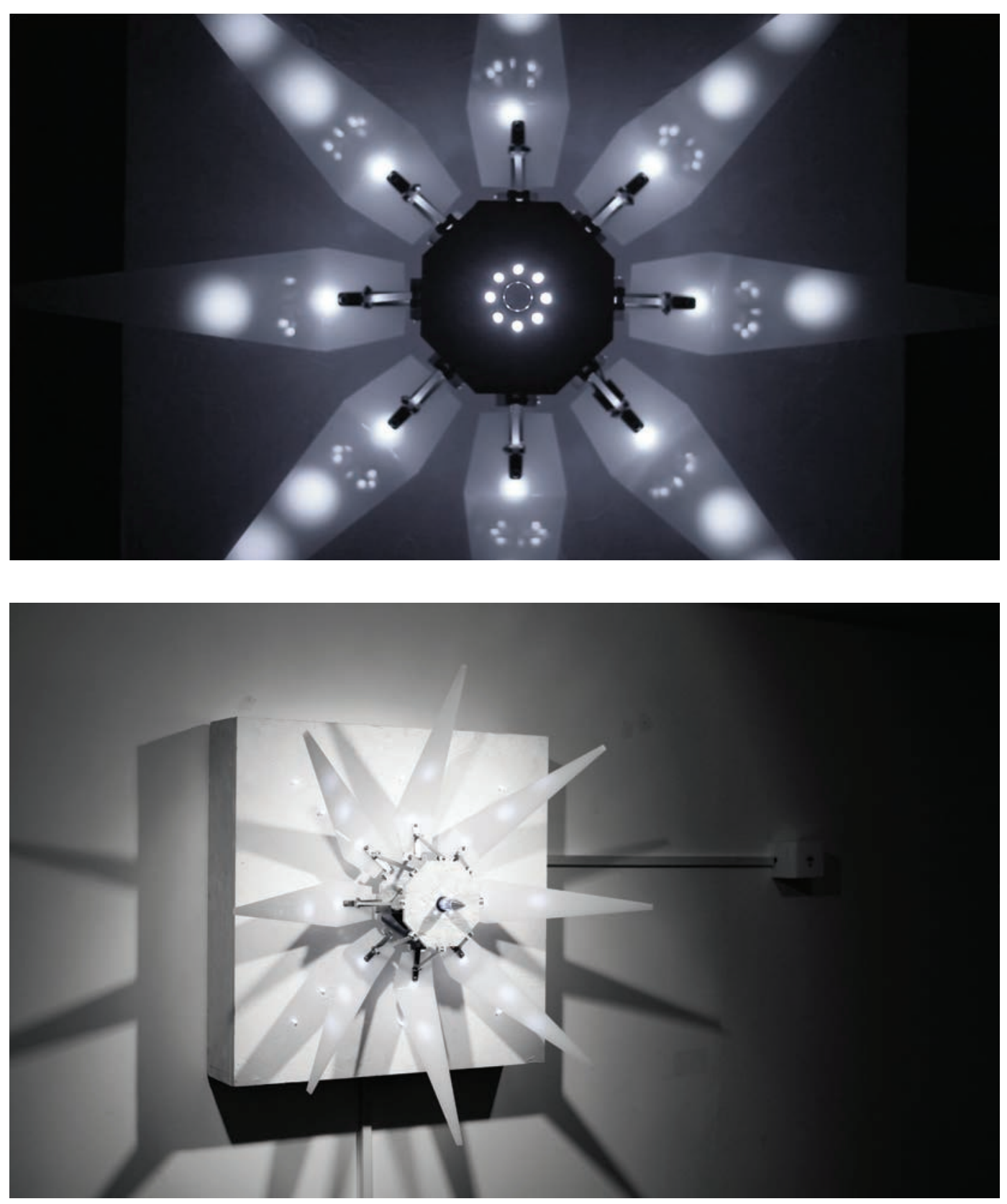


\section{Metaphase Sound Machine 2015}

\section{Dmitry Morozov}

Freelancer Artist

Russia

vtol.studio@gmail.com

\section{Dmitry Morozov}

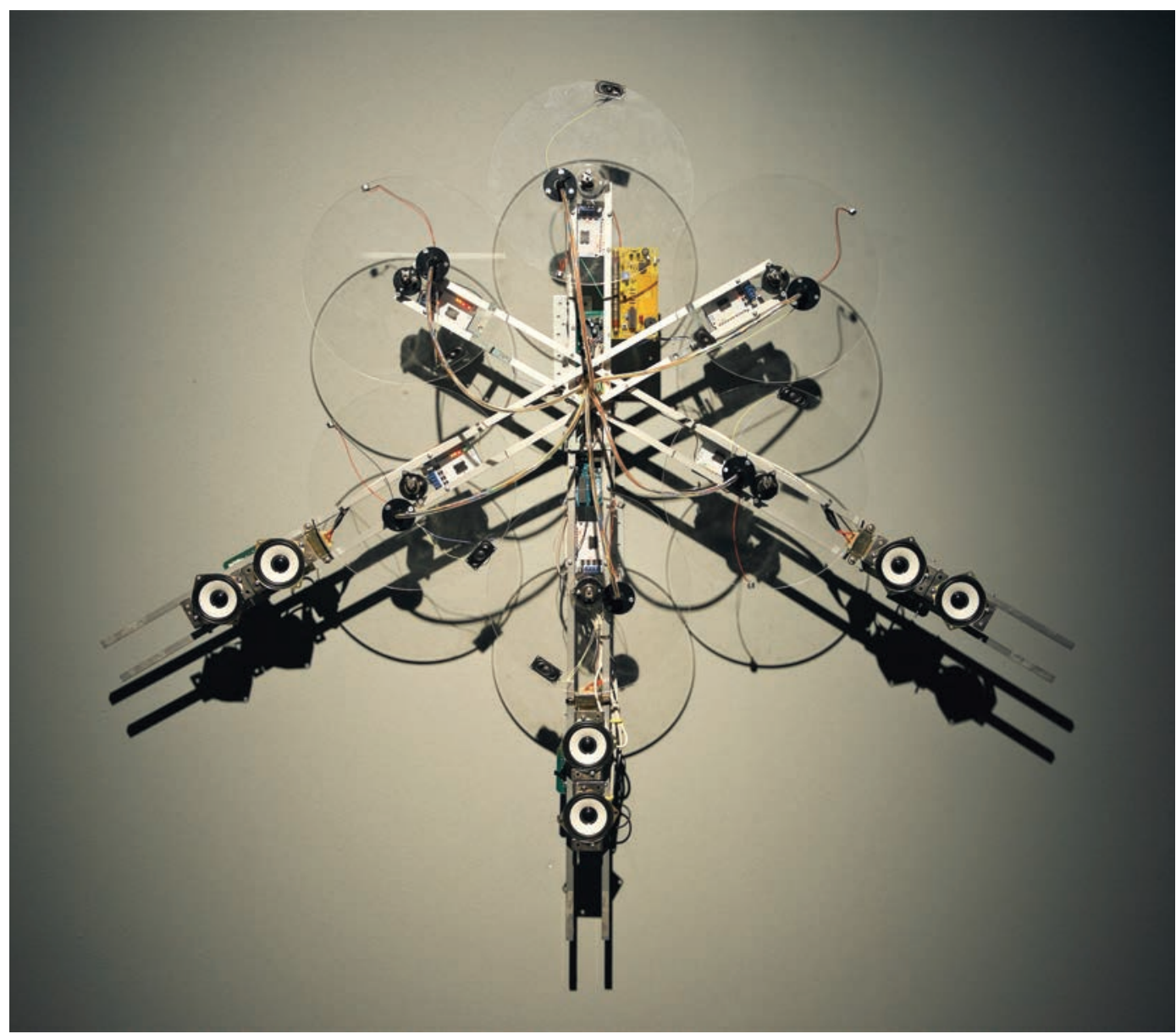


Russian artist Dmitry Morozov's Metaphase Sound Machine plays off of our increasing dependence on the information and electronic noise that permeates our everyday lives. The project is based on the ideas of American physicist Nick Herbert, who created the Metaphase Typewriter-invented as a quantum device capable of communicating with ghosts—and Quantum Megaphone, a speech synthesis machine [5]. According to Morozov, Herbert's interests also included the mixing of hallucinogenic drugs, paranormal activity, the nature of consciousness, and speculative connections. These early interests contributed to Herbert's desire to design a quantum computer, but they did not confirm any theoretical research. Morozov's piece was inspired by Herbert's work, especially in relation to the amalgam of devices and networks that permeate our daily routines.

The Metaphase Sound Machine works like the spinning radars that manage flight traffic at airports, but instead of looking for moving objects, the machine scans its vicinity for radiation from networks, cellphones, laptops, and other electronic devices. Using an on-board Geiger counter, the machine gathers nearby radiation and translates it into sound waves based on its proximity. The element of randomness in Morozov's work is derived from the data collected by the sensors, making the sounds produced truly unique every time the machine is activated. The kinetic motion of the system attracts visitors, causing a chain reaction as the machine senses their electronic devices, provoking further activation of the machine. 
Pixelbots 2014

\section{Tejaswi Digumarti}

Disney Research and ETH Zürich

Switzerland

tejaswi.digumarti@disneyresearch.com

\section{Javier Alonso-Mora}

MIT

United States

jalonsom@csail.mit.edu

Roland Siegwart

ETH Zürich

Switzerland

rsiegwart@ethz.ch

Paul Beardsley

Disney Research

Switzerland

pab@disneyresearch.com
Pixelbots. (@ 2014 Disney Research and ETH Zürich. Photo: Disney Research.)
Disney Research and ETH Zürich

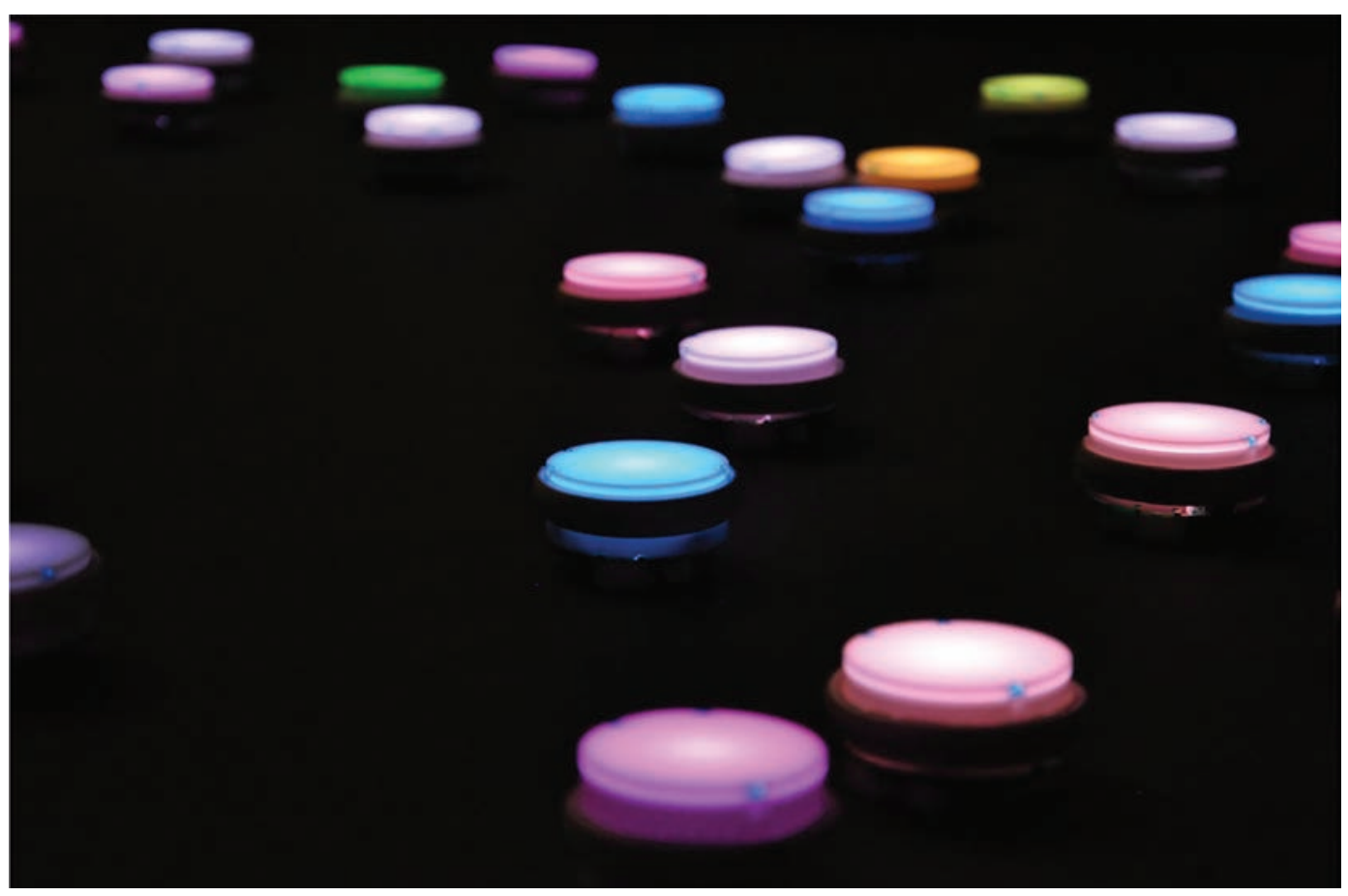

In today's digital media landscape, we are constantly surrounded by displays, from the LCDs found on the phones in our pockets to the ubiquitous screens that greet us whenever we enter a store, airport, taxicab, doctor's office, or educational institution. This plethora of displays both allures us and contributes to the media's saturation of our lives. The truth remains that we are never far from the next form of information display. Disney Research's Pixelbots takes this truth as an inevitability and brings the display into a kinetic form, breaking the screen out of the confines of a rectangular or oval experience. Billed as "Pixels with Personality," the Pixelbots' enticing presence rests on our ability to project human qualities onto objects that move as we do in physical space. 

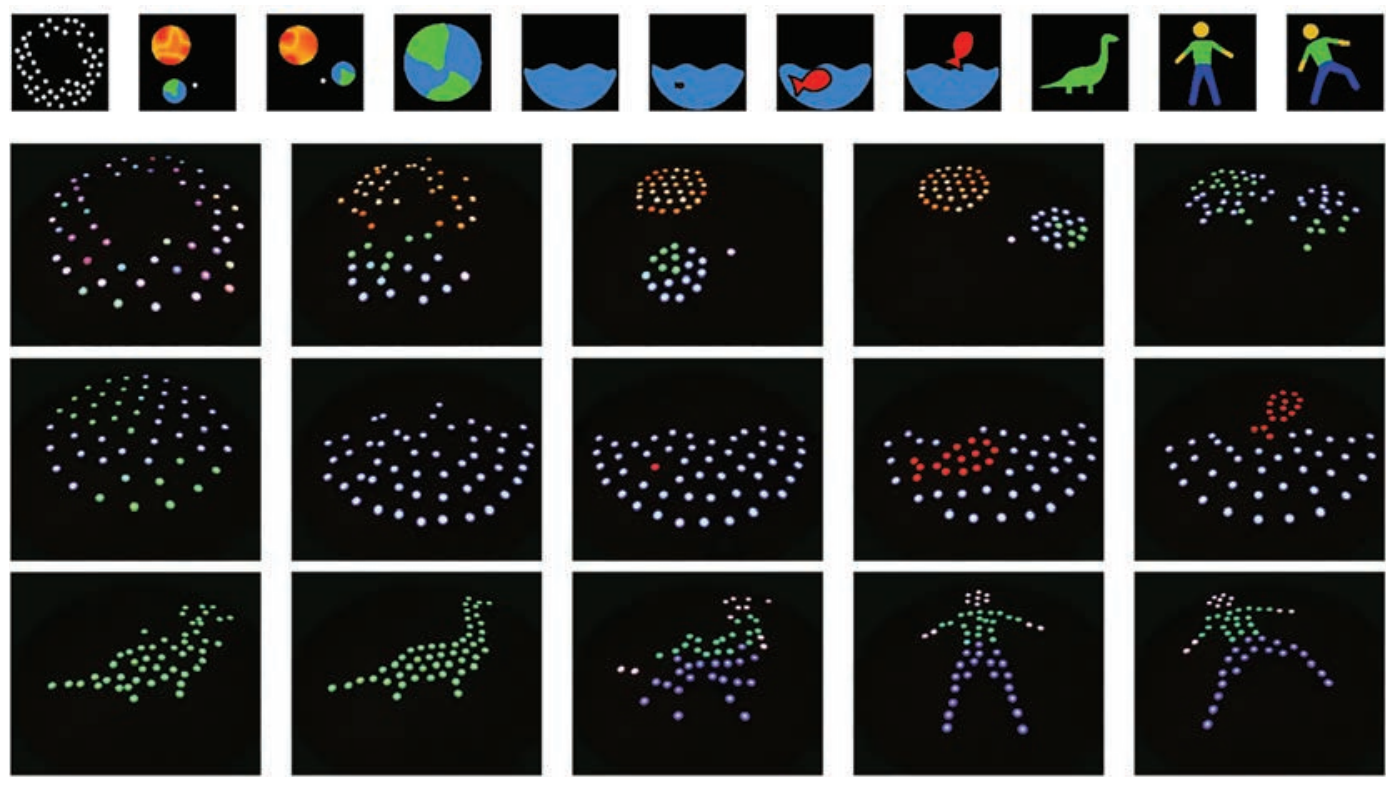

Pixelbots. (@ 2014 Disney Research and ETH Zürich. Photo: Disney Research.)

Whenever we see robots, remote-controlled cars, boats, planes, drones, or anything else moving in controlled formations resembling a flock of birds or an army of ants, we project human characteristics onto them. Sigmund Freud discovered this phenomenon and named it "psychological projection"-the process whereby one projects one's own thoughts, motivations, desires, feelings, and so on onto someone or something else. Pixelbots represents this form of empathetic display, as well as the evolution of how information will manifest itself in the near future. Similar to Greyworld's The Source - a kinetic installation inside the London Stock Exchange consisting of tethered spheres that change color and position based on which stocks are doing well or poorly on the market [6] - Pixelbots shows how information can be arranged dynamically and fluidly on a physical platform and take material shape in the form of clusters or designed dynamic shapes. The screen itself becomes a fluid entity that can be harnessed and remixed into any shape, color, or manifestation one desires. 


\section{Crime Scene: Installation for Two Computers 2003}

Mogens Jacobsen

Freelance Artist

Denmark

jacobsen@artnode.org
Crime Scene. (@ 2003 Mogens Jacobsen)
Mogens Jacobsen

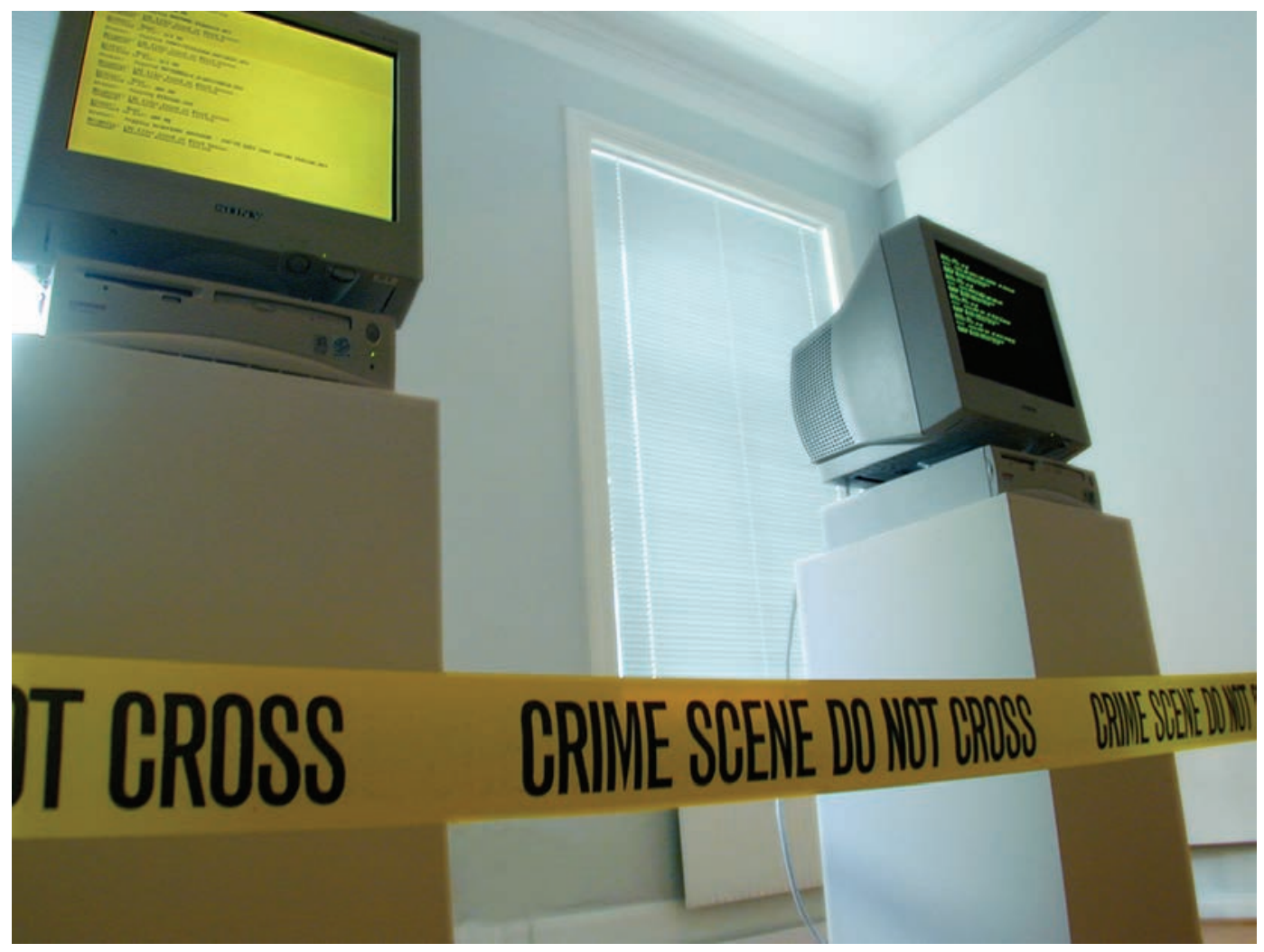

The internet has enabled us to accomplish so many things. The universal appeal and power of the internet to change and augment our daily lives is both undeniable and inevitable. Every day we go online and consume endless amounts of media—audio, video, text, interactive experiences - that can be electrifyingly fun, educational, or a waste of time. Although a vast amount of information is available to us online, not all of it is free or legal to use without some sort of licensing agreement or pay-per-use model. Most of the bigger utility-like companies, such as Google, Yahoo, and Facebook, give away their online services for free; but when it comes to content created by professional companies, such as television studios, app creators, music or movie studios, there is a price that comes along with it. Despite this monetary inevitability, a great deal of data and information travel through the internet illegally, in violation of copyright and intellectual property laws. 


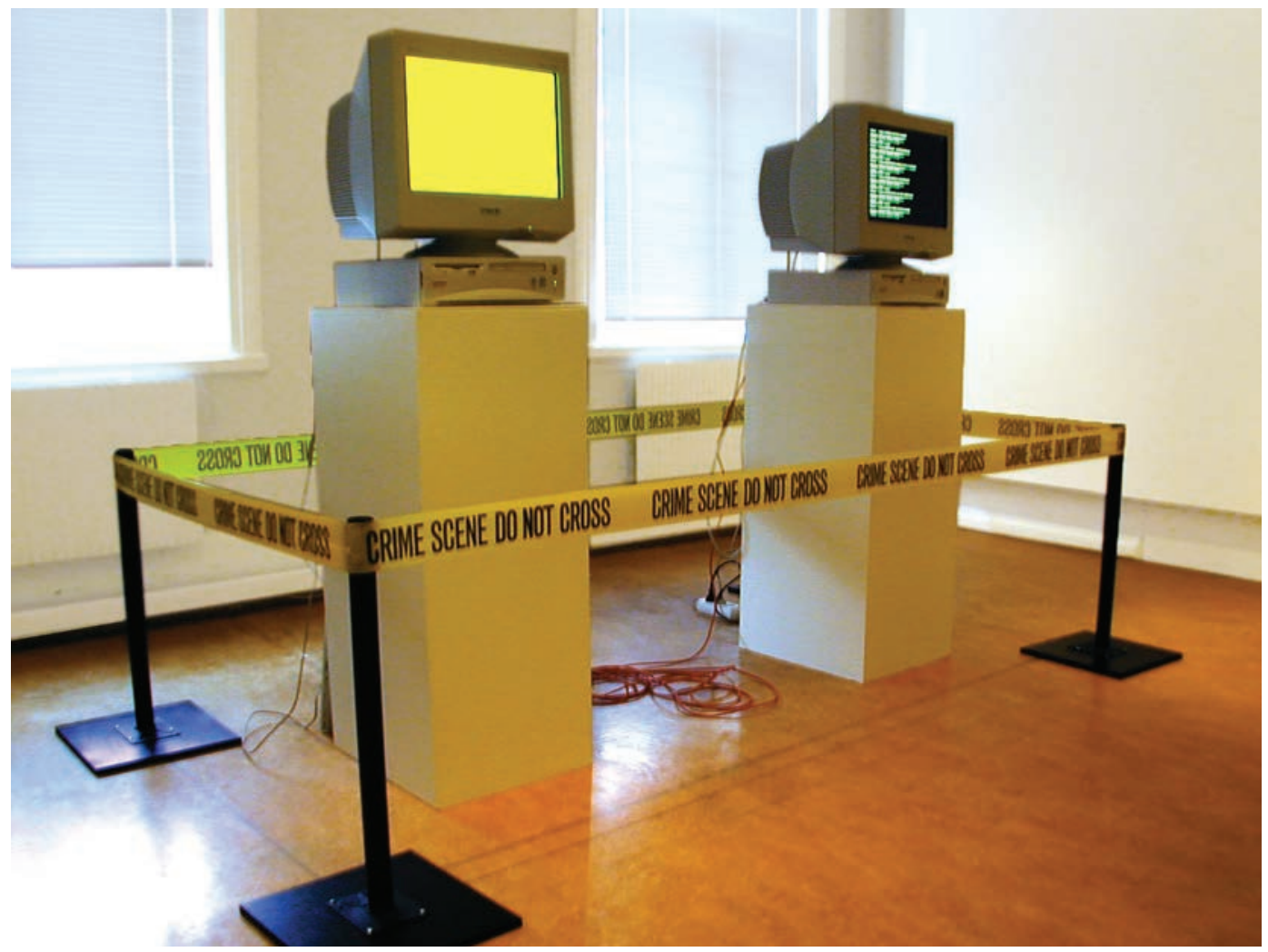

Crime Scene. (@) 2003 Mogens Jacobsen)

As technology gains further ubiquity in popular culture, the rules and contexts that govern its use have begun to draw our attention. From lawsuits against Napster to federal hearings about Microsoft's Internet Explorer, the problem of digital rights management is becoming a widespread phenomenon. Exploring the clash between mass consumption of technology and personal use, Danish artist Mogens Jacobsen's work challenges the incorporeal existence of digital objects and their physical incarnations. Examining the legal restrictions of file-sharing, Crime Scene: Installation for Two Computers is an installation in which a copyrighted file is transferred between two computers ad infinitum. This portrayal of illegal internet activity in physical space adds yet another dimension to how mass culture is striving to amalgamate and restrict digital objects into categories that previously only existed for physical ones. 
Doors 2015

\section{David-Alexandre Chane}

THÉORIZ Studio

France

david@theoriz.com

Romain Constant

THÉORIZ Studio

France

rom.constant@gmail.com

Doors. (@ 2015 THÉORIZ Studio, David-Alexandre Chanel, and Romain Constant)

\section{THÉORIZ Studio}

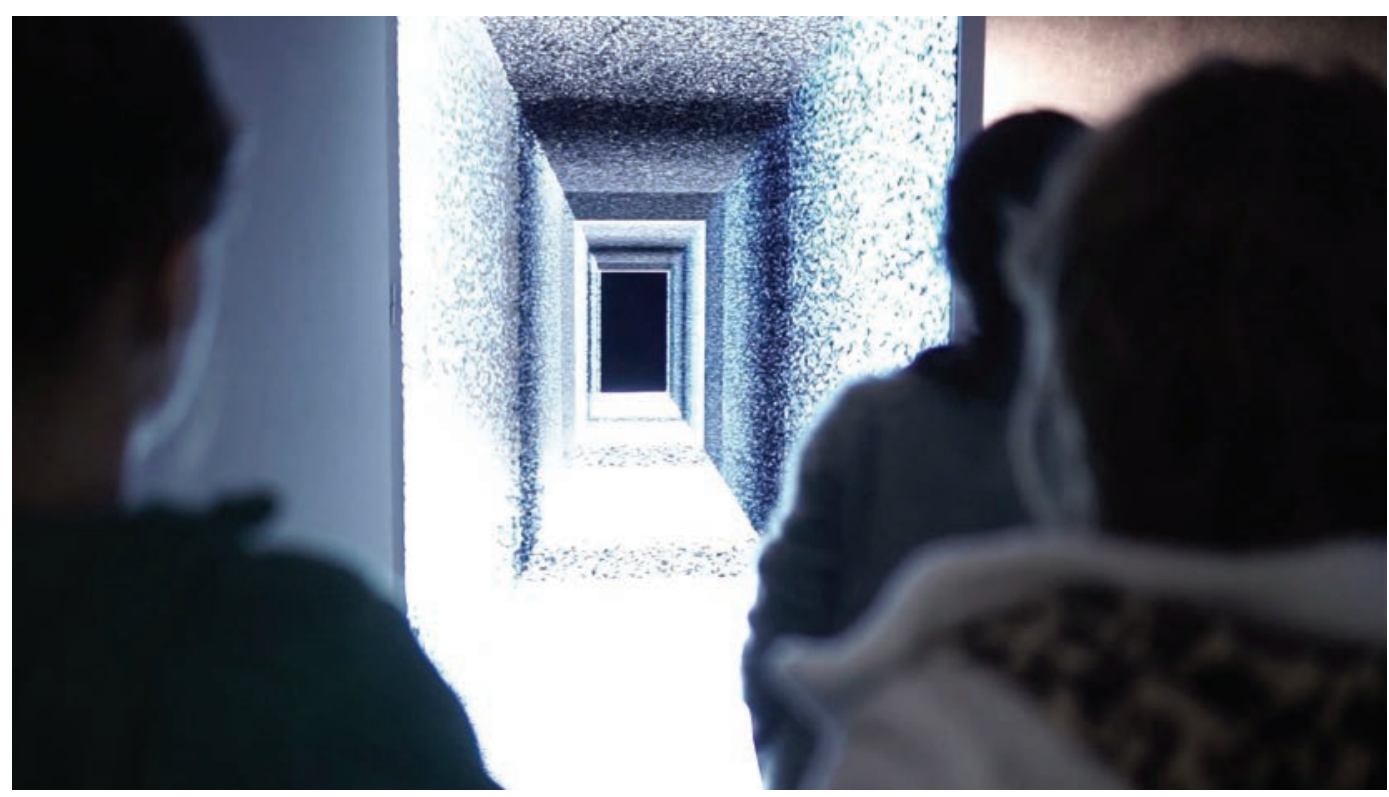

In indoor physical spaces, the door is the main obstacle to entering and exiting rooms and hallways. From a usability perspective, Donald Norman is celebrated for wondering how "such a simple thing as a door" can be "so confusing" [7]. The door as physical object has been transformed metaphorically into a transportation device that allows us to completely shift our perspective from one location to the next. The object itself is often imagined as a "portal" between spaces and worlds, as it was in 1950 in the quintessential fantasy novel, The Lion, the Witch, and the Wardrobe, by C. S. Lewis. The children in the story open an apparently ordinary wardrobe door and are transported to the magical world of Narnia. Many other movies and stories use doors as portals through time and space, such as the phone booth door in the movie Bill and Ted's Excellent Adventure. 


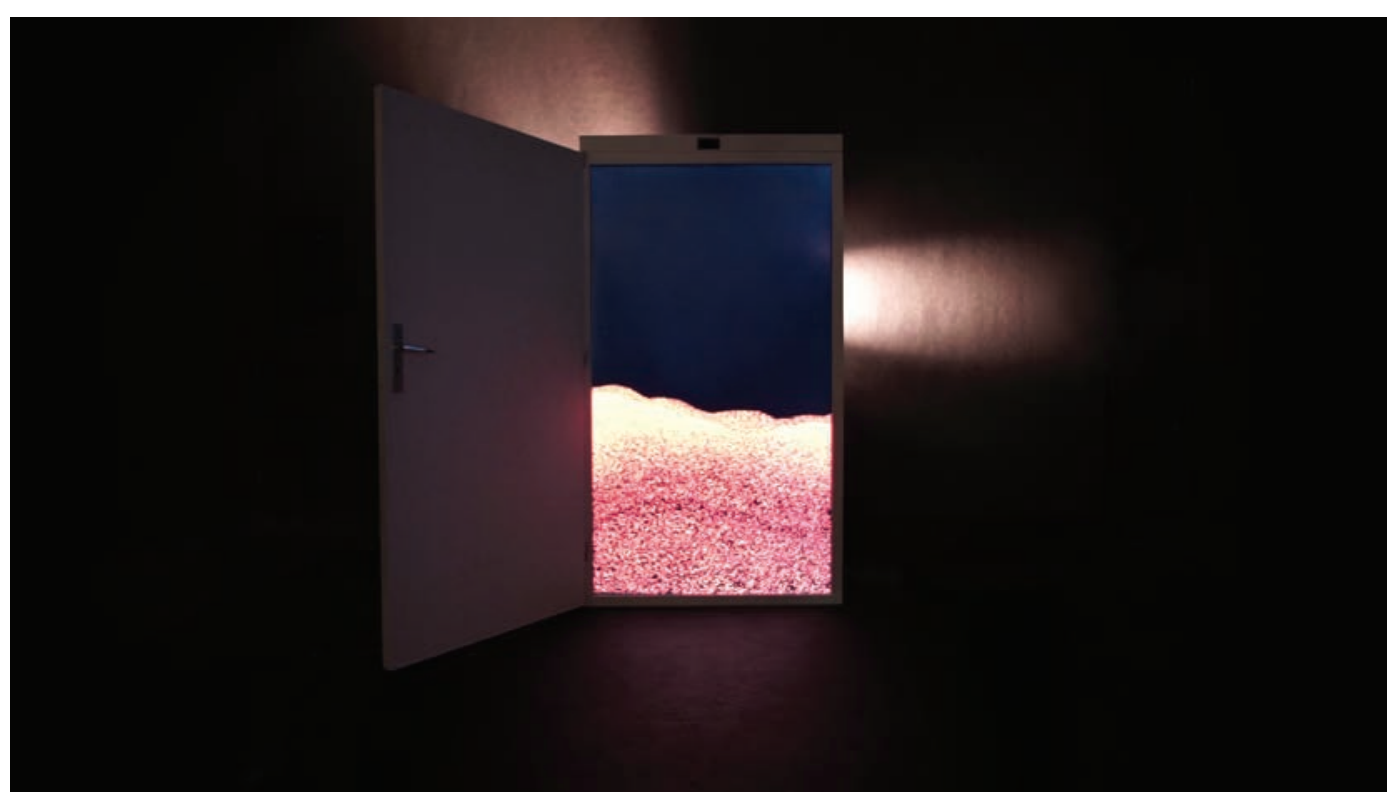

Doors. (@) 2015 THÉORIZ Studio, David-Alexandre Chanel, and Romain Constant)

Doors by THÉORIZ Studio, a group of artists and designers based in Villeurbanne, France, is a portal that takes on the middle ground between virtual and physical space. Built around the structure of an actual door, sensors surrounding the door track visitors' movements and change the portal on the screen's perspective in a real-time anamorphic system that adjusts to their visual angle in real time. The project uses four-channel, immersive spatialized sound so that onlookers can be immersed in virtual landscapes by simply moving their bodies around the space. Doors fits the theme of "data materialities" as it uses the framework of a physical door and manifests itself only through physical interaction with visitors, whose angle of view becomes the pivotal interaction point of data manipulation. 


\section{Facebook Demetricator 2012-Present}

Benjamin Grosser

University of Illinois at Urbana-Champaign

United States

grosser@bengrosser.com

\section{Benjamin Grosser}

Like $\cdot$ Comment $\cdot$ Share $\cdot 7 \mathrm{hrs} \cdot$

@ 56 people like this.

13 shares

View 3 more comments

Like $\cdot$ Comment $\cdot$ Share $\cdot$ recently $\cdot$

\section{$\Omega$ people like this.}

\section{shares}

\section{View more comments}

Networks-especially social networks and news aggregators on the internet, such as Facebook, Vine, Twitter, YouTube, DIGG, and others-rely on numbers to rank and catalog content and status. People interacting online are now using these numbers as a form of "social currency" to rate each other based on how many friends they have, how many "likes" they earn on their Facebook and Instagram posts, and how many votes of approval they need to sell more products on sites like eBay, Amazon, and Etsy. Illinois-based artist Benjamin Grosser takes these numbers and metrics as a critical starting point: recognizing the self-perpetuating system of numericizing online activity (friends, "likes," comments, votes, etc.), he decided to create an antidote. 

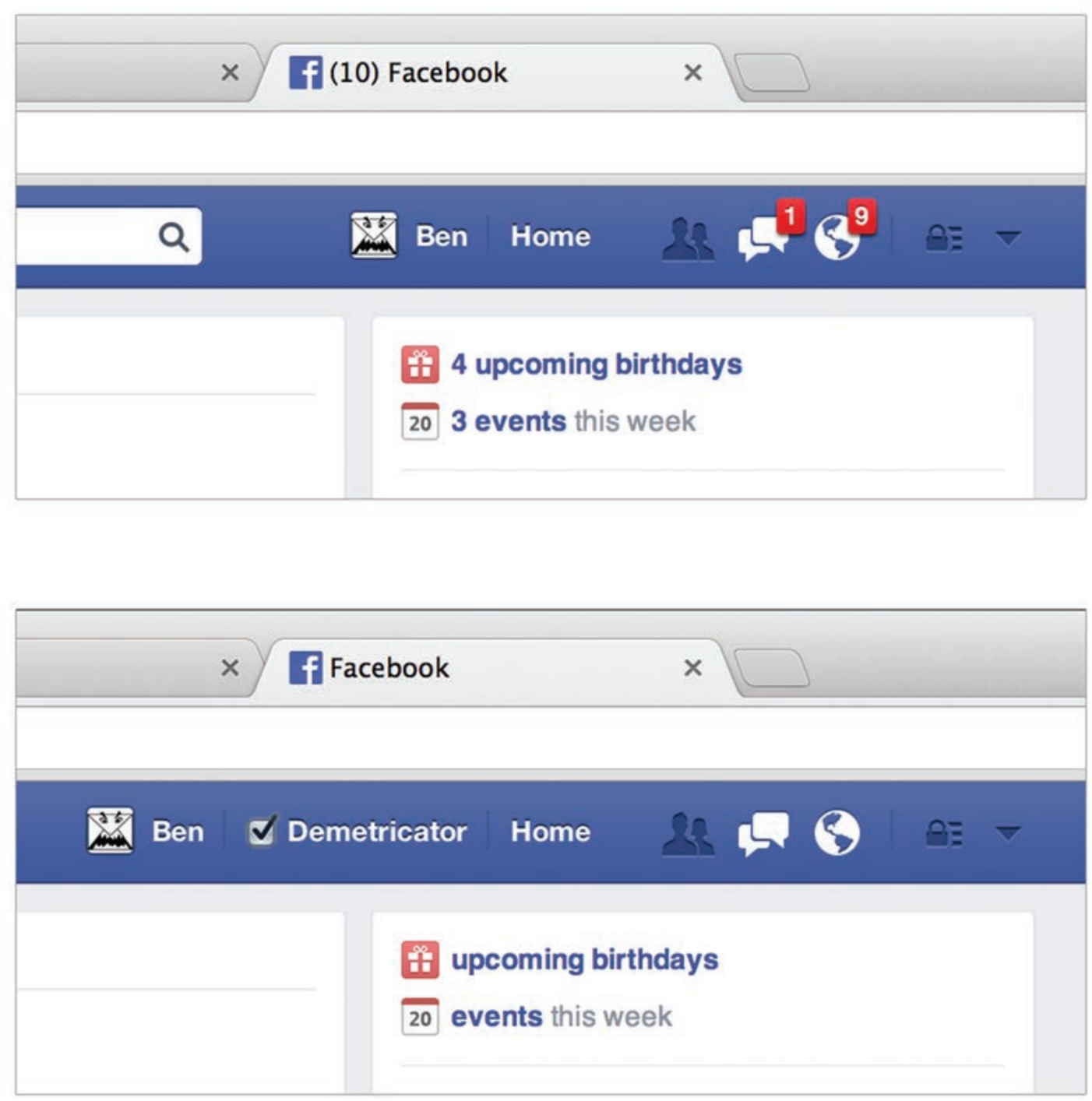

Facebook Demetricator deletes the virtual approval rankings from the interfaces that we interact with every day. Grosser states that his goal was to move the emphasis away from "how many friends you have or ... how much they like your status," and redirect it toward "who [you] are and what [you] said" [8]. Instead of focusing on the metrics, we can relax and engage with the reason we go online in the first place: to connect with others. As a result, using the Facebook Demetricator reminds us how much of our online activity is tracked, measured, numbered, and categorized into rankings and schematics. Ultimately, these analytics are used to elevate and perpetuate these companies' bottom lines. 


\section{Conclusion}

As we experience and move through networks daily, their strengths remain in the ways in which they connect us both figuratively and systematically. Despite the fact that networks exist within software, hardware, devices, and physical infrastructures that are both immense and intangible, artists are able to cleverly reinterpret these systems, in order to expose and humanize them through design and implementation. Artworks can not only manipulate networks and our interactions with them, but they can also adjust them to a scale that is both familiar and colloquial. Often this type of breakdown leads us to a new understanding of complicated systems and allows us to view and experience them in novel or unexpected ways.

The projects exhibited in the Data Materialities Art Gallery emphasize how connected we remain to the physical interfaces enabled by networks, while also exposing the nuances in their interactive capabilities. Things that are typically concealed to the public are both teased out and reverse-engineered in order to elicit a response. Since these systems are typically hidden entities, their revelation and integration into our physical world is a unique experience that renders them relatable by exposing their enormity of scale. Overall, the work presented in the SIGGRAPH 2016 Art Gallery demonstrates novel perspectives on data representation and media sources through unexpected, critical, and profound new channels.

The future of networks, networked objects, and systems has the potential not only to change how we relate to the world around us, but also to affect our interpersonal relationships and our understanding of the complexity of the interconnectedness of our world. My goal in selecting these projects is to shed light on the changing nature and influence of digital entities - screens, network presence, social media, digital copyright law, augmented reality-and the increasingly physical incarnations of the networks we use every day.

\section{References}

I. A. Nagurney, "Networks—The Science-Spanning Disciplines," MeshForum 2005, <http://bit. ly/IT6tRUc>, accessed March 23, 2016.

2. Microsoft, HoloLens, <https://www.microsoft.com/microsoft-hololens/en-us >.

3. Google, Glass, <https://www.google.com/glass/start/>.

4. K. Ch'un-Su, "Flower," The Snow Falling on Chagall's Village, trans. K. Jong-Gil (Ithaca, NY: Cornell East Asia Series, 1998).

5. N. Herbert, Quantum Reality: Beyond the New Physics (New York: Anchor Books/ Doubleday, 1985).

6. Greyworld, The Source (20I5), <greyworld.org/archives/3I >.

7. D. Norman, The Design of Everyday Things (New York: Basic Books, 1988), Revised Edition (November 5, 2013), 3.

8. B. Grosser, <http://bengrosser.com/projects/facebook-demetricator/>. 


\section{Leonardo Network News}

The Newsletter of the International Society for the Arts, Sciences and Technology and of l'Observatoire Leonardo des Arts et Technosciences

Sign up to receive the Leonardo Network Newsletter at <http://bit.ly/sign-up-for-leonardo-news>.

To submit news and updates for the newsletter, email <isast@leonardo.info>.

\section{CALL FOR PAPERS: LEONARDO SPECIAL SECTION "ART AND CANCER"}

Cancer remains the second leading cause of death worldwide. Although there are many successful examples of art-science collaboration in various disciplines, the number of art-science initiatives directed toward cancer research is very small. The focus of this special section is to investigate whether combining principles of art, science and technology with those of cancer biology can advance cancer research. To address this issue, we seek submissions related to innovative, cutting-edge topics that combine scientific methodologies with artistic practices. We are specifically interested in studies that lead to establishing new paradigms in the prevention, diagnosis and treatment of and eventual cure for cancer, providing novel perspectives for oncologists beyond what has been revealed by biological research alone. The guest editor for this special section is Leonardo author Dhruba Deb, a researcher at the Hamon Center for Therapeutic Oncology Research, UT Southwestern Medical Center, Dallas, TX. See <leonardo.info/ isast/journal/calls/artandcancer.html>.

\section{SCIENTIFIC DELIRIUM MADNESS ART/SCIENCE RESIDENCY}

Leonardo/ISAST and the Djerassi Resident Artists Program (DRAP) continue their collaboration with the annual Scientific Delirium Madness Art/Science Residency, which brings together artists and scientists for a monthlong retreat in the Santa Cruz mountains in California. During the course of the residency, artists working in a variety of media collaborate with scientists working in various disciplines to explore and transform the boundaries of art and science. In addition to collegial time, the artists and scientists contribute to a regular series of blogs, LASER Talks, an Open House/ Open Studio public gathering at the Djerassi residency, papers and a special section in the Leonardo journal.
The July 2016 residency participants are Maja Spasova, Adam Zaretsky, David Bowen, Teoma Naccarat, John McCallum, Hannah Rogers, Juanita Rockwell, Asa Callow (NAKFI Fellow), Christine Metzger, Mattheo Farinella, and Weidong Yang. To find out more about this program, see <leonardo. info/art-science-residencies>.

\section{PARTNERS IN ART AND SCIENCE}

The Leonardo Affiliate Program provides a collaborative environment in which leaders from top-ranked universities and independent nonprofits in the cross-disciplinary field of art, science, and technology can interface and share best practices, research, and opportunities with their peers across institutional boundaries. Leonardo Affiliate members also receive a number of benefits and opportunities, including free and discounted advertising opportunities, deals on Leonardo publications, and eligibility to nominate graduate students for the Leonardo Fellowship Program. See $<$ leonardo.info/affiliates>.

\section{CREATIVE DISTURBANCE}

Creative Disturbance is an international, multilingual network and podcast platform supporting collaboration among the arts, sciences and new technologies communities, where new communities of thinkers are fostered and developed and unlikely connections emerge. One means of both sharing and spurring such interactions is through a dynamic collection of podcasts crowdsourced and produced by Creative Disturbance members. These "conversations" help illuminate and inform others on matters of interest across the Creative Disturbance community. Creative Disturbance is currently in a prototype stage, with an organizational node at the University of Texas at Dallas, as part of the Leonardo Initiatives of ArtSciLab of the Arts and Technology program, operated by faculty, students, and research fellows.

Nora Abushadi, a student at The American University in Cairo, has documented on Creative Disturbance the new biennial conference, Cairotronica, a symposium of electronic and new media arts that was held in Cairo, Egypt, in May 2016. The symposium included a program of activities, exhibitions, talks, workshops, and screenings by local, regional, and international artists as well as academics and technology experts. Cairotronica aims to inspire, educate, and challenge students and audiences across the region. See $<$ CreativeDisturbance.org $>$. 


\section{LEONARDO NETWORK NEWSLETTER}

The Leonardo Network Newsletter is a bimonthly, online publication of Leonardo/ISAST, bringing news and opportunities to the attention of readers interested in the creative spaces where art, science, and technology connect. Stay up to date with upcoming LASER and DASER events, as well as Leonardo publications, art-science-related calls for papers, exhibition openings, and conferences relevant to the art-science community. Sign up to receive the newsletter at $<$ http://bit.ly/sign-up-for-leonardo-news $>$.

\section{NEW TO THE LEONARDO BOOK SERIES: SCREEN ECOLOGIES}

Images of environmental disaster and degradation have become part of our everyday media diet. This visual culture focusing on environmental deterioration represents a wider recognition of the political, economic, and cultural forces that are responsible for our ongoing environmental crisis. And yet efforts to raise awareness about environmental issues through digital and visual media are riddled with irony, because the resource extraction, manufacturing, transportation, and waste associated with digital devices contribute to environmental damage and climate change. Screen Ecologies examines the relationship of media, art, and climate change in the Asia-Pacific region-a key site of both environmental degradation and the production and consumption of climate-aware screen art and media.

Written by Larissa Hjorth, Sarah Pink, Kristen Sharp, and Linda Williams, Screen Ecologies shows how new media and visual artists provide alternative ways for understanding the entanglements of media and the environment in the Asia-Pacific. It investigates such topics as artists' exploration of alternative ways to represent the environment; regional stories of media innovation and climate change; the tensions between amateur and professional art; the emergence of biennials, triennials, and new arts organizations; the theme of water in regional art; new models for networked collaboration; and social media's move from private to public realms. A generous selection of illustrations shows a range of artist's projects. See $<$ mitpress.mit.edu/books/ screen-ecologies>.

\section{LEONARDO REVIEWS}

Leonardo Reviews is the work of an international panel of scholars and professionals invited from a wide range of disciplines to review books, exhibitions, CDs, websites, and conferences. Collectively they represent an intellectual commitment to engaging with the emergent debates and manifestations that are the consequences of the convergence of the arts, science, and technology. New reviews are made available online every month. See <leonardo.info/ldr.php>.

\section{NEW TO THE LEONARDO EBOOK SERIES: ARTS, HUMANITIES, AND COMPLEX NETWORKS}

The e-book Arts, Humanities, and Complex Networks captures the excitement of creators and scholars pioneering the application of network science to culture. Beginning in 20IO, the AHCN symposia tracked breakthrough moments as network theories, big data, and inventive visualizations triggered new insight in fields ranging from I6th-century political history to 2Ist-century art. These papers were presented at the Leonardo Days at NetSci conferences, the High Throughput Humanities conference, and in the Leonardo journal, published by MIT Press. Authors include experts in visualization, sonification, and data exploration from universities and corporate $\mathrm{R} \& \mathrm{D}$ departments internationally. See <bit.ly/arts-humanities-networks $>$.

\section{LEONARDO EDUCATION AND ART FORUM}

A program of Leonardo/ISAST, the Leonardo Education and Art Forum (LEAF) promotes the advancement of arts practice, academic scholarship, and practice-led research by providing practitioners, educators, and students a national and international forum for dialogue at the intersections of art, science, and technology. See <http://leonardo.info/isast/ LEAF.html>.

Join the LEAF community: LEAF is open to all individuals who are interested in the issues addressed by Leonardo. Those who wish to become involved with LEAF should send a brief bio and request to join the online forum to the LEAF Chair at <leaf@leonardo.info>. 


\section{Leonardo, The International Society for the Arts, Sciences and Technology}

\author{
Leonardo/ISAST Headquarters \\ 1440 Broadway, Suite 422 \\ Oakland, CA 94612, U.S.A. \\ Tel: 510.858 .7567 \\ Fax: 510.858 .7548 \\ Email: <isast@leonardo.info> \\ Web: <leonardo.info> \\ Facebook: Leonardo/ISAST \\ Twitter: LeonardoISAST
}

\section{Leonardo Music Journal \\ Email: <Imj@leonardo.info> \\ Web: <leonardo.info/Imj>}

\section{Association Leonardo}

8, rue Émile Dunois

92100 Boulogne Billancourt, France

Email: <info@olats.org>

Web: <olats.org>

\section{Leonardo Book Series}

1440 Broadway, Suite 422

Oakland, CA 94612, U.S.A.

Email:<leonardobooks@mitpress. mit.edu>

Web: <leonardo.info/isast/

leobooks.html>

\section{Subscriptions}

MIT Press Journals

One Rogers St.

Cambridge, MA 02142-1209, U.S.A.

Tel: 617.253.2889

Fax: 617.577 .1545

Web: <mitpressjournals.org>

\section{Benefits of Membership}

Artists, scientists, engineers, researchers and others interested in the contemporary arts and sciences are invited to join Leonardo/ISAST. Benefits include reduced rates for Leonardo/ISAST publications, eligibility to participate in Leonardo working groups and special invitations to Leonardo-sponsored events.

For further details, visit $<$ leonardo.info/members.html> or email <isast@leonardo.info>.

Affiliate memberships also available for nonprofit organizations, educational institutions and corporations working at the intersection of art, science and technology. Visit <leonardo.info/isast/orgmembership.html> for more information.

\begin{abstract}
MISSION STATEMENT
The critical challenges of the 21st century require mobilization and crossfertilization among the domains of art, science and technology. Leonardo/ISAST fosters collaborative explorations both nationally and internationally by facilitating interdisciplinary projects and documenting and disseminating information about interdisciplinary practice.
\end{abstract}

\section{PUBLICATIONS}

\section{Journals}

The Leonardo journals are scholarly peer-reviewed journals of record. Leonardo, published bimonthly, is the official journal of Leonardo/ISAST. Executive Editor: Roger F. Malina. Leonardo Music Journal with audio companion is published annually. Editor-in-Chief: Nicolas Collins.

\section{On-line}

The Leonardo On-Line website (<leonardo.info>) publishes organizational information, the Leonardo Electronic Directory and more.

\section{Electronic Journal}

Leonardo Electronic Almanac (<leoalmanac.org $>$ ) is an electronic journal dedicated to providing a forum for those who are interested in the realm where art, science and technology converge. Editor-in-Chief: Lanfranco Aceti.

\section{Leonardo Reviews}

The Leonardo Reviews Project, through a panel of reviewers, publishes reviews of relevant books, journals, electronic publications and events. Reviews are published on the web (<leonardo.info/ldr.html>), and selected reviews are published in Leonardo. Editor-in-Chief: Michael Punt.

\section{The Leonardo Book Series}

The Leonardo Book Series (<leonardo.info/isast/leobooks.html>), published by the MIT Press, highlights topics related to art, science and developing technologies. Editor-in-Chief: Sean Cubitt.

\section{LABS Databases of Master's and PhD Theses}

English LABS: <leonardolabs.pomona.edu>; Editor-in-Chief: Sheila Pinkel.

Spanish LABS: <uoc.edu/artnodes/leonardolabs>

French LABS: <francolabs.univ-paris1.fr>

\section{AWARDS}

Frank J. Malina Leonardo Award for Lifetime Achievement recognizes eminent artists who through a lifetime of work have achieved a synthesis of contemporary art, science and technology. Winners include Gyorgy Kepes, Nicolas Schöffer, Max Bill, Takis and Abraham Palatnik.

Leonardo Award for Excellence recognizes excellence in articles published in Leonardo publications. Winners include Rudolf Arnheim, Otto Piene, Charles Ames, Frieda Stahl, Donna Cox, Janet Saad-Cook, George Gessert, Alvin Curran, Karen O'Rourke, Eduardo Kac, Hubert Duprat with Christian Besson, José Carlos Casado with Harkaitz Cano, Bill Seaman, Arthur Elsenaar with Remko Scha, and Steve Mann.

Leonardo New Horizons Award for Innovation is given to individuals or groups for innovation in new media. Winners include Critical Art Ensemble, Gregory Barsamian, Graham Harwood, Evelyn Edelson-Rosenberg, Jean-Marc Philippe, Jaroslav Belik, Peter Callas, Patrick Boyd, Christian Schiess, Kitsou Dubois, I Wayan Sadra, and Ewen Chardronnet.

Makepeace Tsao Leonardo Award recognizes organizations or groups that have increased public awareness of art forms involving science and technology, particularly through exhibitions. The first award was given to La Cité des Arts et Nouvelles Technologies de Montréal. 
Leonardo Global Crossings Award recognizes excellent work by international artists, professionals and scholars in the globally emerging art-science-technology field. Winners include Abdel Ghany Kenawy and Amal Kenawy (Cairo, Egypt) (2005).

Leonardo-EMS (Electroacoustic Music Studies) Award for Excellence is awarded for the best contribution to the EMS symposium by a young researcher, as decided by a joint jury. Winners include criticalartware (Jon Cates, Ben Syverson and Jon Satrom) and Michael Bullock (2008).

Leonardo Art Science Student Contest Award is a juried award for student work selected from projects received through an open submission process. The first Leonardo Art Science Student Contest award (2008) was given to Hiroki Nishino, Michiko Tsuda, Jaewook Shin, Byeong Sam Jeon, Margarita Benitez and Markus Vogl.

The Leonardo Scholarship for Media Art Histories, a collaborative project between Leonardo/ISAST and the Department for Image Science (Danube University), awards a juried half-tuition scholarship for the Master of Arts (MA) course in Media Art Histories at Danube University to a candidate who demonstrates the potential to contribute to the new field of Media Art Histories in this time of critical worldwide challenges. The first scholarship has been awarded to Fran Ilich Morales Muñoz (2010).

\section{COLLABORATIONS WITH OTHER ORGANIZATIONS}

Leonardo/ISAST frequently collaborates with other organizations on topics of current interest by collaborating on conferences or workshops and by publishing special sections in Leonardo or co-sponsoring events. Current collaborators include:

- a2ru (U.S.A.)

- ACM SIGGRAPH (U.S.A.)

- Artnodes (Spain)

- Association Leonardo (France)

- College Art Association (U.S.A.)

- Electronic Music Foundation (U.S.A.)

- Fondation Langlois Research Documentation Center (Canada)

- MIT Press (U.S.A.)

- Pomona College (U.S.A.)

- Sabanci University (Turkey)

- School of the Art Institute of Chicago (U.S.A.)

- University of Dallas at Texas, ArtSciLab (U.S.A.)

- University of Plymouth (U.K.)

For more information, please visit <leonardo.info/collablist.html>.

\section{LEONARDO PROJECT WORKING GROUPS}

Leonardo hosts working groups on projects with a topical focus:

Leonardo Abstracts Service (LABS) Peer Reviewers

Yiannis Colakides, Tom Leeser, Emmanuel Mahe, Soraya

Murray, Timothy Murray, Andrea Polli, Martin Reiser, Charissa

N. Terranova, lannis Zannos

Leonardo Education and Art Forum (LEAF)

JD Talasek, Chair; Alan Boldon, Chair-Elect. See

$<$ leonardo.info/isast/LEAF.html> for more information.

\section{Book Series Committee}

Sean Cubitt, Editor-in-Chief; Annick Bureaud; Steve Dietz; Machiko Kusahara; Roger Malina; Jose-Carlos Mariategui; Laura U. Marks; Anna Munster; Monica Narula; Michael Punt; Sundar Sarukkai; Joel Slayton; Mitchell Whitelaw; Zhang Ga

\section{AFFILIATE MEMBERS}

Leonardo/ISAST invites organizations and corporations working at the intersection of art, science and technology to join the Affiliate Membership Program. Visit <Leonardo.com/ Affiliates $>$ for more information.

Affiliate Members Arizona State University Art Museum; Art Center College of Design, Media Design Practices/Lab \& Field; California Institute of the Arts, Herb Alpert School of Music; Digicult; Djerassi Resident Artists Program; Minerva Foundation; Ontario College of Art \& Design University; Plymouth University; Polytechnic Museum, Moscow, Russia; Pomona College; School of the Art Institute of Chicago, Sound Department; University of California, Davis, Art/Science Fusion Program; University of California, Los Angeles, Art|Sci Center; University of California, Santa Cruz, Institute of the Arts and Sciences; University of Delaware; University of San Francisco, College of Arts and Sciences; University of Technology Sydney, Creativity \& Cognition Studios; University of Texas at Dallas, Arts and Technology; University of the Arts London, Central Saint Martins, Art and Science Program; York University

\section{LEONARDO/ISAST}

Leonardo/ISAST Governing Board of Directors

Marc Hebert, Chair, President; Gordon Knox, Secretary; Greg Harper, Treasurer; Roger Malina, Chair Emeritus; Nina Czegledy; Tami Spector; JD Talasek; Darlene Tong; John Weber

\section{Director}

Patricia Bentson

Deputy Director

Danielle Siembieda 
IN HOUSE AD 


\section{AT THE}

\section{of COMPUTER INTERACTIVE GRAPHICS \& TECHNIQUES}

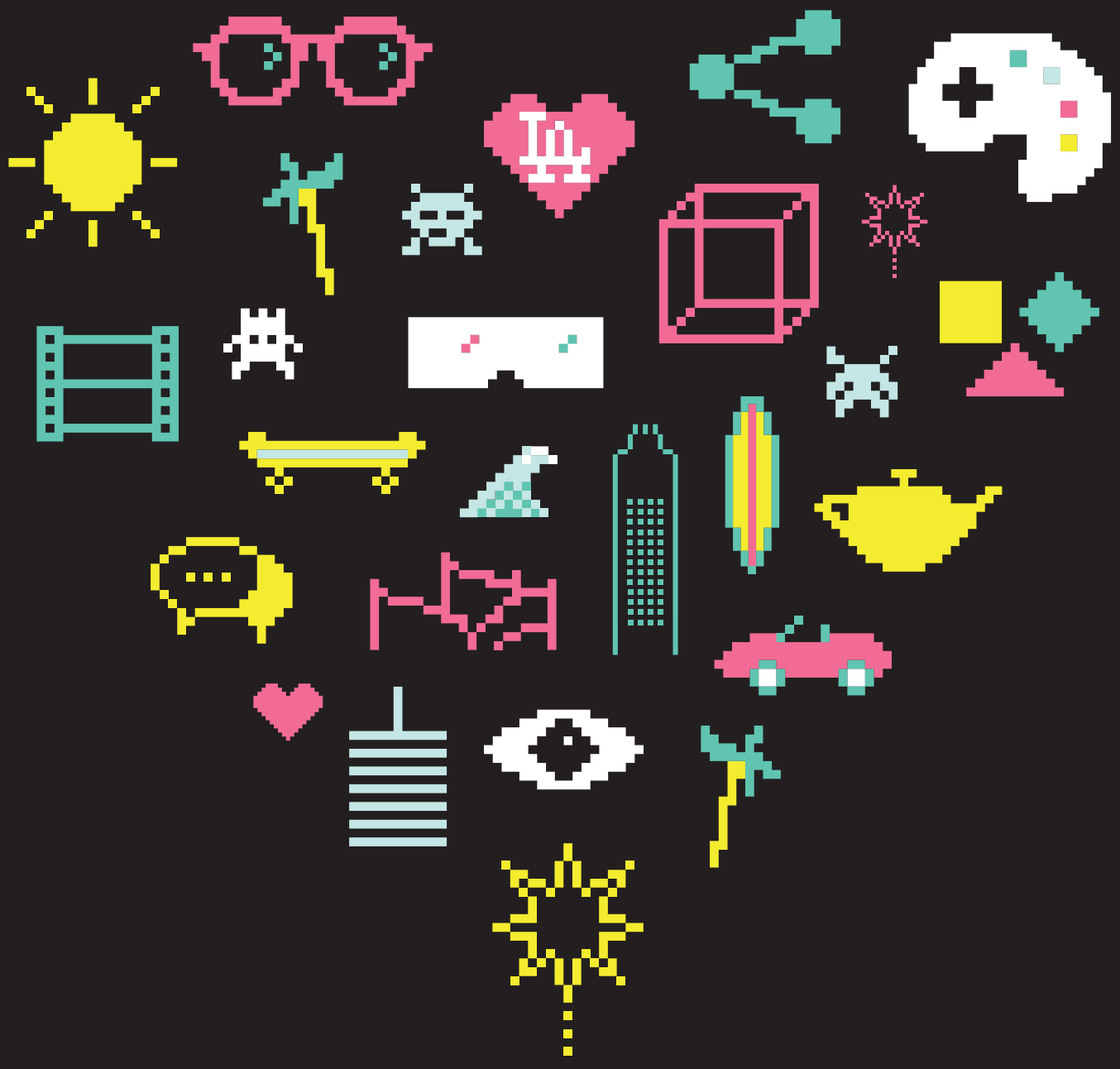

SIGGRAPH 2017

30 JULY - 3 AUGUST los Angeles, California

S2017.SIGGRAPH.ORG $f G+\cdots \square$ in

THE 44TH INTERNATIONAL CONFERENCE AND EXHIBITION ON

Computer Graphics \& Interactive Techniques

(acm) Sponsored by ACMSIGGRAPH 